\title{
ANATOMY AND PHYSIOLOGY OF A COLOR SYSTEM IN THE PRIMATE VISUAL CORTEX ${ }^{1}$
}

\author{
MARGARET S. LIVINGSTONE ${ }^{2}$ AND DAVID H. HUBEL
}

Department of Neurobiology, Harvard Medical School, Boston Massachusetts 02115

Received August 16, 1983; Revised October 28, 1983; Accepted October 28, 1983

\begin{abstract}
Staining for the mitochondrial enzyme cytochrome oxidase reveals an array of dense regions (blobs) in the primate primary visual cortex. They are most obvious in the upper layers, 2 and 3 , but can also be seen in layers $4 \mathrm{~B}, 5$, and 6 , in register with the blobs in layers 2 and 3 . We compared cells inside and outside blobs in macaque and squirrel monkeys, looking at their physiological responses and anatomical connections. Cells within blobs did not show orientation selectivity, whereas cells between blobs were highly orientation selective. Receptive fields of blob cells had circular symmetry and were of three main types, Broad-Band Center-Surround, Red-Green DoubleOpponent, and Yellow-Blue Double-Opponent. Double-Opponent cells responded poorly or not at all to white light in any form, or to diffuse light at any wavelength. In contrast to blob cells, none of the cells recorded in layer $4 \mathrm{C} \beta$ were Double-Opponent: like the majority of cells in the parvocellular geniculate layers, they were either Broad-Band or Color-Opponent Center-Surround, e.g., red-oncenter green-off-surround. To our surprise cells in layer $4 \mathrm{C} \alpha$ were orientation selective. In tangential penetrations throughout layers 2 and 3, optium orientation, when plotted against electrode position, formed long, regular, usually linear sequences, which were interrupted but not perturbed by the blobs.

Staining area 18 for cytochrome oxidase reveals a series of alternating wide and narrow dense stripes, separated by paler interstripes. After small injections of horseradish peroxidase into area 18 , we saw a precise set of connections from the blobs in area 17 to thin stripes in area 18, and from the interblob regions in area 17 to interstripes in area 18. Specific reciprocal connections also ran from thin stripes to blobs and from interstripes to interblobs. We have not yet determined the area 17 connections to thick stripes in area 18. In addition, within area 18 there are stripe-to-stripe and interstripe-to-interstripe intrinsic connections.

These results suggest that a system involved in the processing of color information, especially color-spatial interactions, runs parallel to and separate from the orientation-specific system. Color, encoded in three coordinates by the major blob cell types, red-green, yellow-blue, and black-white, can be transformed into the three coordinates, red, green, and blue, of the Retinex algorithm of Land.
\end{abstract}

The mammalian striate cortex is the first cortical receiving area for visual information from the thalamus. As such it is presumably engaged in analyzing or relaying most or all of the signals involved in visual perceptionsignals concerned with form, color, movement, texture,

\footnotetext{
${ }^{1}$ We thank Debra Broihier and Yu-Wen Wu for the histology; Olivia Brum for secretarial help; David Freeman for electronics and computer assistance; Marc Peloquin for photography; Nigel Daw, D. Louise Edwards, Simon LeVay, Susan McConnell, William Quinn, and Paul Desan for reading of the manuscript; and Edwin Land, S. Hollis Perry, and Michael Burns for their patience in many discussions. The work was supported by National Institutes of Health Grants R01 EY00605, EY01995, and EY07042, and by the Klingenstein Fund.

${ }^{2}$ To whom correspondence should be addressed.
}

and depth. Exactly what the visual cortex does to analyze visual signals has been the concern of neurophysiologists since the 1950's, when specialized responses to direction of movement and contour orientation were first observed.

In the past 20 years it has become increasingly apparent that the striate cortex is organized in a modular fashion. The basis of this concept is the grouping of cells according to the characteristics of the visual stimuli to which they best respond, the most fundamental of which is receptive field position. Given the systematic topographic mapping of the visual fields on the striate cortex (Talbot and Marshall, 1941; Daniel and Whitteridge, 1961), it was no suprise to learn that cells with similar receptive field positions are grouped together. Because 
of the scatter in receptive field positions of neighboring cells and the finite size of each receptive field, a single point on the cortex corresponds not to a point in the visual field, but to an area. In the macaque monkey the mapping is such that, regardless of position in the cortex, the cortical distance that must be traversed in order to go from a point corresponding to one area of the visual field to a point corresponding to an entirely new area is roughly $2 \mathrm{~mm}$ (Hubel and Wiesel, 1974b). Presumably, then, whatever analysis the striate cortex performs on such an area of visual field must take place in a block of cortex whose surface area is about $4 \mathrm{~mm}^{2}$.

Cells in the striate cortex are grouped according to several stimulus parameters in addition to receptive field position. The first to be studied were eye dominance and receptive field orientation. For both, the groupings take the form of vertically arranged parallel slabs spanning the full cortical thickness (Hubel and Wiesel, 1968, 1974a, 1977; LeVay et al., 1975). When a recording electrode moves through the cortex parallel to the surface, say in layers 2 and 3, all possible values of orientation and eye dominance are repeated over and over. In particular, in any $2 \times 2 \mathrm{~mm}$ block of cortex all values of a parameter such as orientation are represented at least once (otherwise all parts of the visual field would not be fully analyzed), and we may think of the striate cortex as made up, like a crystal, of many repeating modules, all having roughly the same organization and each containing the machinery necessary to take care of every orientation, for both eyes. Eye dominance columns and orientation columns were first inferred from physiological experiments, and although classical stains gave no hint of these subdivisions, more refined anatomical methods have made it possible to see both types of columns directly (Hubel et al., 1974a, 1977b; LeVay et al., 1975).

In 1980, the concept of a modular organization of primate area 17 took on a new dimension with the discovery of a pattern of regularly repeating blob-like structures most conspicuous in layers 2 and 3 , revealed by staining for the mitochondrial enzyme cytochrome oxidase (Horton and Hubel, 1980; Humphrey and Hendrickson, 1980). Two years earlier, M. Wong-Riley (personal communication) had observed these structures in sections perpendicular to the cortical surface and had noted their similarity to the puffs of label found in layer III after injection of radioactive proline into the lateral geniculate body (Weber et al., 1977) or into the eye (Hubel and Wiesel, 1978). These blobs, as we term them from their appearance in tangential section (Oxford English Dictionary, 1978), have been found in all primates so far studied, but in no nonprimates (Horton and Hubel, 1981; Horton, 1983). In tangential sections they are oval, measure roughly $150 \times 200 \mu \mathrm{m}$, and in the macaque monkey lie centered along ocular dominance columns, to which their long axes are parallel (Horton and Hubel, 1981; Hendrickson et al., 1981). Thus the rows that they form, like ocular dominance columns, are perpendicular to the $17 / 18$ border and are more regular in the parts of the cortex representing the visual field periphery than in the parts representing the fovea. In squirrel monkeys, ocular dominance columns are not well defined and, consistent with this, the blobs do not tend to form rows.
Blobs extend pillar-like through the full thickness of layers 2 and 3 , and can also be seen more faintly in layers $4 \mathrm{~B}, 5$, and 6 , where they lie in precise register with the overlying upper layer blobs. In between, layers $4 \mathrm{~A}$ and 4C stain uniformly and densely for cytochrome oxidase, and here no blobs are seen. The blobs can be seen with stains for other enzymes, including another mitochondrial enzyme, succinate dehydrogenase (Horton, 1983), and a nonmitochondrial enzyme, glutamate decarboxylase (Hendrickson et al., 1981). The heightened enzyme activities could reflect a heightened overall neuronal activity of the blob tissue as compared with the surrounding (non-blob) matrix, perhaps because of a lower response selectivity, or the blob and non-blob tissues could be structurally different, containing different cell types and different neuropil elements-or both of these could be true. That blobs are in any case regions of heightened activity is indicated by their preferential labeling with 2deoxyglucose in squirrel monkeys exposed to diffuse light (Humphrey and Hendrickson, 1983) and in macaques stimulated by parallel stripes in any single orientation (Horton and Hubel, 1981).

When we began the physiological studies to be de scribed, we also set out to examine the inputs to the blobs (Livingstone and Hubel, 1982). Injections of either $\left[{ }^{3} \mathrm{H}\right]$ proline or horseradish peroxidase into the lateral geniculate body of macaque and squirrel monkeys resulted in puffs of label in layer 3 , especially in its deeper part, in precise register with the cytochrome blobs. The proline labeling could be the result of transneuronal transport via layer $4 \mathrm{C}$, but the orthograde labeling with horseradish peroxidase (not lectin conjugated) makes it more likely, although still not certain, that the projection is direct. Fitzpatrick et al. (1983) meanwhile found evidence indicating that in the squirrel monkey the sources of the projection are the geniculate layer intercalated between magnocellular and parvocellular layers and a second small-cell layer ventral to the magnocellular layers. In the macaque these layers are gossamer (Hubel et al., 1977a) and perhaps less likely to be the sole source of a system as prominent as the one we are about to describe.

Given this system of blobs, with distinct staining properties and inputs, it was natural to ask whether the cells had distinctive physiological properties, and whether their outputs were special. In the present paper our two primary objectives were to compare response properties of cells within and outside the upper layer blobs, and to learn whether the two systems differed in their outputs to other parts of the cortex. The results suggest that the blobs are part of a system separate from the already known system of orientation-tuned cells, but running in parallel with it, and concerned mainly with the sensation of color.

\section{Materials and Methods}

Unless otherwise specified, we used young adult $\mathrm{Ma}$ caca fascicularis monkeys (20) for these experiments. A few recordings were made from three young adult female squirrel monkeys (Saimiri sciureus). The animals were initially anesthetized with sodium thiopental or, in later experiments, with an inhalation mixture of halothane 
(1\%), air, and oxygen. They were paralyzed with intravenous gallamine triethiodide to prevent eye movements, artificially respirated, and their eyes were fitted with contact lenses so as to bring a tangent screen at $1.5 \mathrm{~m}$ distance into focus.

\section{Physiological recording techniques}

We recorded single unit activity by inserting a tungsten microelectrode (Hubel, 1959) through a small hole in the skull and dura at an angle of 10 to $20^{\circ}$ to the brain surface. To dampen pulsations the hole was sealed with wax around a guard tube. For plotting of poststimulus time histograms, the recorded action potentials were converted to pulses with a Schmitt trigger circuit. Three or four electrolytic lesions $(2 \mu \mathrm{A} \times 2 \mathrm{sec})$ were made in the course of each penetration, often at points that served to bracket blobs or identify layers. We found that the stain for cytochrome oxidase was ideal for finding electrode tracks, lesions, and boundaries of layers. By selecting electrodes for small tips (10 to $15 \mu \mathrm{m}$ from tip to the beginning of insulation) and low impedance $(<1$ megohm at $1 \mathrm{kHz}$ ), it was possible in all penetrations to record activity from units, most single but sometimes in pairs or triplets, against a background of unresolved activity, at all points in each penetration. We found it most efficient to study the response properties of cells at intervals of $50 \mu \mathrm{m}$ along each track, so that in a typical penetration 4 to $5 \mathrm{~mm}$ long we could make 80 to 100 observations (e.g., Figs. 2, 3, 5, 6, and 7). The spacing of $50 \mu \mathrm{m}$ was chosen because that was about the distance required to replace one set of units by another, as judged by firing patterns, shifts in optimal orientation, exact receptive field position, and so on.

For visual stimulation we used either a hand-guided slide projector or, for averaging responses, a microprocessor-driven optic bench. Orientation tuning curves, poststimulus time histograms, ocular dominance histograms, and plots of optimum orientation, ocular dominance, and orientation selectivity as a function of electrode track distance were generated with the help of a Hewlett-Packard microcomputer (model 9826). Poststimulus time histograms were made for various spot sizes; then curves of response rates versus spot size were automatically generated, and the rates were determined for designated periods during the "on" and the "off" phases. All of this was repeated for several wavelengths of light and for white light. Colored stimuli were made by inserting color filters into the light path of the slide projector or optic bench. The filters were either broadband Kodak Wratten no. 29 (red), no. 16 (yellow), no. 58 (green), no. 45 (cyan), and no. 47B (blue), or narrowband interference filters (Baird Atomic B-1, half bandwidth $7 \mathrm{~nm}$ ). For dark adaptation studies the background was made as dim as possible; otherwise the screen was lit diffusely by a background light of roughly $-1.5 \mathrm{log}$ candles/meter.

At the end of the recording session, the monkey was deeply anesthetized with sodium thiopental and then perfused transcardially with fixative $(0.75 \%$ paraformaldehyde, $2.25 \%$ glutaraldehyde in buffered saline, $0.1 \mathrm{M}$ sodium phosphate, $\mathrm{pH}$ 7.4). Sections were cut on a freezing microtome at 30 to $60 \mu \mathrm{m}$ thickness and reacted for cytochrome oxidase (Wong-Riley, 1979b).
Note on layering and cortical areas

In this paper we adhere to Lund's (1973) system for naming the layers in area 17 . We use the term "area 18 " in the sense that others use "visual area 2," to refer to the topographically organized single representation of the visual field just anterior to area 17.

\section{Part I: On the Physiological Differences between Cells In and Outside of Blobs}

We began by making tangential penetrations through the upper layers of macaque and squirrel monkey striate cortex, recording receptive field properties of cells at 50$\mu \mathrm{m}$ intervals, and making lesions at several positions along each track so that we could later compare the physiological properties of neurons at any point along the track with the pattern of cytochrome oxidase staining.

\section{Results}

\section{Orientation tuning of cells in blobs}

In the first few experiments, when we looked back at the description of the physiological properties of cells that the histology showed to have been in blobs, the descriptions read "very broadly oriented," "sounds like layer 4," or "lousy orientation." From then on we graded the orientations from A to D ("Selectivity Index"), designating as A a cell as well oriented as any in striate cortex, D a cell lacking any obvious orientation preference, and $\mathrm{B}$ and $\mathrm{C}$ intermediate degrees of selectivity. This grading was sometimes determined by plotting Cartesian or polar histograms (Fig. 1), but was usually assessed subjectively by listening to the response of a unit while stimulating with a hand-held projector. Of course the judgments were made blindly with respect to (and prior to) the histology.

The combined recordings and track reconstructions consistently gave the following results. Outside the blobs (surrounding and between them), for a given electrode position both isolated cells and unresolved background activity were almost always sharply tuned to one and the same orientation. On approaching a blob there was a sudden fall in orientation selectivity, generally from the A's or B's characteristic of interblob regions to C, cells with broad orientation tuning, in which optimum orientation could be assigned only after a struggle. Within a short distance of 50 to $100 \mu \mathrm{m}$ there was a further decline to a complete absence of orientation, both in the resolved units and in the unresolved background hash. At the same time spontaneous activity increased markedly so that we had the feeling of entering a quite different structure - the impression one has on entering the lateral geniculate or layer $4 \mathrm{C}$ of area 17 . On leaving a blob we encountered the reverse sequence: an increase in the sharpness of the orientation tuning first to $\mathrm{C}$ and then to $\mathrm{B}$ or $\mathrm{A}$, and a concomitant fall in spontaneous activity. The following figures document this description.

Figure 2 gives the results from a $3.25-\mathrm{mm}$ penetration passing tangentially through layers 2 and 3 of macaque striate cortex, in the course of which we studied 57 cells. Figure $2 A$ shows polar histograms for six representative units. Of these the first two were well oriented and 


\section{Selectivity A}

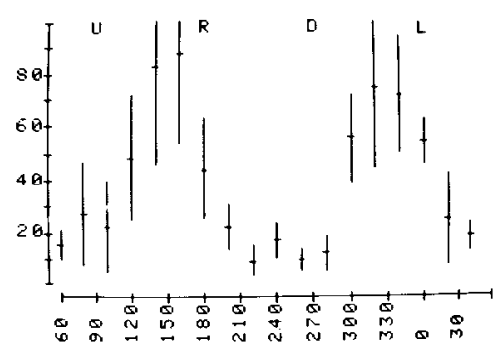

$\theta=$ Movement Direction

Radius $=$ Response

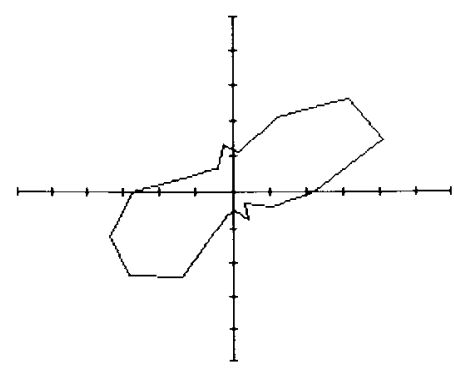

\section{Selectivity D}
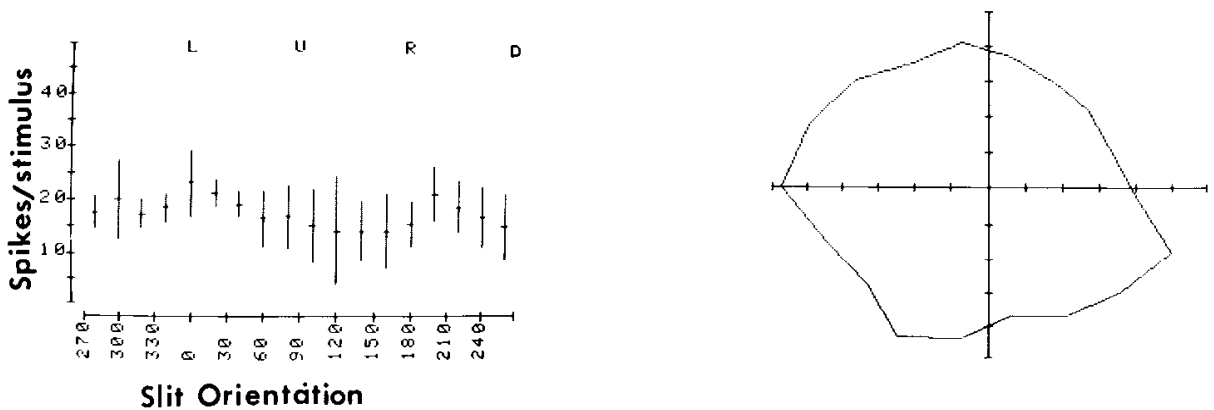

Figure 1. Left, Orientation tuning curve of a well oriented (Selectivity $A$ ) and an unoriented (Selectivity $D$ ) cell in monkey striate cortex. Error bars indicate standard deviation. For stimulus orientation, $0^{\circ}$ indicates vertical. Right, Polar-coordinate histograms of the same two cells. The angle represents the preferred direction of movement and the radius represents the rate of firing in response to that direction of movement. classed as A's. They responded best to a vertical slit moved to the left or right. The middle two units, classed as D's, had no obvious orientation preference, as shown by roughly circular polar histograms. The last two units were again well oriented (A's). The track reconstruction shows that the first two and last two cells were well away from blobs, whereas the middle two were within the junction of two confluent blobs.

Figure $2 B$ shows the same penetration but with plots of ocular dominance (OD), preferred orientation, and Selectivity Index (SI) for orientation tuning, against depth. The very first cells recorded in the penetration were in a blob and were unoriented. Subsequent losses or dips in orientation selectivity occurred at $0.65 \mathrm{~mm}$, $1.6 \mathrm{~mm}$, and finally at $2.7 \mathrm{~mm}$, where two confluent blobs were associated with an uninterrupted sequence of unoriented cells, but an abrupt shift in eye preference at the boundary. Cells in blobs lacked orientation specificity at all depths in layers 2 and 3 , from the upper part of layer 2 , as in this example, down to blobs traversed just above layer $4 \mathrm{~A}$. As we will discuss later, blob cells in macaque striate cortex tend to be more strongly monocular than non-blob cells, consistent with the finding that blobs are centered on ocular dominance columns. In this particular penetration we apparently grazed an ipsilateral eye blob and then passed through a contralateral eye blob, without seeing any oriented cells between.

Lining up by eye the histology with the graph of selectivity index suggested that the loss of orientation selectivity correlated with darker cytochrome oxidase staining. We thought of evaluating the histology automatically, but to correlate a simple densitometry scan with the selectivity index is difficult because the very bright blood vessels and detritus generate large high frequency signals. J. Richter of the Massachusetts Institute of Technology Artificial Intelligence Laboratory generated a convolved image of this histology by subtracting the signals of the high-contrast, small-diameter elements from the original image, and then plotted a profile of the density (down $=$ denser) of the convolved image along the electrode track. Figure $2 B$ shows this profile aligned with our assessment of the orientation selectivity. The correlation again indicates that the unoriented units are within regions that stain more darkly for cytochrome oxidase.

Figure 3, from another macaque monkey, shows two 

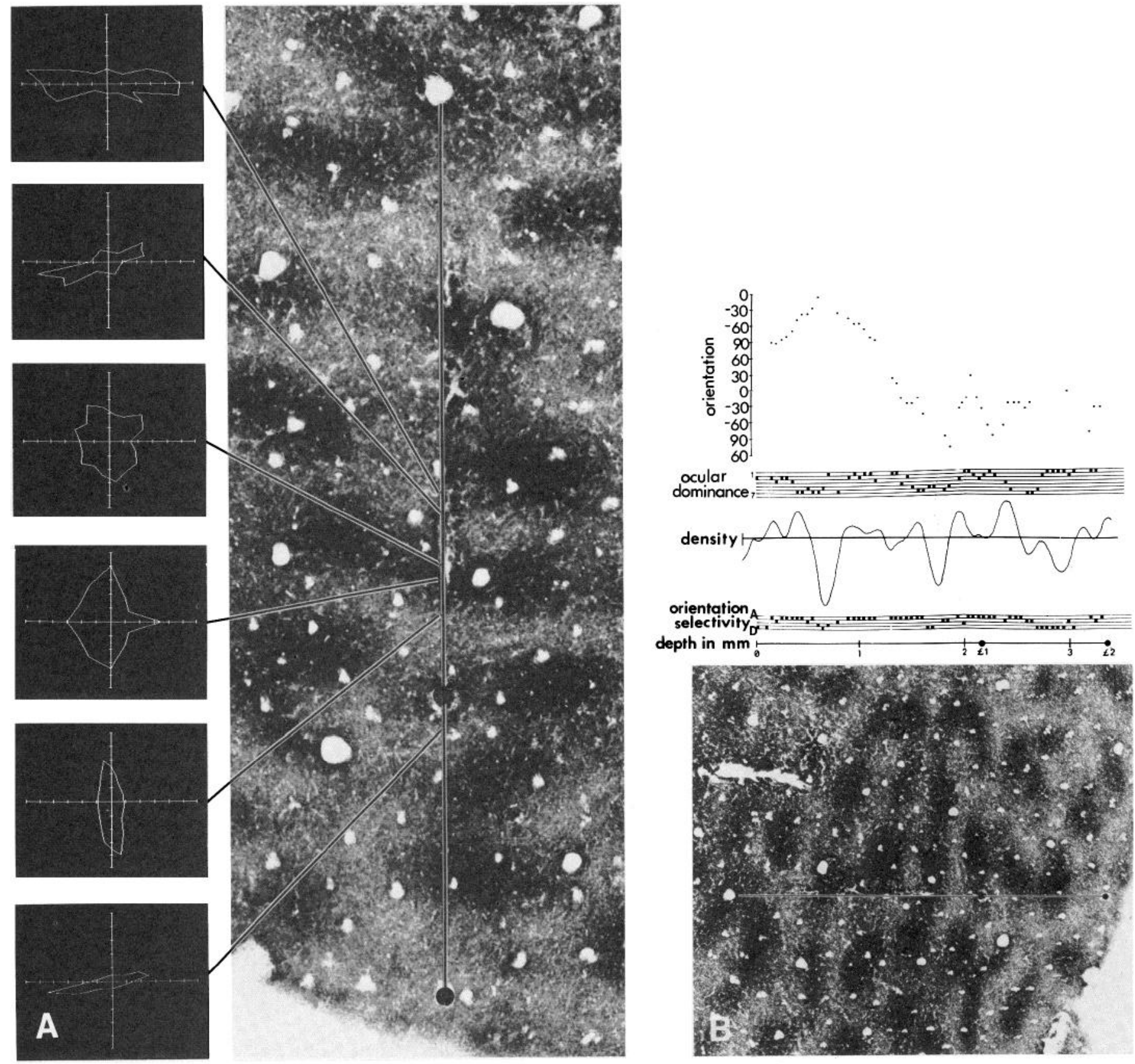

Figure 2. Receptive field properties of units in a penetration through the upper layers of macaque parafoveal striate cortex. The section was stained for cytochrome oxidase. The lesions have been emphasized with dots. A, Polar histograms for six of the units encountered in this penetration at the positions indicated. The penetration goes from top to bottom. $B$, The same penetration with all of the units encountered scored, from above downward, for orientation tuning preference in degrees $\left(v e r t i c a l=0^{\circ}\right)$; ocular dominance from 1 (top) to 7 (bottom) ( 1 indicates a cell driven exclusively by the contralateral eye, 7 indicates a cell driven exclusively by the ipsilateral eye, and 2 to 6 are intermediate); densitometry scan (down $=$ darker), along the electrode track, of the convolved image of the histology; sharpness of orientation tuning where $A(t o p)$ indicates a well oriented unit and $D$ (bottom) an unoriented unit with B and C intermediate.

parallel penetrations, both entirely within layers 2 and 3 of the striate cortex. In Figure $3 A$ we show polar histograms of orientation tuning for 18 of the units encountered. Again, the elongated histograms are from cells outside the blobs and the round ones from cells within blobs. Figure $3 B$ shows the orientation, ocular dominance, and orientation selectivity of all 96 units encountered in these two penetrations.

In the course of recording from $79 \mathrm{~mm}$ of macaque striate cortex above layer 4 , we encountered 72 blobs, as judged from the histology, 63 of which were associated with a decrease in orientation selectivity, with at least one electrode position, and usually two or three, recording both cells and background hash with a selectivity of $D$. Blobs and lack of orientation specificity are thus well correlated. One of the exceptions can be seen in Fig. $3 B$, where in the upper penetration cells apparently in a blob at $0.9 \mathrm{~mm}$ showed no loss of orientation selectivity. We 


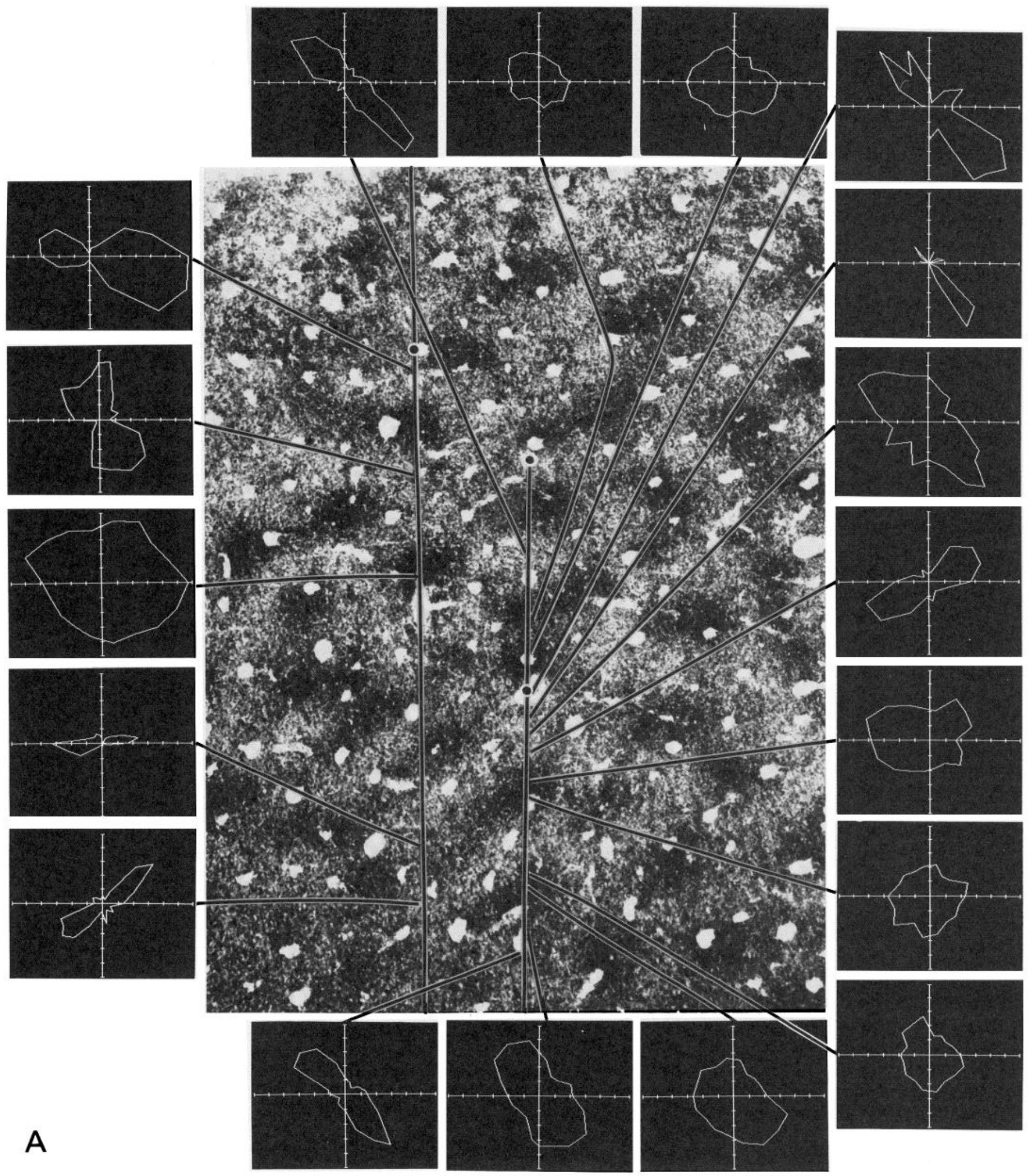

Figure 3. This figure is similar to Figure 2, but it is from a different experiment in which we made two parallel penetrations in layers 2 and 3 of macaque parafoveal striate cortex. The section was stained for cytochrome oxidase. The lesions have been emphasized with dots. A, Polar histograms of 18 of the units encountered in these two penetrations. The penetrations go from bottom to top. B, For both penetrations we have plotted orientation preference (top), ocular dominance $(O D$, middle) and orientation selectivity $(S I$, bottom) at $0.05-\mathrm{mm}$ intervals. 

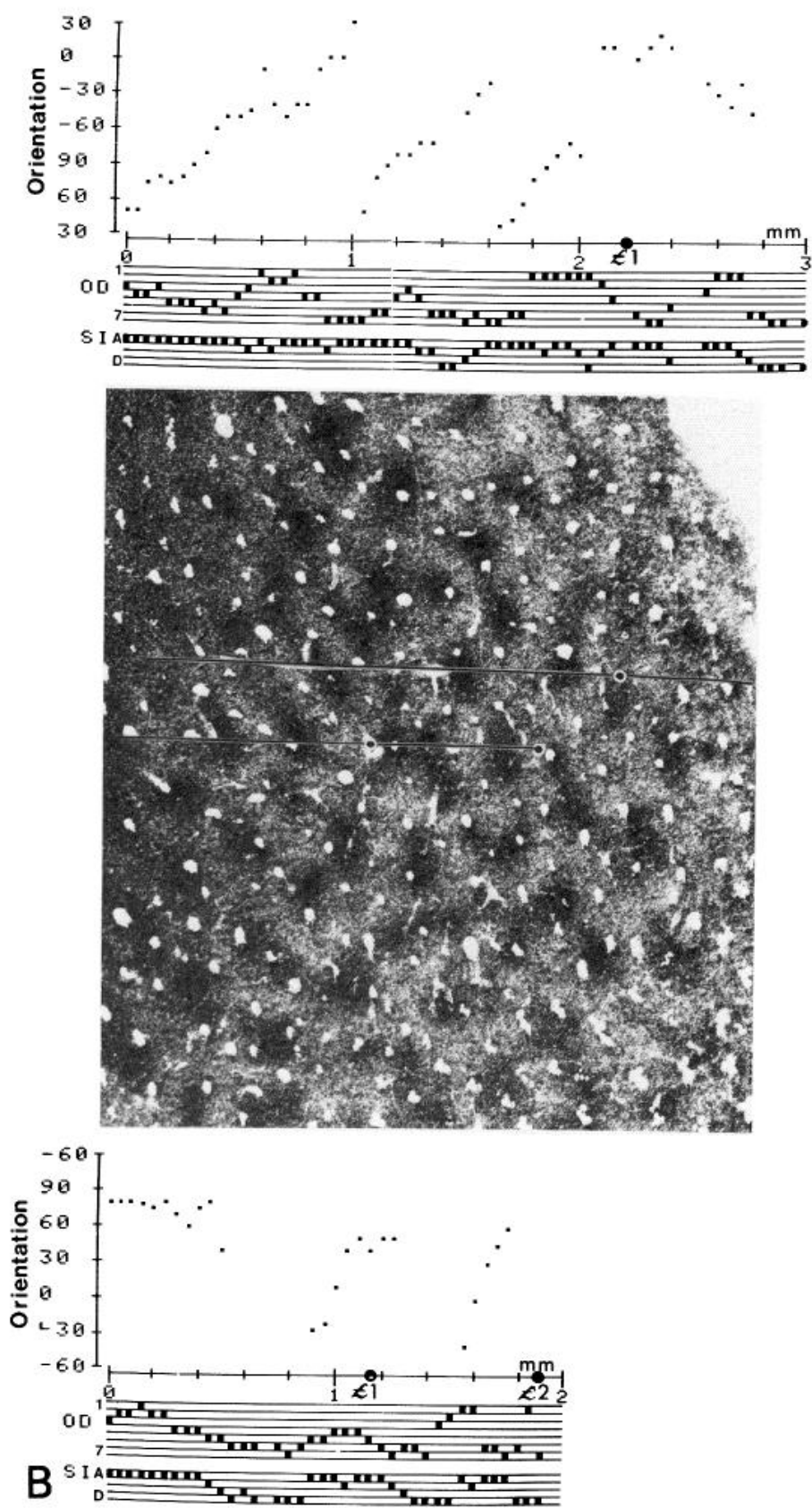

Figure $3 B$

do not know whether such apparent exceptions are genuine or represent failures in precisely correlating the histology with the recording. In traversing most blobs our impression was that all of the activity was unoriented, not only the activity from isolated cells but also from unresolved background hash, in marked contrast to the high orientation selectivity of both (reflecting the grouping of cells of like orientation) between blobs. Figure $2 B$ and $3 B$ illustrate the consistent finding that cells encountered at the edges of blobs tended to be poorly oriented (B's and C's). A blob thus seems to be made up of a core of unoriented cells surrounded by a shell of poorly oriented cells.

In a few experiments we recorded from squirrel monkey striate cortex. In all, we encountered eight blobs in
$18 \mathrm{~mm}$, from each of which we recorded at least one, and usually several, completely unoriented units.

The historically minded reader may have wondered how so prominent a group of cells could have been missed by so prominent a pair of investigators (Hubel and Wiesel, 1968, 1974a). We, of course, wondered the same thing and can think of several possible reasons. (1) Injured cells become sensitive to almost any visual stimulus so that orientation selectivity can be lowered or lost. Thus lack of orientation was probably sometimes wrongly imputed to injury. (2) With no anatomical indication of nonhomogeneity in the upper cortical layers, it would have been easy to dismiss occasional, apparently sporadic groups of unoriented cells. (3) A sudden series of monocular nonoriented cells could be interpreted as entering layer $4 \mathrm{C}$, which occasionally might have seemed remarkably superficial. (4) The prominence was ill-begotten.

There have, certainly, been occasional indications that things were more complicated, one of the most striking of which was Dow's (1974) observation of a cluster of unoriented double-opponent cells in layer 2-3, clearly above layer 4 , made at a time when, unfortunately, the anatomical method of labeling blobs was unavailable.

\section{Ocular dominance of blob cells}

In the macaque, since blobs are centered on ocular dominance columns, one might expect blob cells to show stronger eye preference than surrounding non-blob cells. We compared the ocular dominance of oriented upper layer cells (A's and B's) with that of unoriented upper layer cells (C's and D's), and the unoriented cells, as expected, tended to be more monocular (primarily but not exclusively ocular dominance groups $1,2,6$, and 7 ) than the oriented cells. This is shown in the upper histograms of Figure 4. In the squirrel monkey, on the other hand, the unoriented cells showed no such tendency toward strong eye dominance. This was also to be expected, since in the squirrel monkey it has so far not been possible to demonstrate ocular dominance columns anatomically (Tigges et al., 1977; Hendrickson et al., 1978; Hubel and Wiesel, 1978; Hendrickson and Wilson, 1979), and physiologically only modest fluctuations in ocular dominance have been seen (Hubel and Wiesel, 1978).

\section{Organization of orientation around blobs}

We observed extremely regular sequences of orientation preference in about half of the penetrations (see Figs. $2 B$ and $3 B$ ). Most of the remaining penetrations were also regular but showed one or more reversals or sudden discontinuities in the progression of orientation preference (Hubel and Wiesel, 1974a). Occasional penetrations showed abrupt breaks in the sequences with shifts of up to $90^{\circ}$. Finally, we occasionally went through regions in which there was no obvious order in the orientation sequences. Whenever there were long linear sequences of orientation shifts both before and after a blob, we could ask whether this straight-line sequence was interrupted or perturbed by the blob. Usually it was not, and the rates of change of orientation before and after a blob were within $15 \%$ of each other (Fig. 5). In 
Livingstone and Hubel
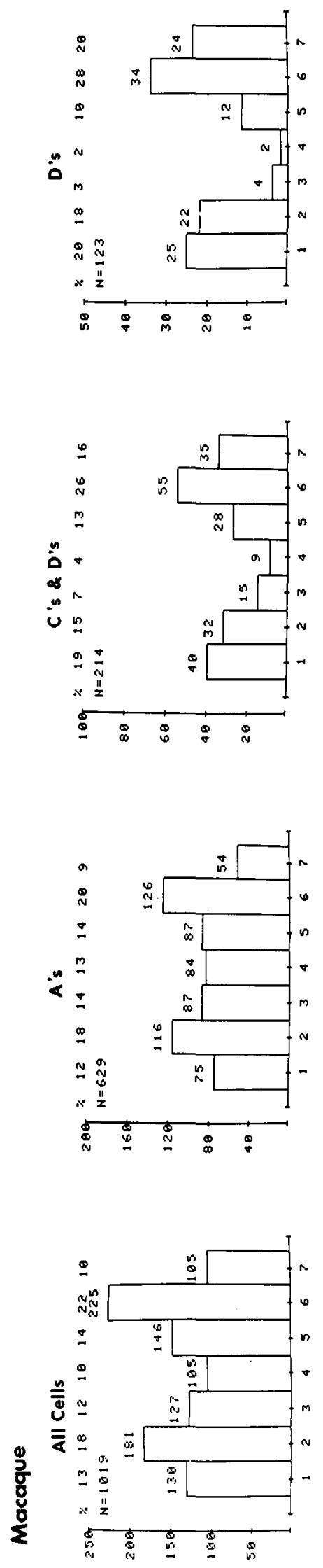

Vol. 4, No. 1, Jan. 1984

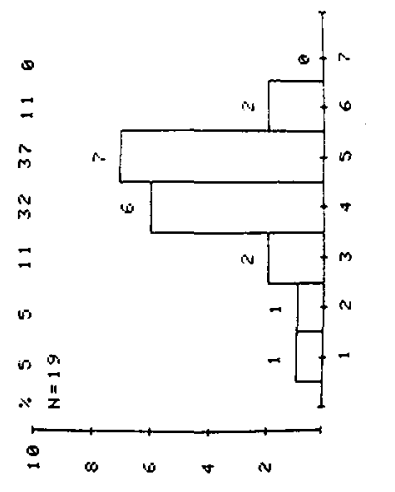

焉

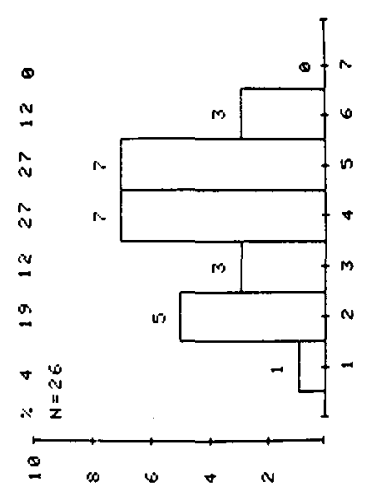

送

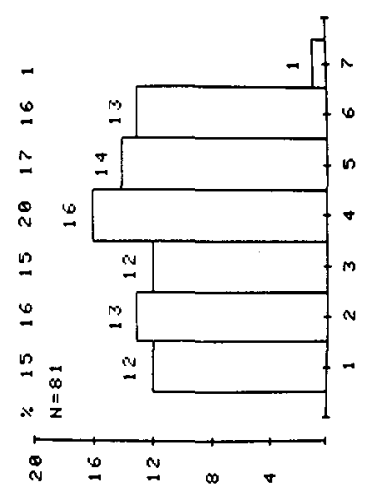

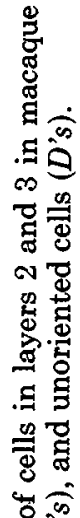

卷它

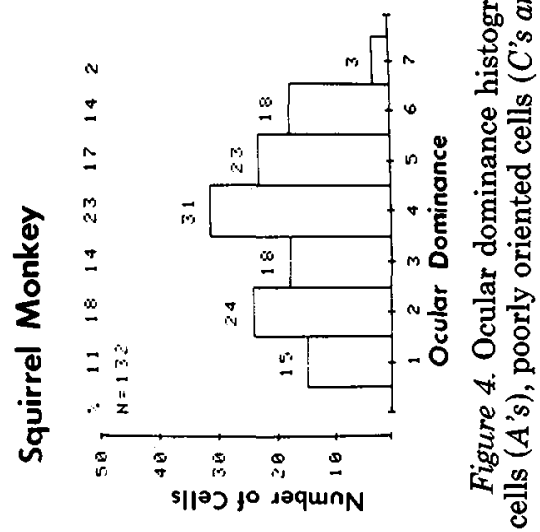




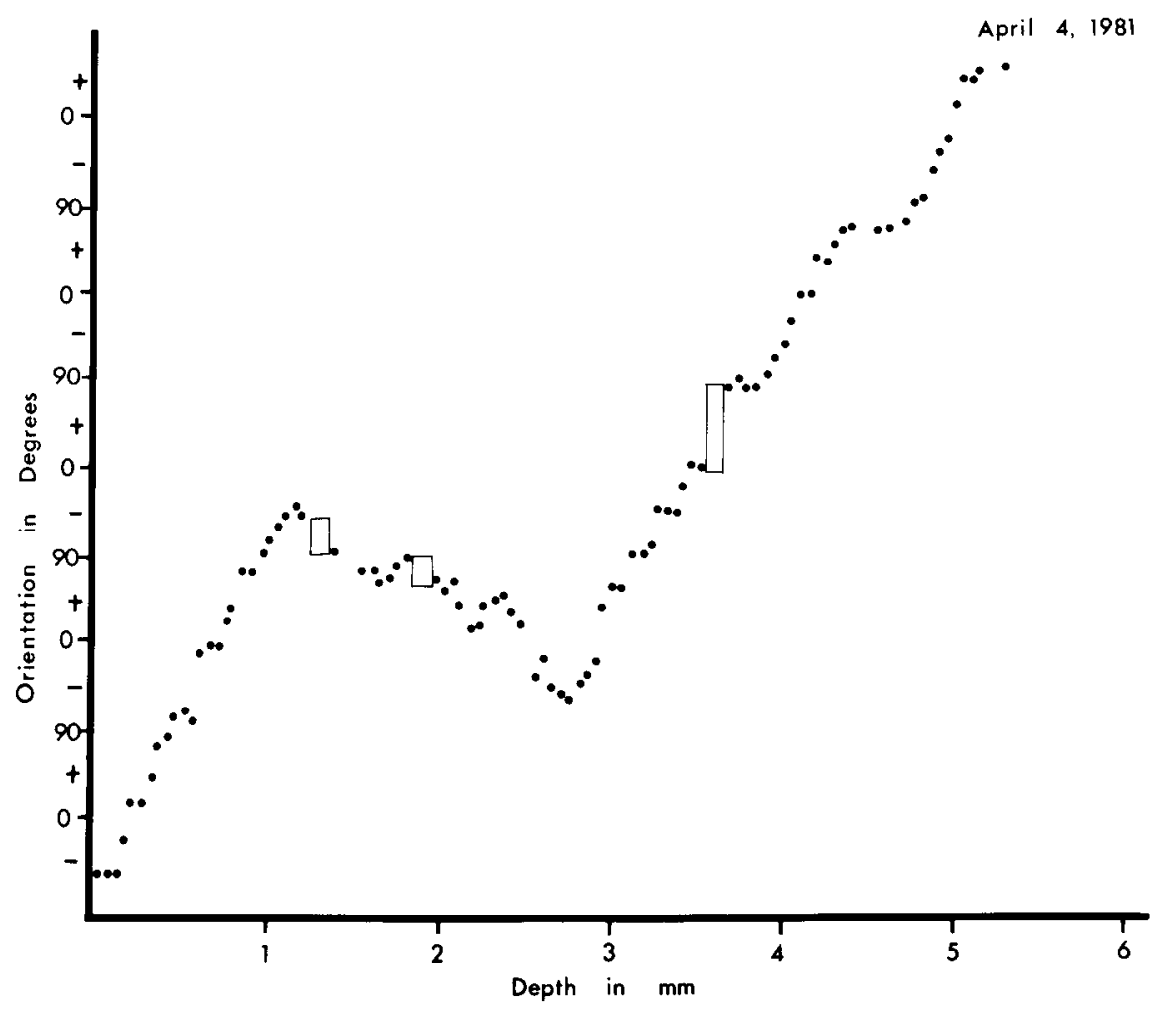

Figure 5. Orientation preferences of units in a single 5-mm-long penetration in layers 2 and 3 of macaque parafoveal striate cortex. The orientation preference changes in a remarkably regular way, with only two reversals in the entire $5 \mathrm{~mm}$. The rectangles indicate blobs, where there is no orientation preference, and the sequence continues linearly as if the blob were not there.

two experiments we made parallel penetrations close together to compare the orientation sequences of the two penetrations. One of these experiments is illustrated in Figure 6, for a pair of almost tangential penetrations 75 $\mu \mathrm{m}$ apart, each traversing $3.5 \mathrm{~mm}$ of upper layer cortex. Over this distance the preferred orientation went through five complete cycles of $180^{\circ}$, in remarkably linear sequence. The orientation preferences of units at points beside each other along the two tracks were virtually identical except that the two penetrations were interrupted at slightly different points by blobs. In both penetrations the orientation sequence resumed after each blob, just as though the interruption had never occurred. Thus there appears to be no distortion of the orientation sequence around the blobs. Neither is there any indication that iso-orientation lines are organized either radially or concentrically around blobs (Braitenberg and Braitenberg, 1979), since two parallel penetrations show linear sequences of orientation preference with the same slope, even when one track goes through the center of a blob and the other track skims or entirely misses the same blob.

In another experiment, shown in Figure 7, we made three parallel penetrations, two of them (penetrations 1 and 3) $100 \mu \mathrm{m}$ apart, and the third (penetration 2) $1 \mathrm{~mm}$ lateral to them. Again the two adjacent penetrations were remarkably similar in their sequences of orientation preference, even though they were far enough apart to intercept different blobs. The third penetration was less similar to the other two, suggesting that iso-orientation lines may be parallel over short distances, but far from parallel over longer distances.

\section{Part II: On the Color Properties of Blob Cells}

In the first series of experiments we concentrated on learning how consistent the lack of orientation specificity was in the blobs. We ended up fully convinced that cells within blobs in layers 2 and 3 lacked orientation specificity, and cells outside blobs were well tuned. A lack of orientation selectivity in the blob cells could have one of two explanations: the cells could be of lower order, with center-surround receptive fields like those of layer 4 or the lateral geniculate body; or they could be of higher order, pooling the inputs of the neighboring orientationspecific cells surrounding the blobs and consequently responding to line segments in all orientations. We quickly eliminated the second possibility: the blob cells classified as D turned out to have circularly symmetric receptive fields and gave vigorous responses to appropriately placed stationary round spots. We therefore set out to compare blob cells with the concentrically organized cells that have already been described at various levels in the macaque visual system and which are summarized in the next paragraphs (for review, see Gouras and Zrenner, 1981). Then, under "Results" in this section we describe in detail the receptive field properties of blob cells. In Part III, for comparison, we describe the receptive fields of cells in the other layers, especially $4 \mathrm{C}$. 


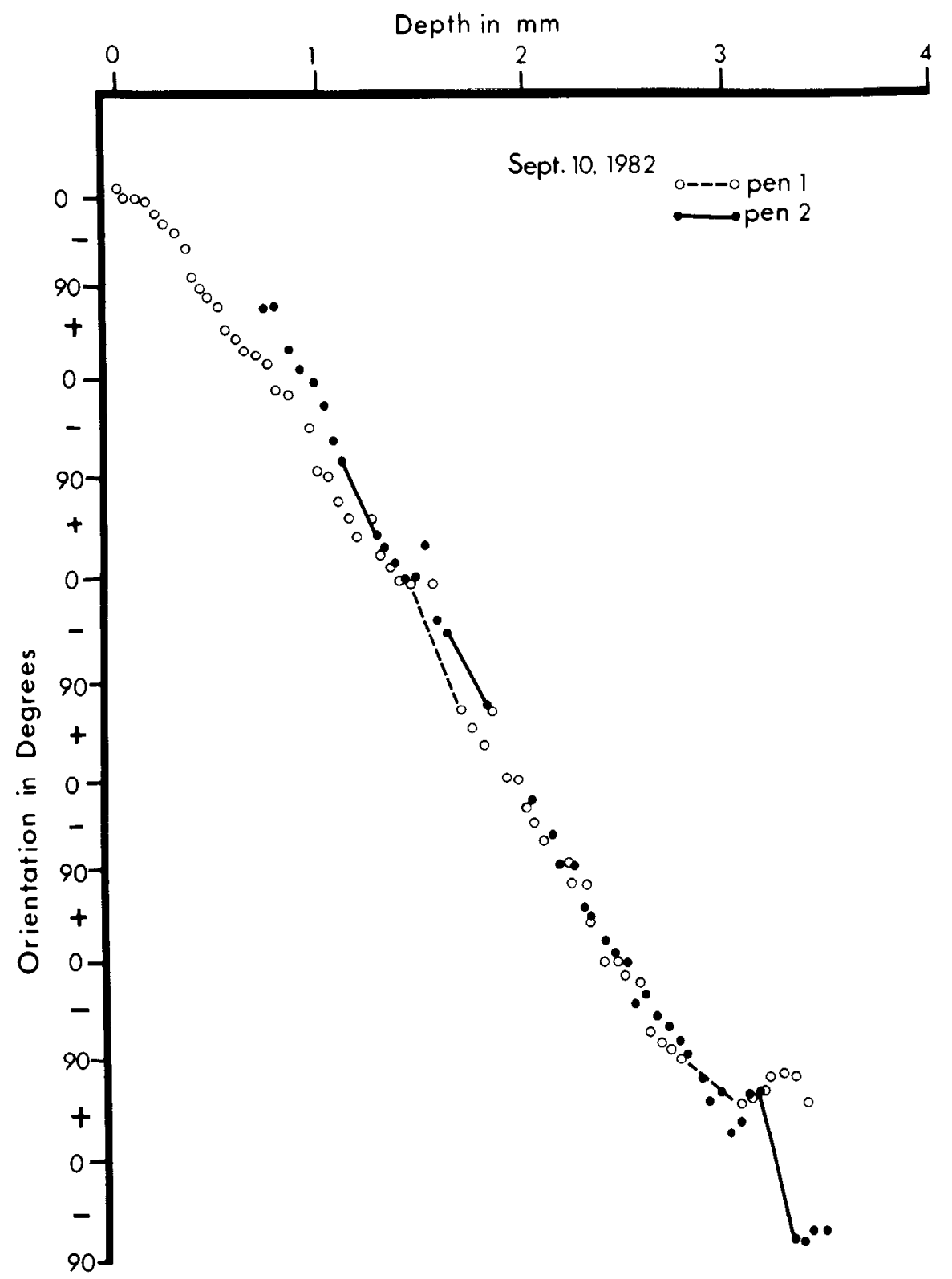

Figure 6. Orientation preferences along two parallel penetrations in layers 2 and 3 of macaque parafoveal striate cortex. The two penetrations were $75 \mu \mathrm{m}$ apart. The lines connecting points indicate blobs, where there was no orientation.

The terms "type 1," "type 2 ," etc., coined in 1966 when receptive fields of macaque geniculate cells were first described (Wiesel and Hubel, 1966), are brief but neither self-explanatory nor easy to remember; therefore, we are appending to them a new set of more descriptive terms (Fig. 8).

Unless indicated otherwise, all of the descriptions pertain to the macaque monkey.

\section{A summary of previously described types of circularly symmetical cells}

1. Color-Opponent Center-Surround (type I) cells. In the dorsal four (parvocellular) geniculate layers in the macaque monkey three types of cells have been described: Color-Opponent Center-Surround (type I), Color-Opponent Center-Only (type II), and Broad-Band (type III)
(Fig. 8) (Wiesel and Hubel, 1968; Krüger, 1977; Schiller and Malpeli, 1978; Creutzfeldt et al., 1979). By far the most common of these, accounting for about $80 \%$ of the total, is the Color-Opponent Center-Surround (type I). These have not been found in the magnocellular layers. Their fields are concentric, with an on or off center and an opposing surround; they show wavelength opponency, in that the spectral sensitivities of the center and surround differ. The original impression (Wiesel and Hubel, 1966) was that the center system received contributions from one of the three cone types and the antagonistic surround from another; and of the three possible cone combinations two were observed: the red cones were pitted against the green, or the green against the blue. (For brevity we shall refer to the three cone types as red-, green-, and blue-sensitive, or simply as red, green, 


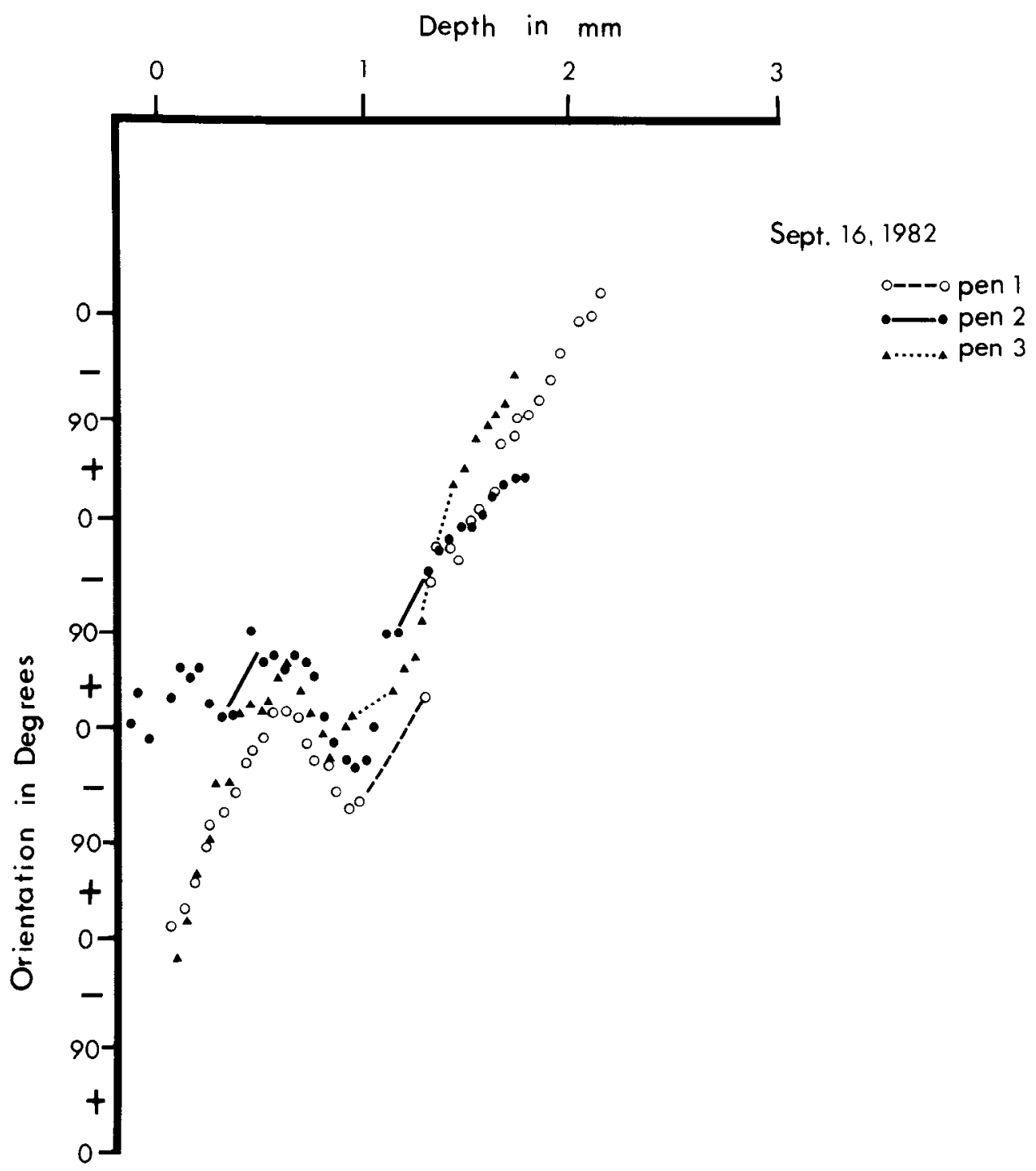

Figure 7. Orientation preferences of units along three parallel penetrations in layers 2 and 3 of macaque parafoveal striate cortex. Penetrations 1 and 3 were $100 \mu \mathrm{m}$ apart and penetration 2 was $1 \mathrm{~mm}$ lateral. The lines indicate blobs.

and blue, despite the looseness of that terminology.) No concerted attempt was made to distinguish by chromatic adaptation a cell fed by blue cones in opposition to green from one fed by blue cones in opposition to a combination of green and red cones, or red versus green as opposed to red versus green-plus-blue. At the retinal ganglion cell level the most thorough studies of that type (e.g., DeMonasterio et al., 1975; DeMonasterio and Schein, 1982) indicate that cells of type I are either red versus green $(56 \%)$ or blue versus green-plus-red, i.e., blue versus yellow (18\%), with 3 to $4 \%$ each of green versus blueplus-red and red versus blue-plus-green. Although similar types, and in similar proportions, might reasonably be expected to be present in the geniculate, we wish to emphasize that, in using "yellow versus blue" or "Y-B" in this paper to describe a class of opponency, we have no evidence to distinguish between yellow versus blue and green versus blue.

Recognition of a Color-Opponent Center-Surround cell is generally easy. With light at one end of the spectrum, on or off responses sum over a large area; at the other end the opposite type of response is evoked from a much smaller area (the center), and a spot filling that central area evokes the same response as a much larger spot. At intermediate wavelengths or with white light, a small center-size spot is far more effective than a large spot in activating or suppressing a cell, and consequently with white light alone these cells are not distinguishable from Broad-Band cells. The response to a center-size white spot (in contrast to a large spot) is never improved when a color filter is inserted into the light path, unless the white spot is so bright that the light scatters into the surround. Presumably this is because a center-size spot is too small to activate the surround system to any detectable extent, even if the two systems overlap.

2. Color-Opponent Center-Only cells (type II) make up roughly $10 \%$ of the parvocellular layer geniculate cells; like type I cells, they have not been observed in the magnocellular layers. They have no field surround, but 
Broad Band (Type III)

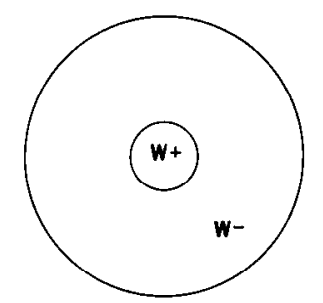

Color-Opponent Center-Surround

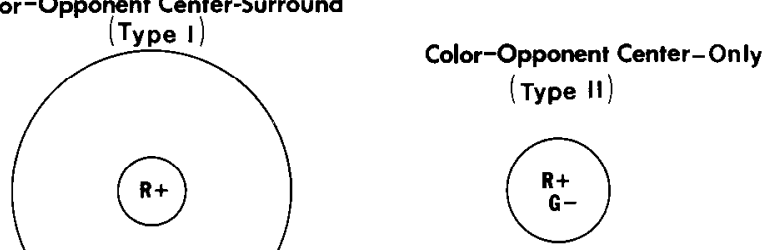

Figure 8. 'Types of radially symmetrical cells found in the primate visual system. All except Double-Opponent have been seen in the parvocellular geniculate layers; all but Color-Opponent Center-Surround have been seen in cortical blobs.

are fed by two completely superimposed and antagonistic sets of cones, either red versus green or blue versus yellow. They give on responses to a spot of light at one end of the spectrum, off responses (or suppression of spontaneous firing, or both) to a spot of light at the other end, and no response at some intermediate wavelength; white light similarly evokes a weak response or none, so that simply introducing a color filter into a beam of white light can enhance a weak response or produce a response where there was none. Whatever the spectral composition of the light, a large spot is not less effective than a small one.

3. Broad-Band cells (type III) make up the remaining $10 \%$ of cells in the parvocellular layers. These are centersurround cells that show no opponent-wavelength effects. Large spots always evoke weaker responses than center-size spots, a spot of any particular size gives the same kind of response (on or off) for all effective wavelengths, and the responses evoked by a white spot, whatever its size, are not enhanced by interposing a color filter. For these cells the spectral sensitivities are the same for all parts of the receptive field and hence the proportions of the three cone types feeding in are constant. In particular, spectral sensitivites are identical for center and surround. From one such cell to the next the spectral sensitivity curves may not be identical, but the breadths of the curves and the narrowing following chromatic adaptation indicate that the cells receive inputs from more than one cone type, perhaps most frequently from red and green (DeMonasterio and Gouras, 1975) and possibly from all three (Wiesel and Hubel, 1966).

Information on rod input to the three geniculate cell types just described is still fragmentary. Some of the Color-Opponent Center-Surround and Broad-Band cells clearly receive rod inputs; many equally clearly do not (Wiesel and Hubel, 1966).

4. Broad-Band with Tonic Red Surround cells (type $I V)$. The ventral two (magnocellular) geniculate layers contain two main cell types, Broad-Band (type III), and a type not found in parvocellular layers, originally termed type IV (Wiesel and Hubel 1966). Type IV cells, like Broad-Band cells, have center-surround receptive fields, and both center and surround have broad spectral sensitivities. They are different, however, from Broad-Band cells in that the center and surround produce responses with different time courses and have different spectral sensitivities. Responses from the center are very brief and, depending on the cell, may be on or off. In most cells this brief response is reduced when the stimulus is enlarged, indicating the presence of a short time course inhibitory surround, but, in addition, surround stimulation evokes a profound tonic suppression of spontaneous firing, which is usually stronger for long-wavelength light than for middle or short, or for white light. This tonic surround suppression, found in both on- and off-center type IV cells, undoubtedly explains the striking and lasting silence in the magnocellular layers brought on by a large red spot-a silence both in the cell observed and in the background unresolved activity, which otherwise sounds like a beehive. Ventral layer cells tend to have their spontaneous and evoked discharges grouped in bursts at 25 to $35 / \mathrm{sec}$, with discharge rates within bursts reaching levels of about $200 / \mathrm{sec}$. The bursts tend to be synchronized so that the unresolved background activity, like the cells, seems to buzz. This type of firing pattern does not occur in the parvocellular layers. Some ventral layer cells show linear spatial summation within their field centers, as do parvocellular layer cells, and others do not (Kaplan and Shapley, 1982). They have lower contrast thresholds than do dorsal layer cells (Shapley et al., 1981).

5. Double-Opponent cells have not been described in the retina or lateral geniculate body of primates. They were first observed in the goldfish retina by Daw (1968), who with Pearlman later made a concerted search for them in the macaque lateral geniculate, but failed to find any (Daw, 1972). Double-Opponent cells have been described in macaque striate cortex (Hubel and Wiesel, 1968; Dow, 1974; Poggio et al., 1975; Michael, 1978).

Double-Opponent cells have center-surround receptive fields. Both center and surround when stimulated alone showed color opponency. The center resembles the receptive field of a Color-Opponent Center-Only (type II) cell, receiving two opponent sets of cone inputs; the surround likewise has opponent-color inputs, opposite in sign to the inputs feeding the center. An example is a cell with field center $R+G-$ and surround $R-G+$. Such a cell tends to respond poorly or not at all to white light spots of any size or shape, or to diffuse light of any spectral composition.

As with the other cell types described, recognition of Double-Opponent cells requires no special equipment or extensive measurements. A small spot evokes on responses to light at one end of the spectrum and off responses to light at the other end; white light can evoke 
a weaker response than colored light produced simply by interposing a suitable filter; and for a given wavelength composition and intensity, a large spot always evokes a weaker response than a small spot of center size.

Our object in this part of the study was to determine whether the unoriented cells in the blobs fell into any of the five classes described here, or into some other classes. It was important to categorize as many cells as possible, at several different eccentricities. For this it did not seem necessary to plot spectral sensitivity curves: such plots, with and without chromatic adaptation, are necessary if one is to establish with certainty the cone types feeding into a cell from the different parts of the receptive field. For our purposes it was enough to plot response amplitude against stimulus spot diameter for light at several wavelengths and for white light.

To establish the presence of opponency, spatial or chromatic, it is not necessary to evoke on responses with one stimulus and off responses with the other: the opponency is clear if one of the two stimuli evokes a response and both together give a reduced response or none. In fact, as Barlow (1953) originally showed for center-surround cells, if the opposing surround response cannot be demonstrated by an annulus alone, it can usually be brought out by tonically activating the center system with a small spot while flashing on and off a second, large spot. In a color-opponent cell the analogous procedure is to bathe the field in light of one wavelength while testing with light of another wavelength. We assume that the point of opponency is to render ineffective things like diffuse light or white light, rather than to permit a cell to have two kinds of response.

\section{Results}

\section{Receptive field properties of blob cells}

The unoriented upper layer blob cells could be subdivided into the groups listed in Table $\mathrm{I}$, to which the reader is encouraged to refer frequently. The two outstanding features of blobs were the abundance of DoubleOpponent cells, in contrast to their apparent absence in the geniculate and in layer $4 \mathrm{C}$ of the striate cortex (see Part III), and the apparent lack of Color-Opponent Center-Surround cells, which in the geniculate form the most common type.

In layers 2 and 3 of macaque monkey striate cortex, we recorded from 532 class D (unoriented) cells of which 173 were foveal and 359 nonfoveal, but the first 328 cells were collected with the main aim of pinning down the association between blobs and lack of orientation specificity: only the final 204 cells were examined closely enough to determine receptive field type (Table I). Ninety-one of these 204 had fields in the fovea, a term we use here, loosely, to refer to the central 2 to $2 \frac{1}{2}{ }^{\circ}$ of visual field. The remaining 113 cells recorded more medially had fields 6 to $10^{\circ}$ from the fovea and are termed "non-foveal." Of the categories of cells listed in Table I, " $3 / 4$ Double-Opponent" is a variant of Double-Opponent cells. "Miscellaneous color" includes cells that had circularly symmetric ficlds with color-opponent centers but could not be further categorized because they were killed or damaged, plus a few cells with very special properties related to binocularity, to be described below.

1. Broad-Band cells. Next only to Double-Opponent cells, Broad-Band cells were the most important class of blob cells. Fifty-two ( 26 foveal, 26 nonfoveal) of the 204 nonoriented cells (Selectivity Index D) were classed as Broad-Band. As shown in Table I, the proportion of Broad-Band cells was only slightly higher in nonfoveal blobs than in foveal blobs. Most of the Broad-Band cells had relatively strong surround antagonism, as is shown in the area response graphs of Figure 9 for a typical oncenter Broad-Band cell. On-center cells outnumbered off-center cells by more than two to one.

Most of these cells gave vigorous responses at all wavelengths from $440 \mathrm{~nm}$ to $680 \mathrm{~nm}$, and thus probably received inputs from all three cone types.

2. Type IV. We categorized a cell as type IV (for this type we are at a loss to think of a pithy descriptive name) if center stimulation was effective over a broad range of wavelengths and if the response evoked by diffuse light (especially at long wavelengths) was much more sustained than the response to a small spot. Nineteen of the $204 \mathrm{D}$ cells were classed as type IV, but in this we were conscious of being somewhat arbitrary since, in blobs, Type IV cells as just defined were more variable than in the geniculate. Many of the cells that we did not classify as type IV nevertheless had surround responses that were more sustained than the center responses. These tonic diffuse light responses were on for some cells and off for others. Figure $10 a$ shows poststimulus time histograms from a cell that we put in group IV because of the broadband on-center, the suppression of the initial on-burst by the surround, and especially the maintained suppression of spontaneous firing by large red spots. Cortical type IV cells often showed the characteristic rhythmic, bursty firing seen in geniculate type IV cells.

3. Center-Only Color-Opponent cells (type II). These cells ("COCO" in Table I) formed only a small proportion $(13 \%)$ of the total blob population; they thus seemed to be about as common in blobs as they are in the geniculate. We saw examples of red-on, green-off; red-off, green-on; and blue-on, yellow-off. Figure 11 shows response histograms from a red-on, green-off cell, with no difference between responses to small (center-size) and large spots. In this cell the long wavelength system prevailed over the short, so that white gave a weak on-response. For most type II cells, however, the two systems were balanced, so that white light evoked no response.

4. Double-Opponent cells. Double-Opponent cells made up the largest class of blob cells. They were about as common in the foveal region of the cortex as in the nonfoveal cortex. A typical Double-Opponent cell's behavior is illustrated in Figure 12. This cell had an R+ $\mathrm{G}-$ center and an $\mathrm{R}-\mathrm{G}+$ surround. In the poststimulus time histograms of Figure $12 a$, responses to small $\left(0.5^{\circ}\right)$ and large $\left(10^{\circ}\right)$ spots are shown for red, blue, and white light. Both the on response to a small red spot and the off response to a small blue spot were virtually obliterated by enlarging the spots to include the surround. We could not evoke surround responses with annuli, but the lack of response to large spots clearly indicates the presence 
TABLE I

Distribution of cells in macaque striate cortex

FOVEAL

$\mathrm{n}=477$

\begin{tabular}{|c|c|c|c|c|c|c|c|c|c|c|}
\hline \multicolumn{5}{|c|}{ ORIENTED CELLS } & \multicolumn{6}{|c|}{ UNORIENTED CELLS } \\
\hline \multicolumn{5}{|c|}{ Wu4 oriented $(64 \%)$} & \multicolumn{6}{|c|}{173 unoriented (36\%) } \\
\hline \multicolumn{5}{|c|}{235 tested for color } & \multicolumn{6}{|c|}{113 tested for color } \\
\hline \multirow{2}{*}{$\begin{array}{c}\text { white } \\
142\end{array}$} & \multirow{2}{*}{$\begin{array}{c}\text { black } \\
12\end{array}$} & \multirow{2}{*}{$\begin{array}{l}\text { red } \\
66\end{array}$} & \multirow{2}{*}{$\begin{array}{c}\text { green } \\
5\end{array}$} & \multirow{2}{*}{$\begin{array}{c}\text { blue } \\
10\end{array}$} & \multicolumn{4}{|c|}{$\begin{array}{c}79 \text { color coded } \\
(70 \%)\end{array}$} & \multicolumn{2}{|c|}{$\begin{array}{c}34 \text { not color coded } \\
(30 \%)\end{array}$} \\
\hline & & & & & \multirow{3}{*}{$\begin{array}{l}\text { DO } \\
49\end{array}$} & \multirow{3}{*}{$\begin{array}{c}3 / 4 \\
\text { DO } \\
8\end{array}$} & \multirow{3}{*}{$\begin{array}{c}\mathrm{COCO} \\
17\end{array}$} & \multirow{3}{*}{$\begin{array}{c}\text { mise } \\
5\end{array}$} & \multirow{3}{*}{$\begin{array}{l}\mathrm{BB} \\
26\end{array}$} & \multirow{3}{*}{$\begin{array}{c}\text { type } \\
\text { IV } \\
8\end{array}$} \\
\hline & & & & & & & & & & \\
\hline & & & & & & & & & & \\
\hline
\end{tabular}

NON-FOVEAL

$\mathrm{n}=1783$

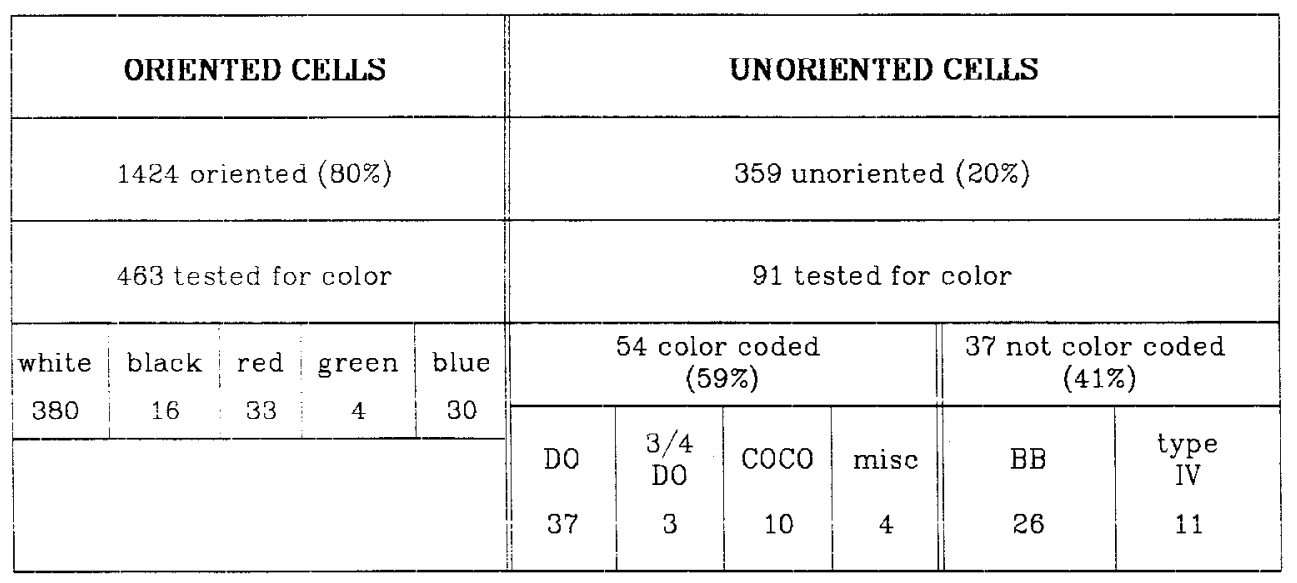

of an inhibitory surround. White light evoked no responses. Graphs of response rates versus spot size are given in Figure $12 b$ for red, blue, and white light; the rates are averaged over the entire stimulus-on period and for $0.4 \mathrm{sec}$ following off.

The Double-Opponent cell of Figure 13 was also an $\mathrm{R}+\mathrm{G}-$ center. The surround antagonism, although clear, was far from complete. This cell was also unusual in that the green system dominated so that white spots suppressed the spontaneous firing and evoked off responses.

Finally, we attempted to bring out the possible significance of these cells for color contrast. Figure $14 A$ shows the responses to small and large spots of a G+, R-center Double-Opponent cell, in which diffuse light and white light both gave weak responses or none. We mounted a center-size $\left(0.5^{\circ}\right)$ circle of cyan paper on a large piece of red paper and centered the cyan spot on this cell's receptive field. When we illuminated the montage with red light from a slide projector with a 620 -nm interference filter the appearance (to us) was of a black spot on a desaturated reddish background. When a large shutter in front of the animal's eyes was opened, the cell responded in the half-hearted manner shown in the top record of Figure $14 \mathrm{~B}$. When illuminated with only blue light $(490 \mathrm{~nm})$ the montage appeared to us as a tepid blue spot on a black background. This produced the middle response of Figure 14B. (These responses should probably not be compared with those of Fig. 14A, in which there was background white light.) When both projectors were turned on and the shutter was opened and closed the cell responsed vigorously as shown in the bottom record. To us (and also to neutral observers) the montage was now a vivid blue on a vivid red background. We thus had a strong impression that the cell responded in parallel with our impression of blue and red, rather than simply to light of a particular wavelength. On the other hand, we have, as discussed below, no evidence that, for these cells, such effects take place over long distances.

Of the 86 Double-Opponent cells in this series we 

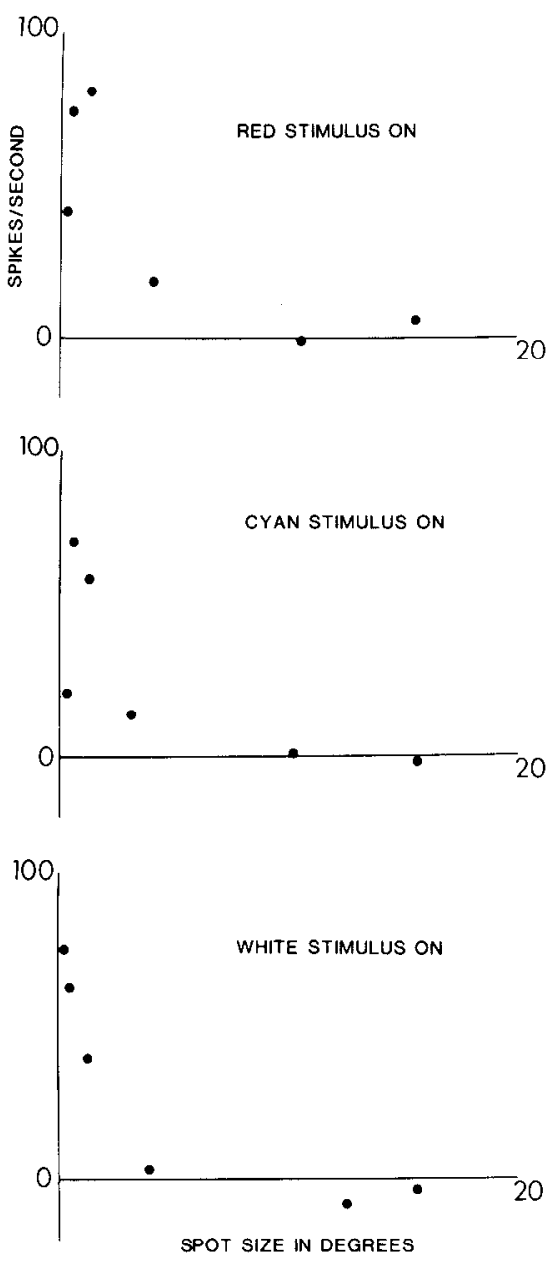

Figure 9. Area response graphs for an on-center Broad-Band cell from layers 2 and 3 of macaque nonfoveal striate cortex. The graphs show average increase in firing rate above the resting rate in impulses per second during the time the stimulus was turned on (time on $=1 \mathrm{sec}$ ). The stimulus was a spot of light, and for all graphs the abscissa is the stimulus size in degrees. The surround antagonism is evident in the abolition of the response for spot sizes larger than $5^{\circ}$. The cyan and red stimuli were produced simply by inserting a Wratten filter in the light path of the optic bench. Each point represents the average response to five stimuli.

studied 71 in enough detail to group them according to probable cone input. The two opponent-center systems were usually balanced, so that a small white spot produced little or no response. We could group most of these well balanced cells by finding with interference filters the wavelength at which a small spot gave no response; i.e., the point at which the response reversed from on to off: for red versus green cells this was in the yellow (560 to $580 \mathrm{~nm}$ ), for blue versus yellow (or blue versus green) cells it was green (480 to $500 \mathrm{~nm}$ ). Table II shows a striking preponderance of red versus green cells over blue versus yellow (or green) cells and a preponderance of $\mathrm{R}+\mathrm{G}-$ cells over all other types. The apparent rarity of $\mathrm{B}-\mathrm{Y}+$ cells has been seen in other studies in macaque retina and geniculate (Wiesel and Hubel, 1966; Gouras and Zrenner, 1979).

5. 3/4 Double-Opponent cells. By this term we mean cells that resembled Double-Opponent cells except for an absence or relative weakness of one of the two surround systems. Although not rare in blobs, these cells were much less common than full blown Double-Opponent cells. To class them separately, rather than as a variant type of double-opponent cell, is admittedly an arbitrary decision. Figure 15 shows an example of a redon green-off center cell, whose surround was green-on only. Large green spots evoked no off response, whereas a large red spot gave about as vigorous an on response as a small one.

6. Correlations with eccentricity. In previous studies of the foveal part of macaque striate cortex, Dow and Gouras (1973), Dow (1974), Poggio et al. (1975), and Zeki (1983) found that a high proportion of cells were color coded, and that many of the color-coded cells had no orientation selectivity. This seemed at odds with the paucity of orientation-unselective cells and of color-opponent cells in the studies of Hubel and Wiesel (1968), but those studies were made mainly in more medial striate cortex, subserving an eccentricity of 6 to $10^{\circ}$. In more foveal striate cortex Hubel and Wiesel (1968) found a higher porportion of color-coded cells. The present series likewise shows a higher proportion of unoriented cells, both color coded and broad band, in foveal cortex as opposed to nonfoveal (Table I). Thus, outside the fovea only $20 \%$ of cells in layers 2 and 3 lacked orientation selectivity, compared with $36 \%$ in the fovea. In four foveal tangential penetrations above layer 4, passing through a total of $18 \mathrm{~mm}$ of cortex, the cells between blobs were all orientation selective (rated A or B). The increase in unoriented cells must therefore be accounted for by cells within blobs, and we accordingly asked whether there were more blobs per square millimeter in the foveal area, or if the blobs were larger.

We looked at tangential sections of blocks made by flattening the entire exposed striate cortex of one side (Welker, 1976). In all, 20 hemispheres were flattened, frozen, and sectioned. In most of these, the blobs in the foveal region appeared larger than the blobs away from the fovea (Figure 16). To check this impression, we made large photographs of sections at several depths in layers 2 and 3 from each of four flattened occipital lobes, from three different monkeys. From each photograph we took 10 areas, each containing 25 to 100 blobs. Each blob (for a total of 4231 blobs) was traced by two people who did not know the origin of the sample, and its area was measured by planimetry. For each eccentricity, we then calculated the average blob size, the ratio of blob to nonblob area, and the average number of blobs per unit area. The results (Fig. 17) show a decrease in average blob size by a factor of 2 on going from the fovea to a region 6 to $10^{\circ}$ out from the fovea (from $0.072 \pm 0.02 \mathrm{~mm}^{2}$ to 0.035 $\pm 0.012 \mathrm{~mm}^{2}$. The number of blobs per unit area showed less change, and the proportion of blob to non-blob area was thus lower.

7. Binocular properties of blob cells. The remarks made in Part I concerning binocularity of blob cells apply equally well to the separate cell categories. Within each category many cells were binocular, but most of these strongly favored one or the other eye, with only a few in ocular dominance groups 3 to 5 .

In all but two blob cells, when responses were evoked separately from each eye the two receptive fields were 


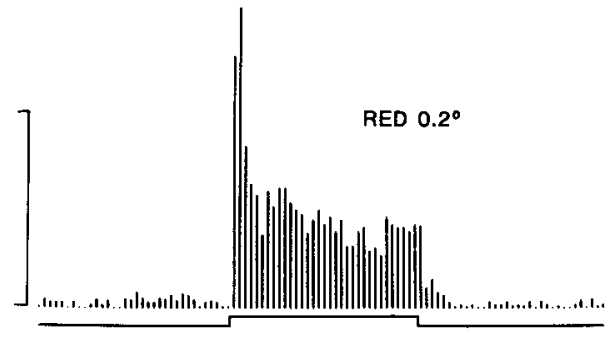

CYAN $0.2^{\circ}$

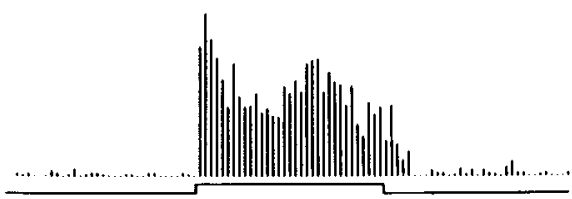

WHITE $0.2^{\circ}$

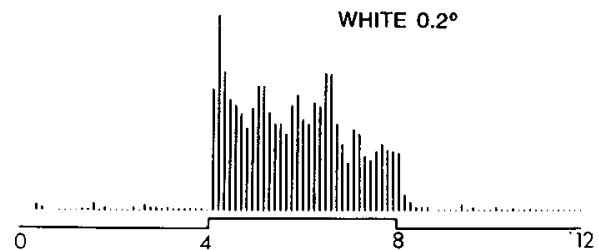

A

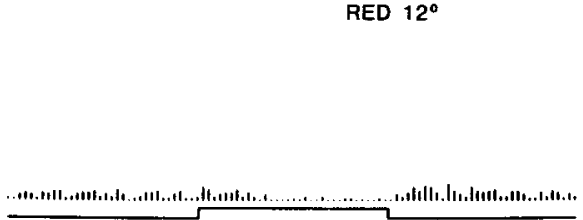

CYAN $12^{\circ}$

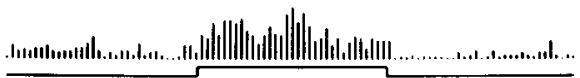

WHITE $12^{\circ}$

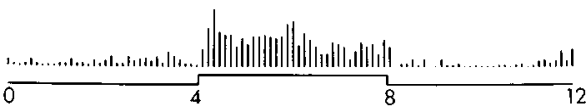

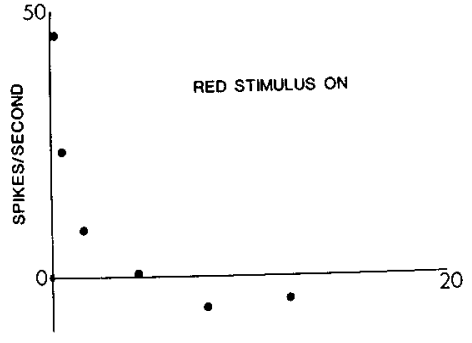
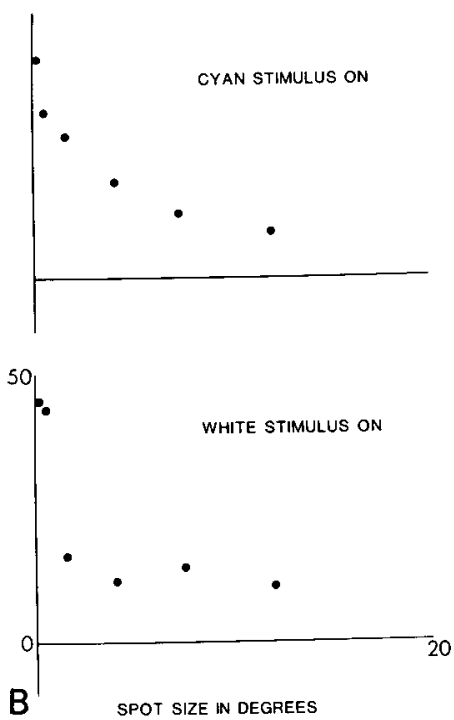

Figure 10. Responses of a type IV cell from a blob in layers 2 and 3 of macaque nonfoveal striate cortex. A, Poststimulus time histograms for small $\left(0.2^{\circ}\right)$ and large $\left(12^{\circ}\right)$ spots. The height of the lines represents the number of spikes per bin (vertical scale $=10$ spikes per bin) and each bin is 120 msec. The abscissa represents time in seconds. The upward deflection in the time scale indicates the period during which the stimulus was turned on. Each graph is the averaged response to 10 stimuli. The center system is Broad-Band, as is the surround, but for long wavelengths the surround actually prevails over the center. $B$, Graphs of response versus spot diameter for red, cyan, and white spots. The response is the average rate of firing during the entire time the stimulus was on, minus the average rate of firing for $4 \mathrm{sec}$ before the stimulus was turned on, to give a difference in firing rate. Each point represents the average response to 10 stimuli. The on-responses to small spots are similar for red, cyan, and white stimuli, but for spots larger than $5^{\circ}$ the response to a red spot is inhibitory, whereas the response to a cyan or white spot is excitatory.

qualitatively similar. In each of the two exceptions, both well resolved single units, the left and right eyes evoked diametrically opposite responses. The first (Fig. 18) was a Broad-Band cell, but on-center in the left eye and offcenter in the right. For either eye a large spot evoked a slightly reduced response with the center system prevailing. The right eye was dominant, so that a large spot stimulating the two eyes together produced an off response that was increased when the left eye was covered, indicating that the responses from the two eyes, although opposite in sign, were algebraically additive (in a way that could hardly occur if the responses were due to two cells). The histology of this penetration was not good enough for us to be certain of the location of the cell, but it is likely that it was in layer $4 \mathrm{~B}$.

The second example, from a different experiment, was even more bizarre (Fig. 19). It was Double-Opponent in each eye, in the right eye $R+G-$ center, $R-G+$ surround; in the left eye $\mathrm{R}-\mathrm{G}+$ center, $\mathrm{R}+\mathrm{G}-$ surround. Large spots evoked no responses, regardless of wavelength.

For each of these strange cells the field centers for the two eyes were in roughly corresponding parts of the visual field, but we cannot say whether the correspondence was exact-and that is crucial to any interpretation. Nevertheless, whatever the relative positions, we are at a loss to imagine any plausible benefit these collector's items could offer the animal.

8. Squirrel monkey blobs. Although we originally set out to examine blobs in macaque monkeys, the squirrel monkey offers some advantages, the chief of which are the large exposure of area 18 on the outer surface of the brain and the relative orderliness of the cytochrome oxidase staining pattern of this area. For these reasons we used squirrel monkeys for the majority of the anatomical studies described in Part IV. Two additional differences make the squirrel monkey interesting. First, the system of ocular dominance columns is much less well developed than in macaques. No anatomical method has so far succeeded in demonstrating them, and even though fluctuations in eye preference can be seen physiologically in long penetrations, they are mild compared to what is seen for macaques or even cats. Second, the color capabilities of squirrel monkeys, hehaviorally measured, are 

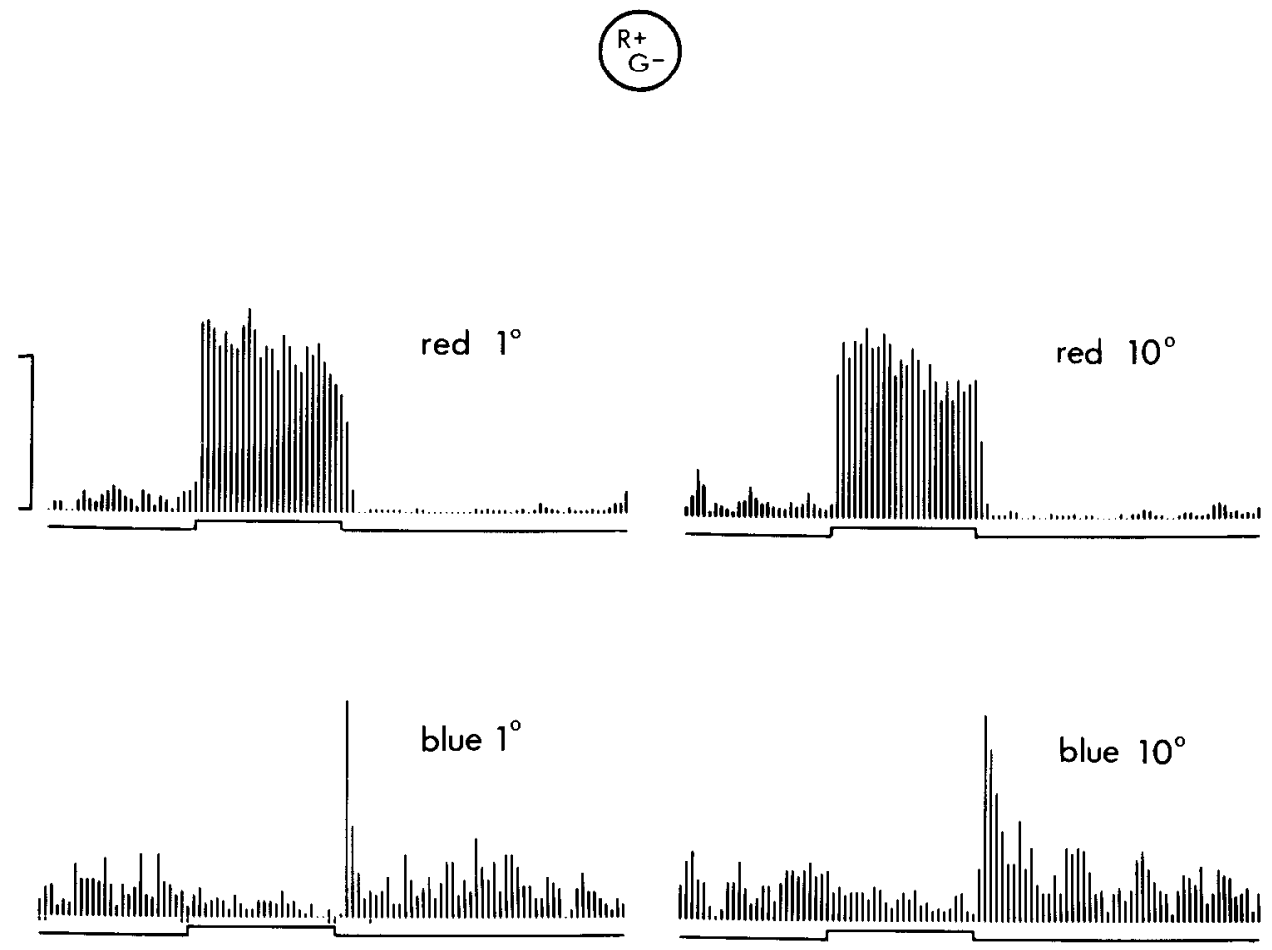

white $1^{\circ}$

white $10^{\circ}$
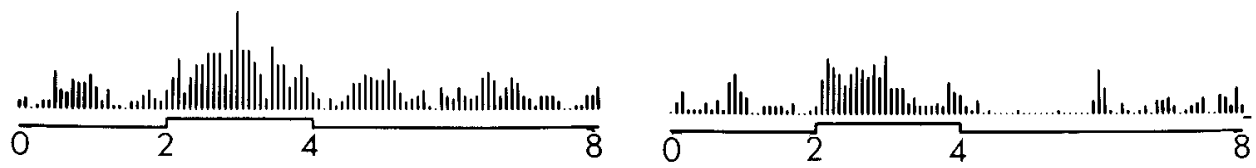

Figure 11. Poststimulus time histograms from a Color-Opponent Center-Only cell in an upper layer blob in macaque foveal striate cortex. The abscissa gives time in seconds. Vertical scale $=10 \mathrm{spikes} / \mathrm{bin} ; 1 \mathrm{bin}=80 \mathrm{msec}$.

poorer than those of macaques (Miles, 1958; Jacobs, 1963; DeValois and Jacobs, 1968), so that if blobs do play a part in color perception, the incidence of color-coded cells in squirrel monkey blobs should be reduced.

We made tangential penetrations in the foveal striate cortex of three squirrel monkeys and encountered eight blobs in $18 \mathrm{~mm}$ of cortex above layer 4. Each blob contained at least one cell completely lacking orientation preference. Of the 11 nonoriented units recorded, 9 were Broad Band, 1 preferred short wavelengths to long but lacked any color opponency, and 1 was a Double-Opponent cell (B+ $\mathrm{Y}-$ center, $\mathrm{B}-\mathrm{Y}+$ surround). Our sample is small but is consistent with the other reports that squirrel monkeys are relatively color deficient.

\section{Part III: On the Physiological Properties of Cells in the Different Cortical Layers}

While our original object was to characterize cells in layers 2 and 3, where the blobs are most prominent, we were also curious to compare cells in and outside the fainter blobs in layers $4 \mathrm{~B}, 5$, and 6 . We therefore made many oblique penetrations through the full thickness of macaque area 17 , keeping track of the physiological properties of cells at $50-\mu \mathrm{m}$ intervals. To reconstruct these penetrations we mostly used histological sections tangential to the surface, since such sections are best for relating recording sites to the blobs. We often flattened the brain between two pieces of Teflon before freezing it. On the other hand, the relationship between physiology and layers can be made out more easily in transverse sections. This is especially important for the transition between layers $4 \mathrm{C} \alpha$ and $4 \mathrm{C} \beta$ which occurs halfway through layer $4 \mathrm{C}$, since to assess the halfway point is easy on transverse sections, but difficult in tangential ones. The physiological changes at this boundary were surprising to us and we accordingly did several experiments with the specific object of pinning down this $\alpha / \beta$ transition.

One asset of the cytochrome oxidase stain is that it demarcates the cortical layers more clearly than does a Nissl stain. In area 17, layer 4A shows up clearly on cytochrome oxidase stain, and the boundary between layers $4 \mathrm{~B}$ and $4 \mathrm{C} \alpha$ is usually crisp, agreeing precisely with autoradiography after geniculate injections with tritiated proline. Finally, on sections stained for cyto- 


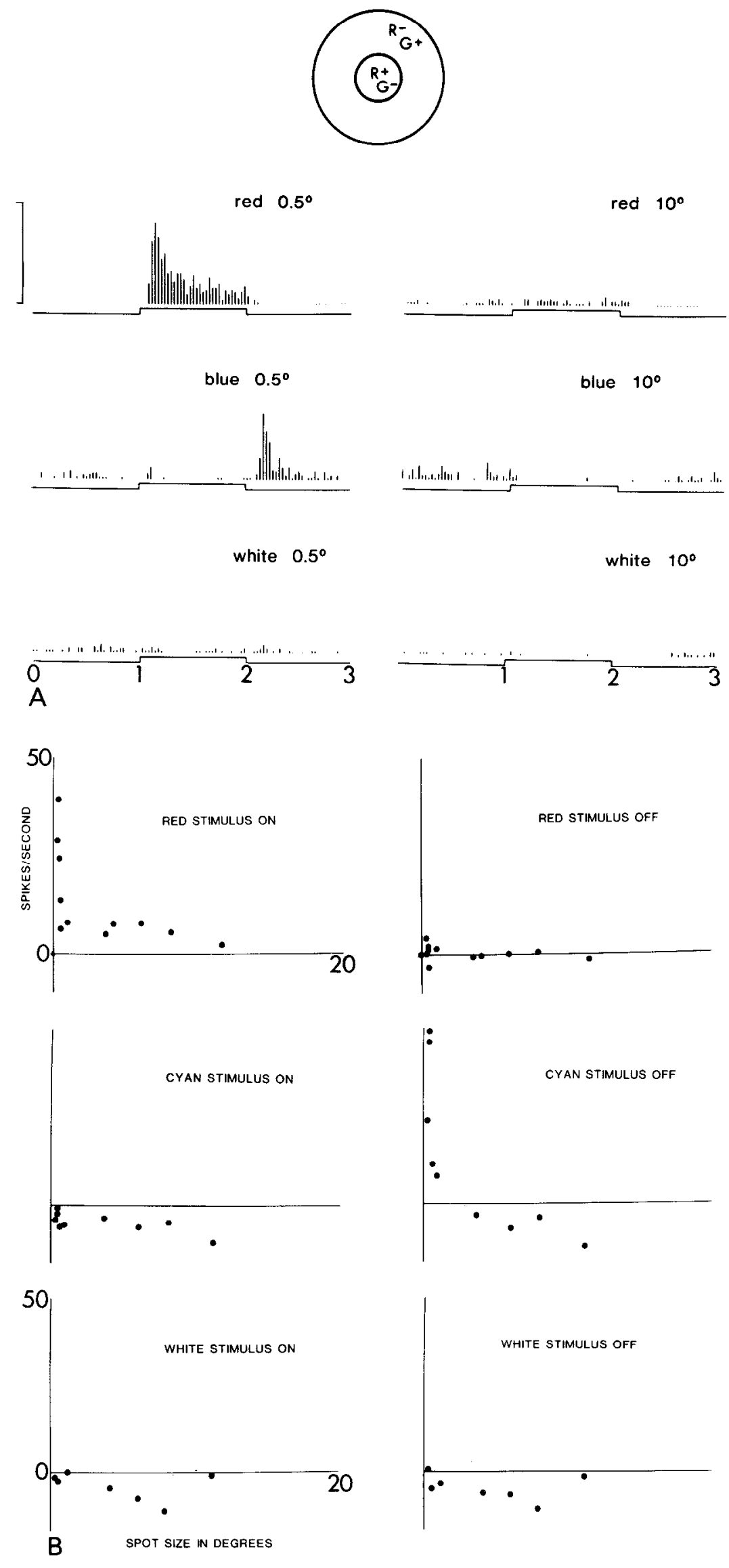

Figure 12. Responses of a red-on green-off center Double-Opponent cell recorded in an upper layer blob in macaque foveal striate cortex. $A$, Poststimulus time histograms. The abscissa gives time in seconds. Vertical scale $=5$ spikes $/ \mathrm{bin} ; 1 \mathrm{bin}=30 \mathrm{msec}$. Each graph is the average of 10 responses. $B$, Area response graphs for (left) the entire stimulus-on period and (right) the first $0.4 \mathrm{sec}$ after the stimulus was turned off. The average firing rate for $1 \mathrm{sec}$ before stimulus onset was subtracted from the average firing rate for the indicated period to give a difference in firing rate. Each point represents the average of 10 responses. 


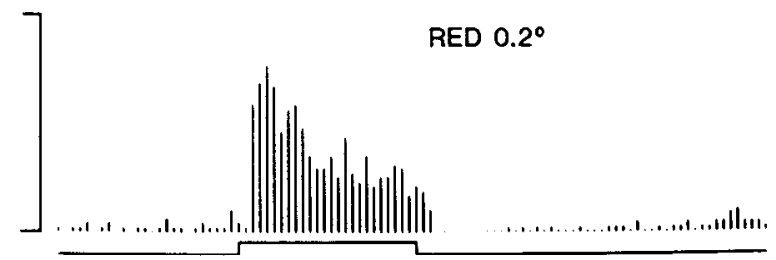

RED $2^{\circ}$

CYAN $0.2^{\circ}$



WHITE $0.2^{\circ}$

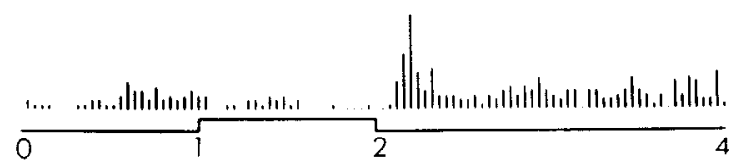

CYAN $2^{\circ}$

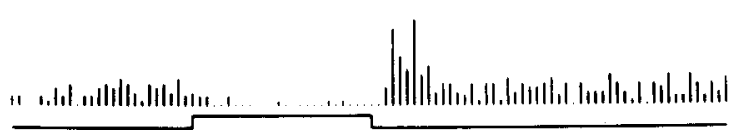

WHITE $2^{\circ}$

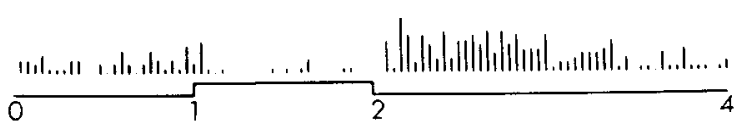

Figure 13. Poststimulus time histograms for another red-on green-off center Double-Opponent cell. In this cell the surround antagonism was weaker than that in Figure 12; the green system prevailed over the red, so that white light in the center gave a suppression of firing plus an off response. The abscissa gives time in seconds. Vertical scale $=5 \mathrm{spikes} / 40 \mathrm{msec}$ bin.

chrome oxidase, small lesions show up very clearly. In Figure 20 we show a montage of three adjacent sections, the first stained for Nissl substance, the second for cytochrome oxidase, and the third an autoradiograph of striate cortex following an injection of tritiated proline into the lateral geniculate. The geniculate injection apparently included both of the magnocellular layers (since $4 \mathrm{C} \alpha$ is continuously labeled), but only the most ventral parvocellular layer (since layer $4 \mathrm{C} \beta$ shows label in ocular dominance stripes separated by label-free gaps). Whereas the upper border of layer $4 \mathrm{C} \alpha$ is poorly defined in the Nissl-stained section, it is sharply defined in both the cytochrome oxidase-stained section and the autoradiograph and is in the same position, higher than the top of the cell-dense layer in the Nissl stain. In this and many other subtotal geniculate injections the layer $4 \mathrm{C} \alpha$ / $4 \mathrm{C} \beta$ border occurred halfway through the thickness of layer $4 \mathrm{C}$.

Most of the cells in these experiments were recorded from layers 2 and 3, but after we found Double-Opponent cells in blobs we were anxious to study layer $4 \mathrm{C}$ because of a report (Michael, 1978; see also Gouras, 1974) that cells in that layer are predominantly or entirely DoubleOpponent, and, conversely, that the Double-Opponent cells in area 17 are nearly all in layer $4 \mathrm{C}$. It seemed important to check this not only because the presence of these cells in layer $4 \mathrm{C}$ would radically affect any interpretation of the origin of blob Double-Opponent cells, but also because of the difficulties (also recognized by Michael) in building up Double-Opponent cells either from cells of the parvocellular geniculate layers, or worse, from magnocellular cells. We therefore did several additional experiments to record from and characterize physiologically a reasonable sample of cells in layer $4 \mathrm{C}$.

\section{Results}

\section{Layer 1}

We have no solid information on this cell-sparse layer. At the beginning of many penetrations, when we were likely to be in layer 1 , the activity was often very faint, with no resolved units-exactly what one would expect in a layer composed mostly of neuropil. The activity, although faint, responded to visual stimulation and was usually orientation selective.

\section{Layers 2 and 3}

Cells within blobs have been described in detail in the previous section. Cells outside the blobs were mostly complex, but some were simple. Their spontaneous activity, in anesthetized animals, was usually very low. They had relatively small receptive fields (less that $1 / 2^{\circ}$ in foveal striate cortex and about $1^{\circ}$ in parafoveal cortex) and were precisely tuned for orientation, but most were not direction selective. Most were not end-stopped, but about one-quarter clearly were.

In this account of blobs and color it would be easy to forget that some of the orientation-selective cells between blobs are also highly selective in their color properties (Table I). Color-coded, orientation-specific non- 


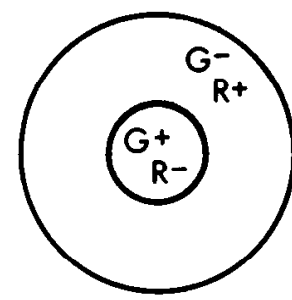

cyan $-l^{\circ}$ spot

cyan $-15^{\circ}$ spot


red $-1^{\circ}$ spot

red $-15^{\circ}$ spot
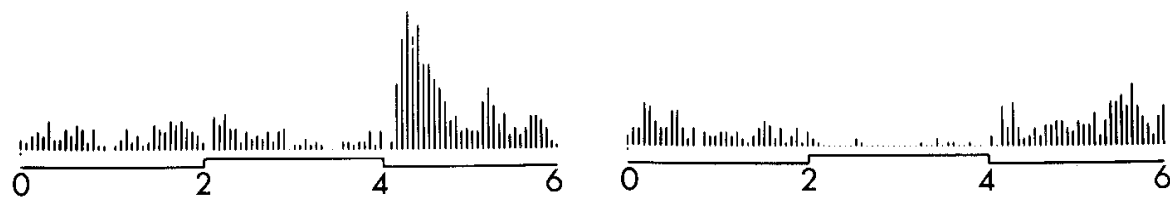

A

red light

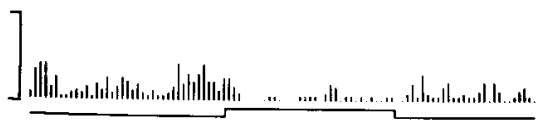

blue light

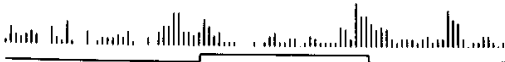

red + blue light

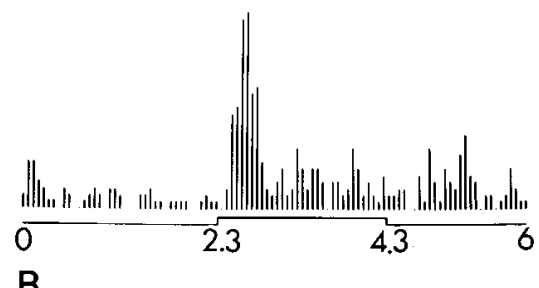

B

Figure 14. Responses of a green-on red-off center Double-Opponent cell in an upper layer blob in macaque nonfoveal striate cortex. A, Poststimulus time histograms. The abscissa gives time in seconds. Vertical scale $=2$ spikes $/ 60$-msec bin. Each histogram is the average of 10 responses. $B$, Poststimulus time histograms of responses to a small (center size) piece of cyan paper on a large piece of red paper illuminated with red light only (top), blue light only (middle), or red plus blue light (bottom). The eyes were occluded for the times before and after the on period with a large shutter. Vertical scale $=2$ spikes/ 60 -msec bin. Each histogram is the average of five responses. 
blob cells were mostly complex: they resembled noncolor-coded (broad band) complex upper layer cells in all respects except that they responded vigorously to colored slits and poorly or not at all to white ones, regardless of the stimulus intensities. For each unit we generally began by stimulating with white slits. If the unit was unresponsive, our first recourse was to use a red filter. Next to white this was the most common preferred stimulus (Table I). For these cells orientation was just as critical as in ordinary white-sensitive cells, and diffuse red light was ineffective. The spectral sensitivity of such redsensitive cells was not the same as that of the red cone but was displaced toward longer wavelengths. Shortwavelength light, like white light, evoked no response, as though an opponent (off) influence were concealed, expressing itself only by making white light ineffective and by displacing and narrowing the spectral sensitivity of the red component by subtraction.

After a red slit, a dark bar on a light background was the next most common preferred stimulus. Such cells were almost as common as those that preferred red. Much more rarely, a green or violet slit was optimal.

Oriented color-coded cells (including cells responding best to dark bars) made up $17 \%$ of the non-blob population 6 to $8^{\circ}$ from the fovea; penetrations at 0 to $2^{\circ}$ from the fovea had a higher proportion, $39 \%$, in agreement with other reports (Poggio et al., 1975).

TABLE II

Probable cone inputs to 71 Double-Opponent cells

\begin{tabular}{lcccc}
\hline Center type & $\mathrm{R}+\mathrm{G}-$ & $\mathrm{R}-\mathrm{G}+$ & $\mathrm{B}+\mathrm{Y}-$ & $\mathrm{B}-\mathrm{Y}+$ \\
No. of Cells & 49 & 13 & 8 & 1 \\
\hline
\end{tabular}

Cells selectively responsive to oriented red slits or dark bars were often found in clusters (Hubel and Wiesel, 1968; Michael, 1981), but the groupings were so small that more than two or three cells were seldom recorded in a sequence. We have had too little experience with blue- and green-sensitive cells to tell whether they are clustered. We still do not know how such clusters are disposed relative to blobs.

\section{Layer $4 A$}

This is the thinnest layer in area 17 and therefore the most difficult to localize precisely or to record from, given that a penetration must be almost tangential to record more than one or two cells in it. In most of our penetrations, when we passed through layer $4 \mathrm{~A}$, we recorded that there was "very fine, fast firing hash" or that the activity was "distant" or "hard to hear." On these occasions we may well have been recording from geniculate afferents.

\section{Layer $4 B$}

Blobs in layer 4B are faint; in some animals they are hard to see but in others they are distinct and can then be seen to lie in precise register with the higher-contrast blobs in layers 2 and 3 ; when they are very faint it helps to superimpose them on upper layer sections, using blood vessels for alignment.

We recorded from 38 cells that we were reasonably certain were in layer $4 \mathrm{~B}$, far fewer than the numbers in layers 2 and 3 , but enough to allow some tentative conclusions. Only one of the penetrations passed through a blob, in which we recorded five cells.

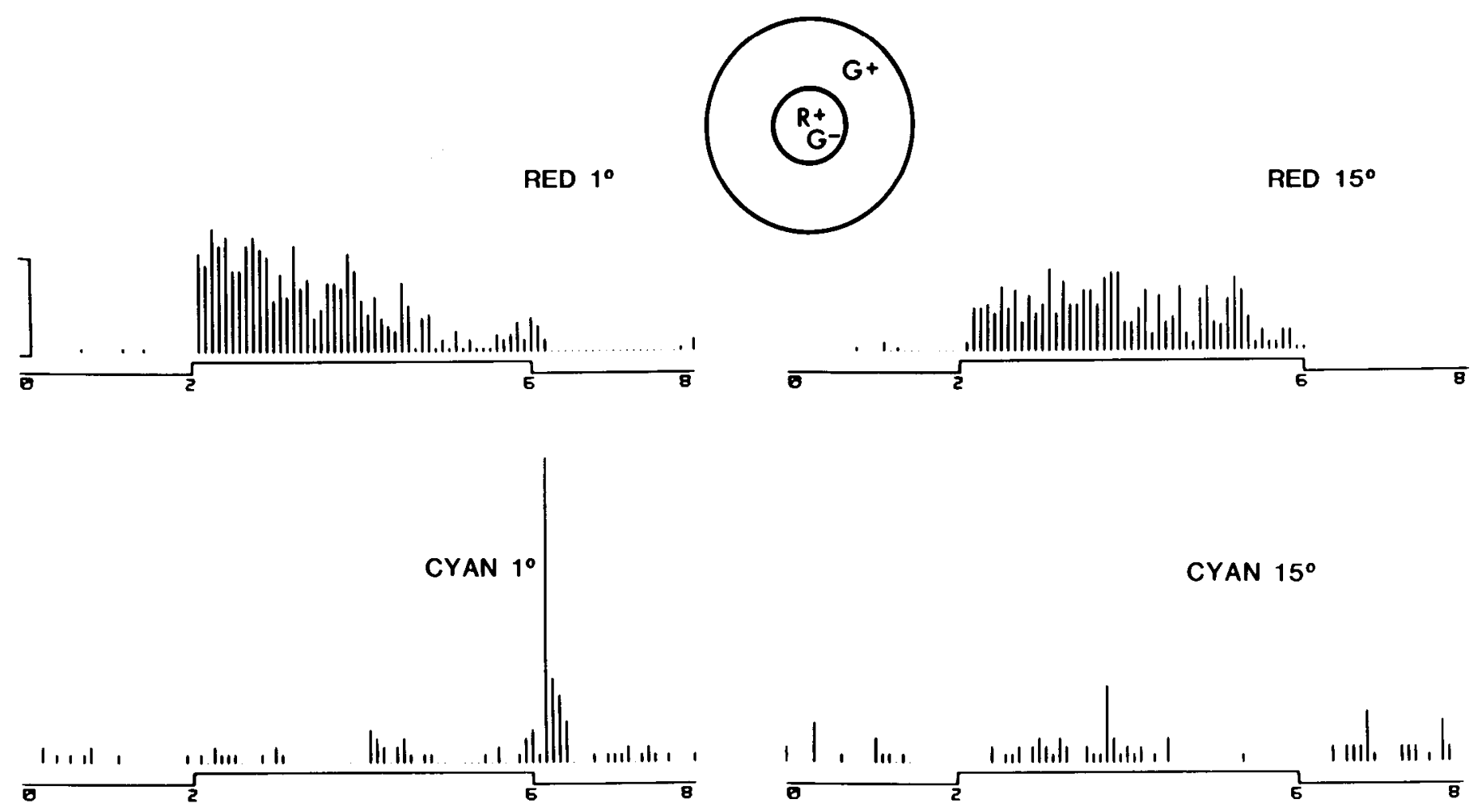

Figure 15. Poststimulus time histograms of a red-on green-off center $3 / 4$ Double-Opponent cell, whose surround lacked a red input; recorded in an upper layer blob of macaque nonfoveal striate cortex. The abscissa gives time in seconds. Vertical scale $=2$ spikes/80-msec bin. Each histogram is the average of five responses. 

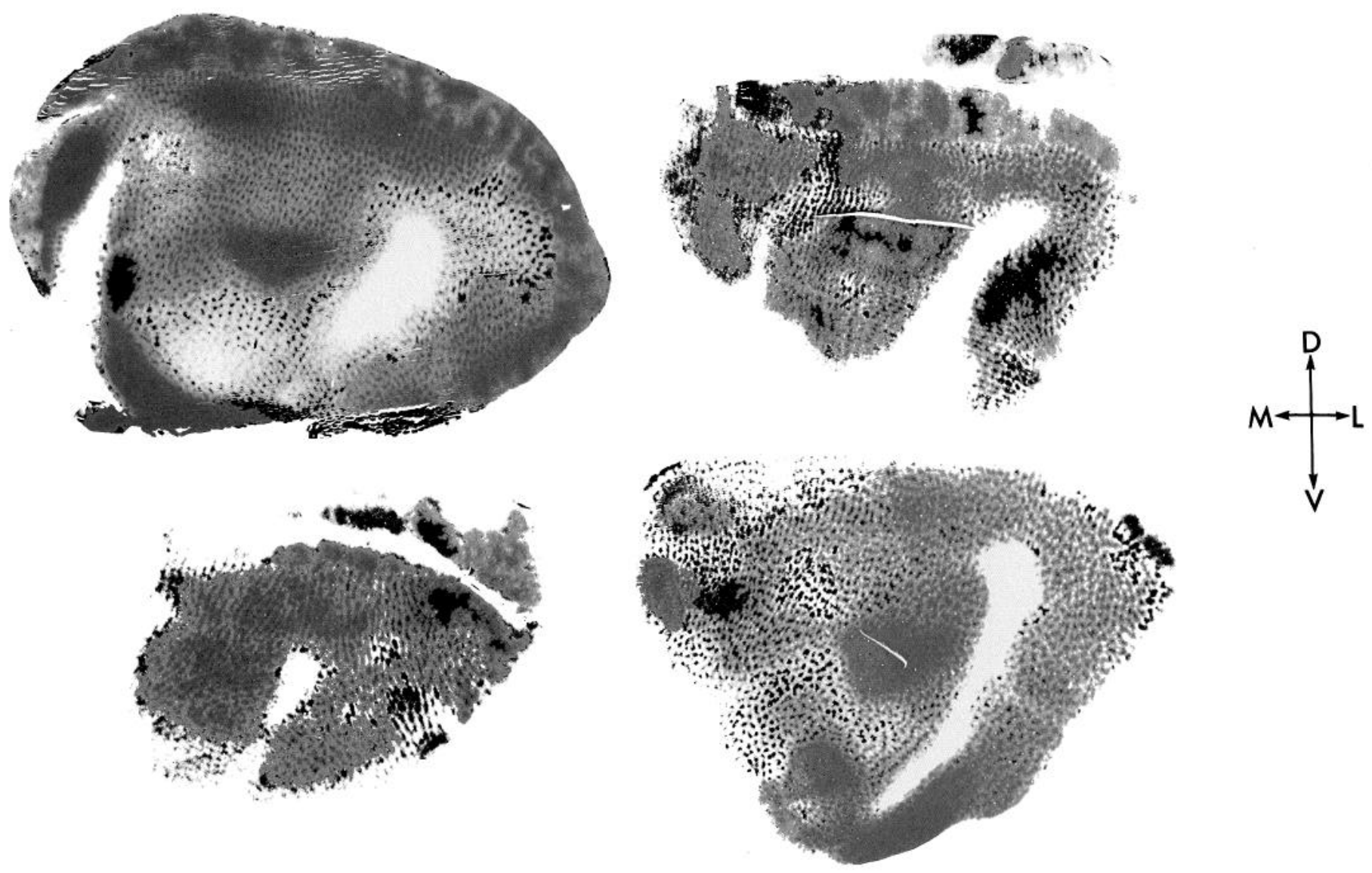

$1 \mathrm{~cm}$

Figure 16. Illustration of the subtle variation of blob size with eccentricity. Cytochrome oxidase-stained sections of area 17 from flattened occipital lobes of four different macaque monkeys. Each section passes tangentially through layers 2 and 3 . In each section the fovea is the rightmost region of area 17 . Measurements were made from many such sections, taken at several depths from each occipital lobe. In each section area 18 occupies part of the rim and shows a coarser pattern of staining.

The non-blob cells of layer $4 \mathrm{~B}$ were all oriented and most, perhaps all, were simple. Two-thirds of them were strongly direction selective, with an on and an off region lying side by side, disposed in such a way that moving a slit from the off to the on region gave a much greater response than movement in the reverse direction, and reversing stimulus contrast reversed the preferred direction of movement. (This is not generally true of complex cells.) Dow (1974) also found a high proportion of direction-selective cells in layer $4 \mathrm{~B}$. The other third of the cells were simple with a central on or off region and two flanking regions of the opposite sign; their responses were not directional. Half of the non-blob cells were strictly monocular (group 1 or 7), and of the rest, most showed strong eye preference (group 2 or 6 ), with only a few in groups 3,4 , and 5 . In all but one of the directionselective binocular cells the preferred direction of movement was the same in the two eyes. The one exceptional unit preferred opposite directions of movement of a vertical bar in the two eyes and, when the receptive fields of the two eyes were superimposed, did not respond well to movement in any direction in the plane of the screen, but did respond specifically to movement toward the animal.

Figure 21 shows a tangential penetration that passed through a blob in layer $4 \mathrm{~B}$. The electrode entered layer $4 \mathrm{~A}$ at $2.3 \mathrm{~mm}$ (just before the second lesion) and stayed in layer $4 \mathrm{~B}$ until $3.0 \mathrm{~mm}$ when it entered layer $4 \mathrm{C} \alpha$. In layer $4 \mathrm{~B}$ we encountered five unoriented cells, which were located directly under a blob; unfortunately we did not test their color properties. In layer $4 \mathrm{C}$, as described below, the cells in the upper half were well oriented and those in the lower half were completely unoriented. The last few units were in layer 5.

\section{Layer $4 \mathrm{C} \alpha$}

Of the 45 units recorded in layer $4 \mathrm{C} \alpha, 38$ were clearly orientation selective, simple, and not directionally selective. Roughly one-third were end-stopped.

The transition from layer $4 \mathrm{~B}$ to layer $4 \mathrm{C} \alpha$ was physiologically distinct. The main change was an increase in spontaneous activity of both cells and the unresolved background activity, which, unlike the isolated units, was unoriented. Both cells and the background were tonically 

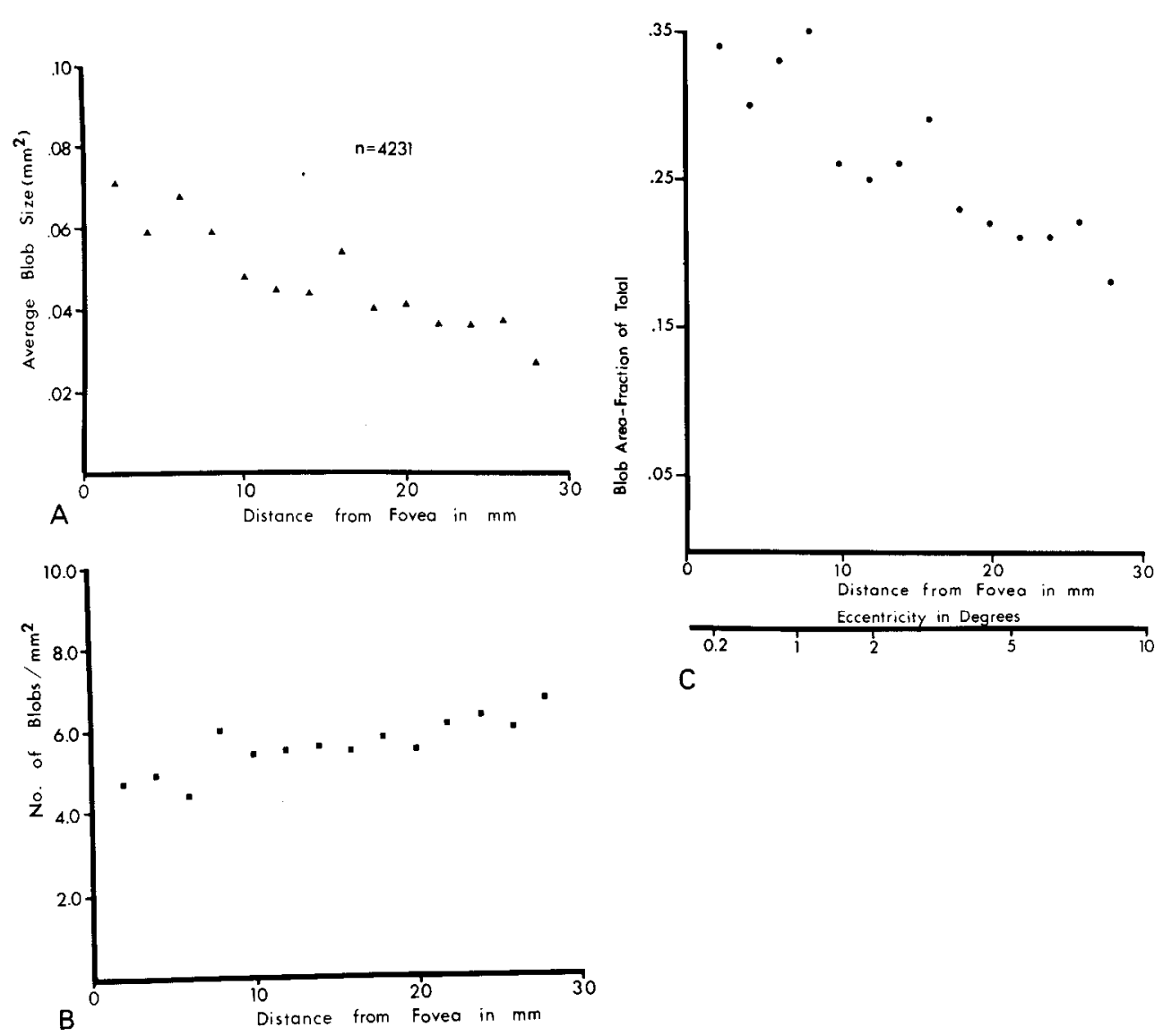

C

Figure 17. Correlation of $(A)$ average blob size, $(B)$ number of blobs per square millimeter, and $(C)$ fraction of total area occupied by blobs, with distance from the fovea.

SMALL WHITE: LEFT EYE ONLY

BIG WHTE; LEFT EYE ONLY
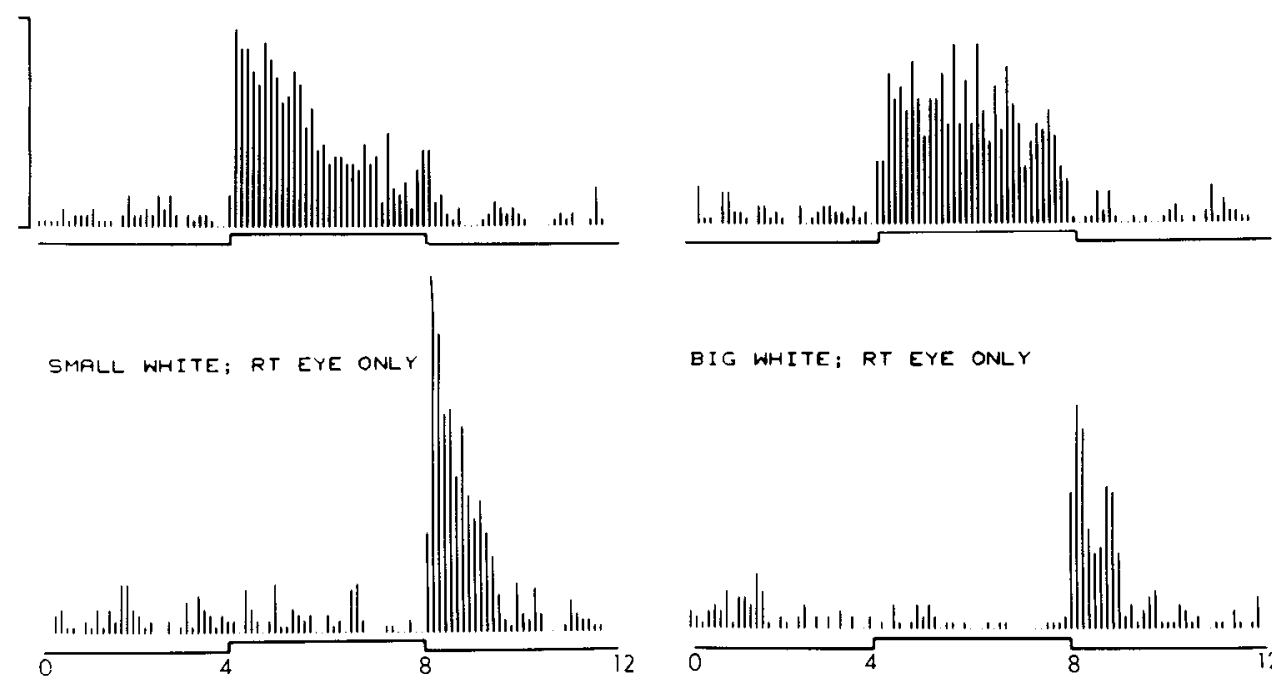

BIG WHITE; RT EYE ONLY

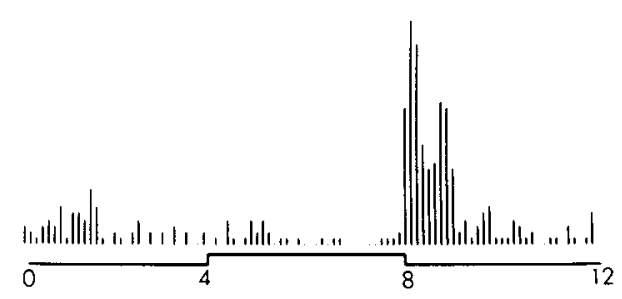

BIC WHITE BOTH EYES

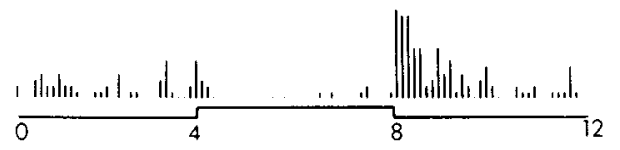

Figure 18. Broad-Band cell with opposite responses from the two eyes. Poststimulus time histograms of an unusual unoriented Broad-Band cell probably located in a blob in layer $4 \mathrm{~B}$ of macaque nonfoveal striate cortex. The abscissa gives time in seconds. Vertical scale $=10$ spikes $/ 120$-msec bin. Each histogram is the average of three responses. 


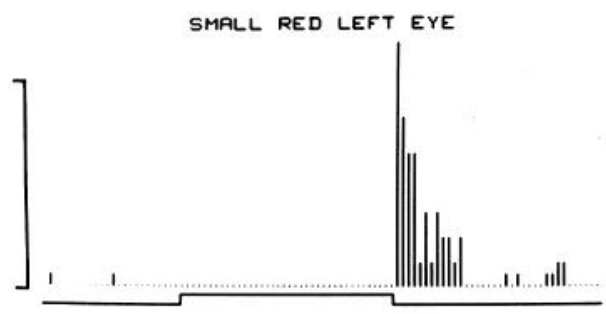

SMALL RED RIGHT EYE
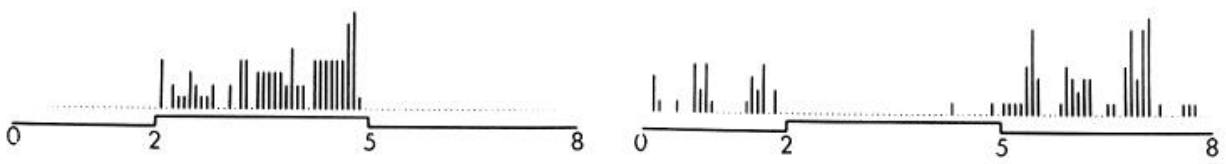

Figure 19. Red-green Double-Opponent cell with reverse opponency in the two eyes. Poststimulus time histograms of a bizarre cell found in an upper layer blob of nonfoveal macaque striate cortex. The centers are $\mathrm{R}+\mathrm{G}-$ in the right eye and $\mathrm{R}-\mathrm{G}+$ in the left. Large spots evoked no responses, which accordingly are not shown. The abscissa gives time in seconds. Vertical scale $=5$ spikes $/ 80-\mathrm{msec}$ bin. Each histogram is the average of three responses.

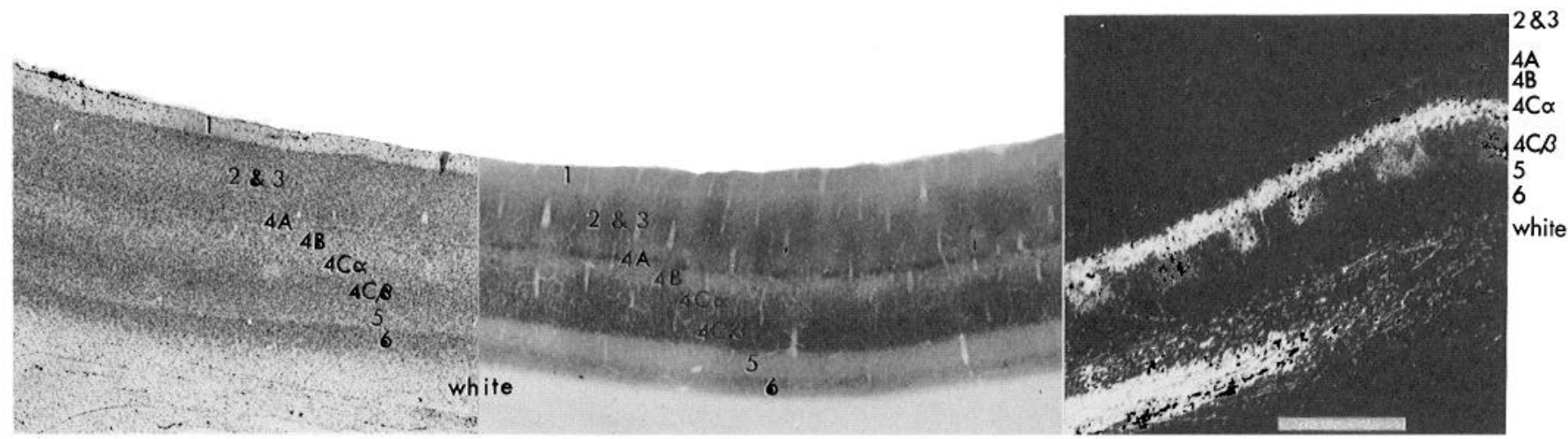

Figure 20. Montage of three adjacent transverse sections from macaque striate cortex. The left panel is from a section stained for Nissl substance, the middle panel is from a section stained for cytochrome oxidase, and the right panel is a darkfield photograph of an autoradiogram. The animal had received an injection of $\left[{ }^{3} \mathrm{H}\right]$ proline in the lateral geniculate nucleus 2 weeks prior to perfusion. Note that the upper border of layer $4 \mathrm{C}$, if defined as the upper limit of the major parvocellular geniculate input as seen autoradiographically, correlates much better with the cytochrome staining pattern than with the Nissl stain. Scale $b a r=1 \mathrm{~mm}$.

suppressed by diffuse red light, just as magnocellular geniculate cells are. Otherwise the cells were not color coded. The unoriented background hash is presumably due to geniculate afferents.

The six cells that showed no orientation selectivity were all seen in the part of a long penetrtion that threaded its way along the $4 \mathrm{C} \alpha / 4 \mathrm{C} \beta$ border, before finally and frankly entering layer $4 \mathrm{C} \alpha$. The assignment of these cells to layer $4 \mathrm{C} \alpha$ is therefore in some doubt. If these cells were indeed in layer $4 \mathrm{C} \beta$, then our results would seem to suggest that all cells in layer $4 \mathrm{C} \alpha$ are orientation tuned. The tuning of the orientation-selective cells was less precise than that of non-blob cells in layers 2 and 3 , and most were assigned to categories B or C. All of the cells were strictly monocular.

We were surprised at this result-almost as surprised as we were to find unoriented cells in layers 2 and 3. Nevertheless the earliest laminar study of monkey area 17 (Hubel and Wiesel, 1968) reported oriented simple cells in upper layer 4C (then called 4B). Bullier and Henry (1980) and Blasdel and Fitzpatrick (personal communication) have also seen simple cells in layer $4 \mathrm{C} \alpha$ but in clumps mixed with complex cells and separate from clumps of unoriented cells. We do not have enough information from this layer to rule out the possibility that there are clumps of unoriented cells lying beneath the blobs. So far no anatomical experiments have revealed any evidence of blobs in layer $4 \mathrm{C}$.

Our finding that layer $4 \mathrm{C} \alpha$ contains orientation-selective units is supported by experiments using 2-deoxyglucose, one of which is illustrated in Figure 22. This macaque received intravenous $\left[{ }^{14} \mathrm{C}\right] 2$-deoxyglucose and was 

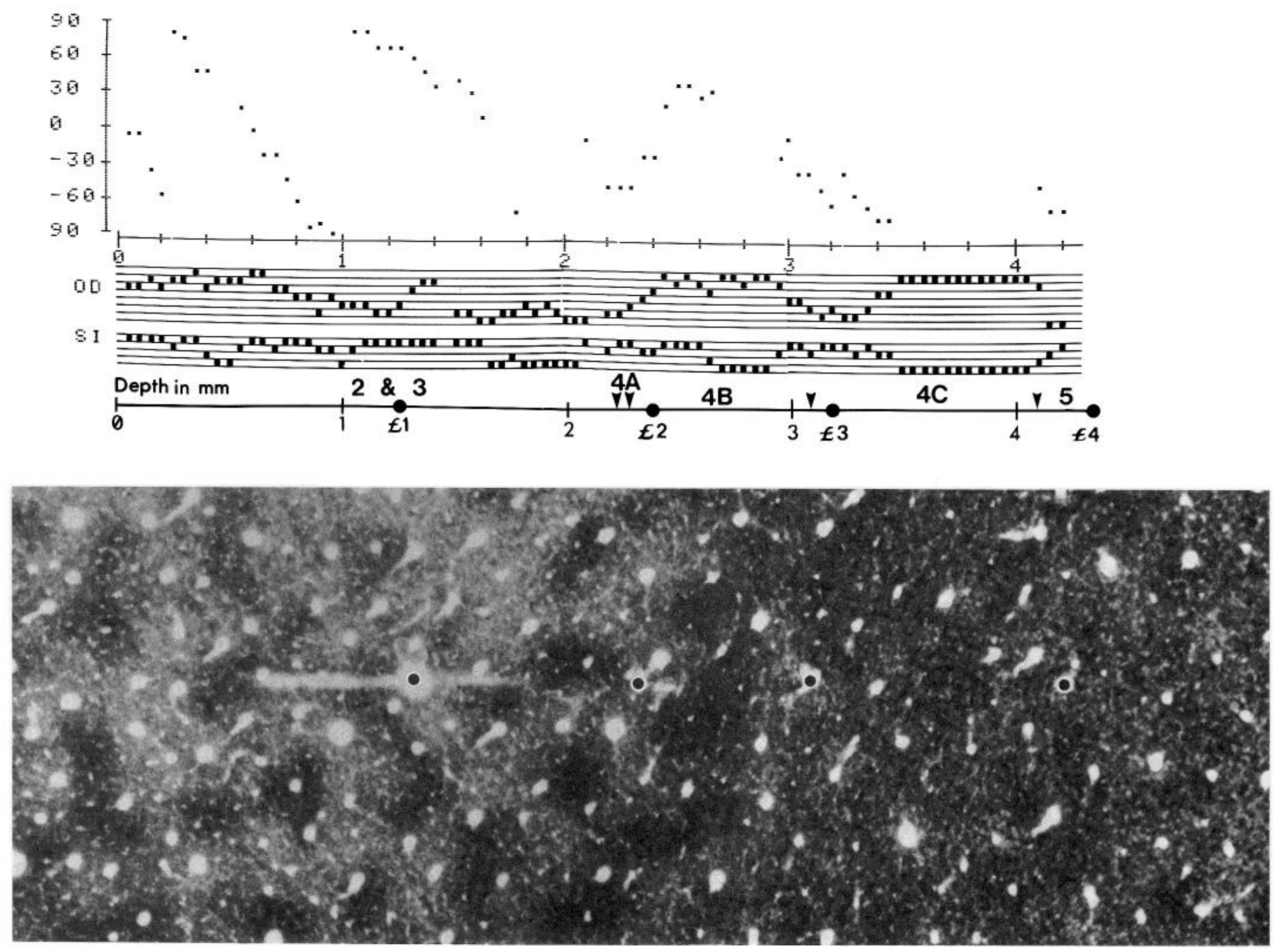

Figure 21. Receptive field properties of units along a penetration in macaque nonfoveal striate cortex. The first half of the penetration was in layers 2 and 3 ; between $2.3 \mathrm{~mm}$ and $3.1 \mathrm{~mm}$ it was in layer $4 \mathrm{~B}$; from $3.1 \mathrm{~mm}$ to $4.1 \mathrm{~mm}$ it was in layer $4 \mathrm{C}$; and the last few units were in layer 5 . In layer $4 \mathrm{~B}$, cells located below blobs were unoriented and cells in the upper half of layer $4 \mathrm{C}$ were oriented.

then stimulated for 45 min with moving vertical black and white stripes of various widths. The autoradiograph on the right shows a faint heterogeneity in the label in the upper layers (outer ring) and also in the more darkly labeled isthmus in the middle. A cytochrome oxidase stain of the adjacent section (left) shows that this isthmus is layer $4 \mathrm{C} \alpha$. The inner parts of the two darkly staining bulges (connected by the isthmus) are in layer $4 \mathrm{C} \beta$ which, on the deoxyglucose autoradiographs, was uniformly and darkly labeled. Humphrey and Hendrickson (1983) likewise found a patchy pattern of deoxyglucose uptake in layer $4 \mathrm{C} \alpha$ in monkeys stimulated with stripes of a single orientation, whereas the labeling was uniform after stimulating with all orientations or diffuse light.

It had seemed strange that in previous deoxyglucose studies (Hubel et al., 1977b), after stripe stimulation the densest patterns seemed to be in layers $4 \mathrm{~B}$ and 6 , since layer $4 \mathrm{~B}$ is only sparsely populated with cells whereas layer 6 is one of the most densely cell-packed layers. With the greater precision of the cytochrome oxidase stain in delineating the layer $4 \mathrm{~B} / 4 \mathrm{C}$ border, it now seems clear that the upper of these densely and periodically labeled regions was layer $4 \mathrm{C} \alpha$, not layer $4 \mathrm{~B}$ (see Hubel et al., 1977b, Fig. 5). This would explain the apparent discrepancy between those results and the deoxyglucose findings of Humphrey and Hendrickson (1983); the results are similar but their assignment of layer $4 \mathrm{C} \alpha$ is probably the correct one.

\section{Layer $4 C \beta$}

At the next transition, which was equally abrupt, receptive fields became smaller and all trace of orientation tuning vanished both for isolated units and for background activity. In four experiments we made a lesion at this transition and cut the brain transversely. In each penetration the lesion was exactly centered in layer $4 \mathrm{C}$. In a fifth penetration, just to relieve the monotony, a lesion was made when we thought we had just entered layer $4 \mathrm{C} \alpha$ and another at the abrupt transition on leaving layer $4 \mathrm{C} \beta$; here the physiologically assessed $\alpha / \beta$ transition occurred at a depth exactly midway between the two 

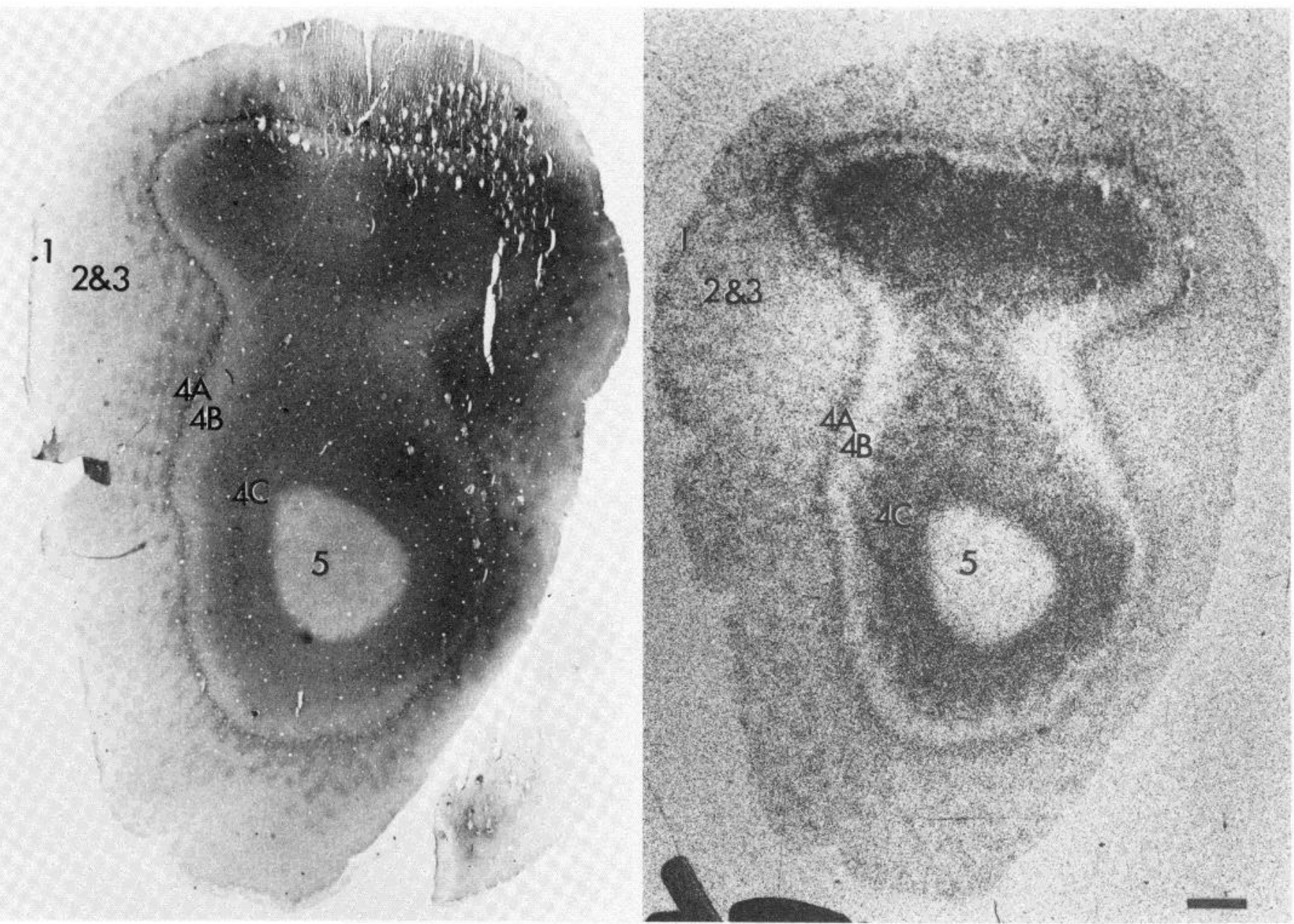

Figure 22. Sections of the striate cortex of a macaque that had been injected with $\left[{ }^{14} \mathrm{C}\right] 2$-deoxyglucose and then stimulated for $45 \mathrm{~min}$ with moving vertical black and white stripes. Scale bar $=1 \mathrm{~mm}$. Left, Cytochrome oxidase-stained section with the cortical layers indicated. Right, Autoradiogram of an adjacent section showing heterogeneity of labeling in layer $4 \mathrm{C} \alpha$ (the isthmus joining the two bulges) as well as in layers 2 and 3 , and homogeneous labeling in layer $4 \mathrm{C} \beta$ (the ring surrounding layer 5 ).

lesions, which were at the top and the bottom of layer $4 \mathrm{C}$.

In these penetrations we recorded from 124 cells in layer $4 \mathrm{C} \beta$, along lengths totaling $6.5 \mathrm{~mm}$. Forty-six cells were Broad-Band and 78 were Color-Opponent CenterSurround (type I). None of the cells were Color-Opponent Center-Only and none were Double-Opponent. The spontaneous activity of both the cells and the background hash was high, as in layer $4 \mathrm{C} \alpha$. The cells and hash were strictly monocular, with abrupt switching from one eye to the other roughly every half millimeter.

We conclude that Double-Opponent cells are either absent or very scarce in layer $4 \mathrm{C}$, subject again to the possibility that this layer is physiologically heterogeneous and contains blob-like clusters of such cells. It seems unlikely, however, that such clusters would have been missed in our survey of $6.5 \mathrm{~mm}$, or that separate independent surveys, such as those of Gouras (1974) or Michael (1978), would have encountered only the clusters.

\section{Layer 5}

The transition from layer $4 \mathrm{C}$ to layer 5 was again distinct: the high spontaneous activity disappeared and cells became orientation selective. Only 21 cells were recorded in layer 5 , and our conclusions as to the physiology of this layer (as with layer 6) must therefore be regarded as tentative. The cells were mostly binocular without strong eye preference. Most of the units responded to a short slit much better than to a longer one. They showed precise orientation tuning (class A) but most of them also responded to a small moving spot, as Palmer and Rosenquist (1974) and Gilbert (1977) have described in layer 5 of the cat striate cortex. None of these cells were direction selective.

In each of two experiments we found one DoubleOpponent cell in layer 5 . These were very similar to Double-Opponent cells in upper layer blobs. When we lined up the upper and lower layer tangential histological sections using radially running blood vessels, the DoubleOpponent cells in layer 5 were located just below blobs in the upper layers.

\section{Layer 6}

We recorded 44 cells in layer 6 . The transition from layer 5 was indicated by an increase in receptive field size, especially its extent in the direction parallel to the orientation axis, in the loss of end-stopping, and, strikingly, in the appearance of direction selectivity. The cells 

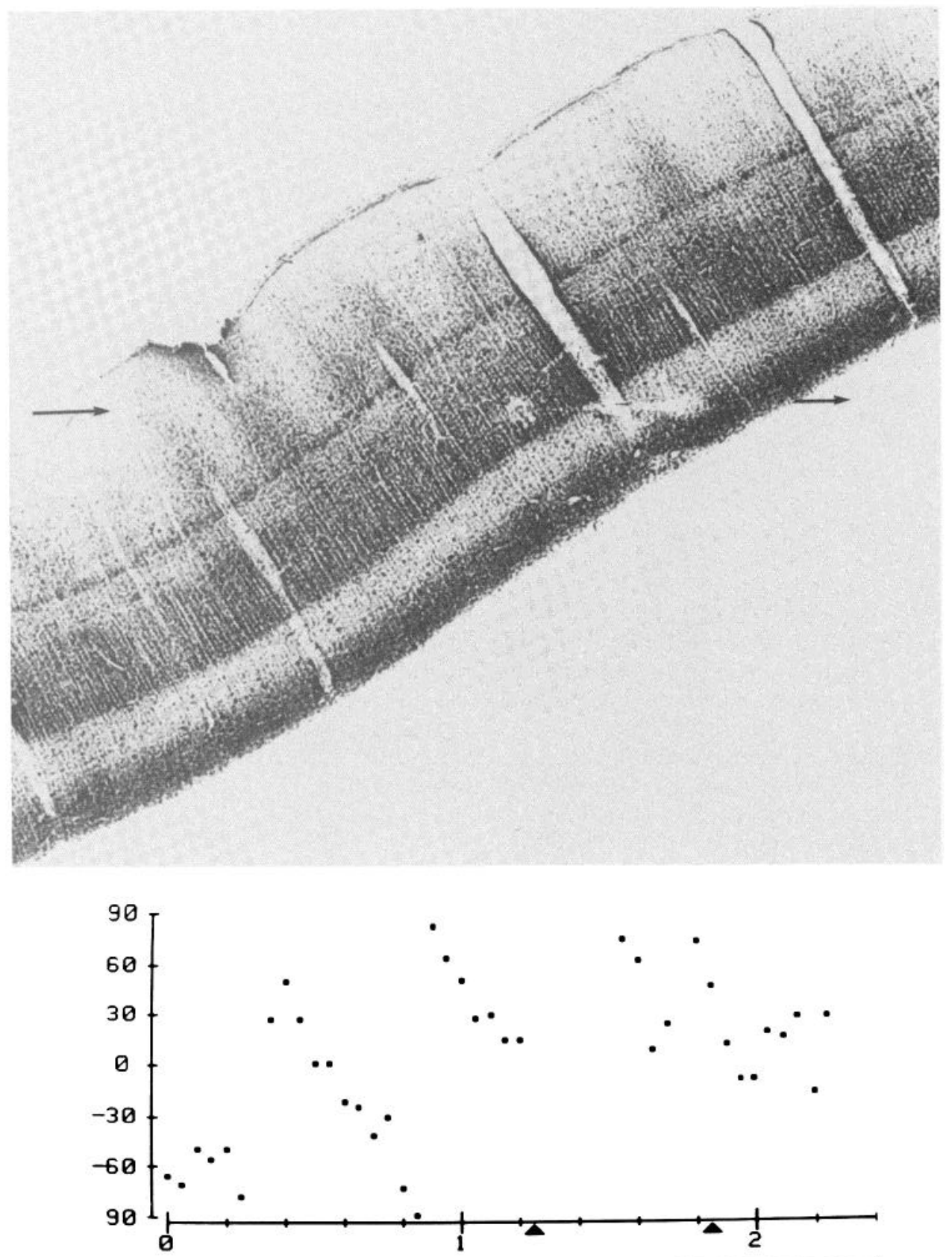

OD

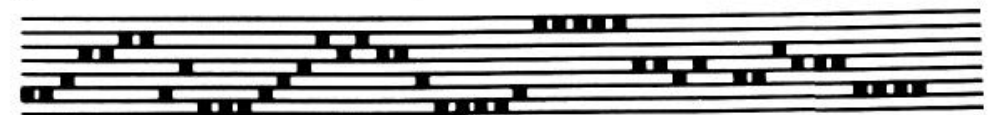

SI

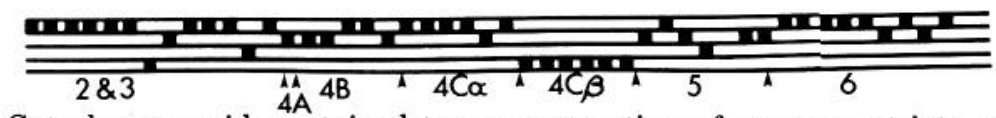

Figure 23. Cytochrome oxidase-stained transverse section of macaque striate cortex showing a penetration through the full thickness of the cortex. Both lesions are visible in this single section and are indicated on the physiology record by triangles, at 1.25 and 1.85 $\mathrm{mm}$. We encountered a blob at approximately $0.3 \mathrm{~mm}$ and recorded one unoriented unit. The orientation sequence was regular all the way from layer 2 through layer $4 \mathrm{C} \alpha$. We made the first lesion at what we thought at the time was the layer $4 \mathrm{C} \alpha / 4 \mathrm{C} \beta$ border, and this lesion was indeed in the middle of layer $4 \mathrm{C}$. We made the second lesion just before a series of strongly direction-selective cells, and this lesion turned out to be at the layer 5 / 6 border.

were similar to the layer 6 complex cells described by Gilbert (1977) in the cat, in responding optimally to very long slits. Many were like the layer $4 \mathrm{~B}$ cells that showed strong direction selectivity, except that they were com- plex, responding to a long slit moved perpendicular to the orientation axis through the entire extent of the receptive field but not to turning on or off a stationary slit. 
In one experiment we saw two unoriented Broad-Band cells in layer 6 . As in layer 5 , these cells lay directly below a blob.

A typical oblique penetration through macaque striate cortex is shown in Figure 23. We recorded from 25 well oriented units as we progressed from layer 1 through layer $4 \mathrm{C} \alpha$. In layer $4 \mathrm{C} \beta$ we recorded six unoriented units, three of which were Broad-Band (type III) intermixed with three Color-Opponent Center-Surround (type I) cells. We retracted the electrode and made the first lesion at the last oriented unit and just before this series of unoriented units. This lesion is smack in the middle of layer $4 \mathrm{C}$. Then, in layer 5 , we recorded from seven complex cells which responded to small spots moving at right angles to the preferred slit orientation. Finally there followed six strongly or completely direction-selective units. We retracted the electrode and made the second lesion between the last non-directional unit and this series of strongly directional units; it turned out to be at the border between layers 5 and 6 .

To summarize some of the results of Part III: we found unoriented, often color-contrast-coded, cells in clusters in layers $4 \mathrm{~B}, 5$, and 6 as well as in layers 2 and 3 . These units were in or directly below the cytochrome oxidase blobs. We have not so far seen such heterogeneity in layer $4 \mathrm{C}$.

We saw a preponderance of strongly direction-selective cells in layers $4 \mathrm{~B}$ and 6 ; those in layer $4 \mathrm{~B}$ were simple and those in layer 6 were complex. This is consistent with the anatomical results of Lund and Boothe (1975), who found that layer $4 \mathrm{~B}$ projects primarily to layer 6 . The fact that both of these layers are rich in directionselective cells is also consistent with the fact that both layers project to the superior temporal sulcus (Lund et al., 1975), MT in New World monkeys (Spatz et al., 1970), which itself contains cells that are highly movement and direction selective (Dubner and Zeki, 1971).

Finally, the two subdivisions of layer $4 \mathrm{C}, \alpha$ and $\beta$, are physiologically very different from each other. Layer $4 \mathrm{C} \alpha$ contains oriented simple cells and therefore resembles layer 4 in the cat. Layer $4 \mathrm{C} \beta$ contains cells indistinguishable, as far as we know, from the parvocellular geniculate cells which form its main input: they were unoriented and either Broad-Band (type III) or Color-Opponent Center-Surround (type I). We did not see either of the two types of color-coded cells that we saw in the blobs, Double-Oponent or Color-Opponent Center-Only (type II).

\section{Part IV: On the Anatomical Connections between Areas 17 and 18}

Since the blobs and the surrounding non-blob regions in area 17 differ both in their physiology and in their thalamic inputs, we were curious to learn whether they also differed in their outputs. An obvious beginning was to look at the projections from area 17 to area 18. Area 18 , which gets a direct, topographically organized input from area 17 (Cragg and Ainsworth, 1969; Zeki, 1969), is, like area 17 , heterogeneous by cytochrome oxidase staining, but the pattern is coarser and forms alternating thick and thin stripes perpendicular to the area 17/18 border rather than polka dots (Figs. 16, 27, and 30; see also Livingstone and Hubel, 1982; Tootell et al., 1983). The patterns in macaque and squirrel monkeys are similar, but in squirrel monkeys the stripes are more regular. We suspected that the blobs in area 17 might project to the stripes in area 18 because of certain similarities in the two regions. First (and obviously), both stain selectively for cytochrome oxidase. Second, both receive direct thalamic input: the blobs in area 17 from the lateral geniculate, the stripes in area 18 from the pulvinar (Livingstone and Hubel, 1982). Third, the cytochrome oxidase-rich regions in both areas seem to be physiologically less specific than surrounding regions, since they can be selectively labeled by deoxyglucose in a variety of stimulus conditions (Horton and Hubel, 1981; Livingstone and Hubel, 1982; Humphrey and Hendrickson, 1983; Tootell et al., 1983). That cells in area 17 projecting to area 18 can be distributed in small patches had been shown by making small horseradish peroxidase injections into area 18 (Wong-Riley, 1978; Maunsell et al., 1980; Tigges et al., 1981).

Since horseradish peroxidase is transported in both anterograde and retrograde directions, we could in principle have studied connections between areas 17 and 18 by injecting label into either area 17 or area 18 . Given the difficulties of making minute horseradish peroxidase injections, the coarseness of the cytochrome oxidase stripes in area 18 made that area a much more inviting prospect.

\section{Materials and Methods}

We used both squirrel monkeys and macaques, more squirrel monkeys than macaques because of the greater regularity of the cytochrome oxidase pattern in area 18 and the fact that, in macaques, except for a 1 to $2-\mathrm{mm}$ strip in front of the area $17 / 18$ border, dorsal area 18 is buried in the lunate sulcus. Our injections were made blind, both with respect to the location in area 18 (thin stripe, thick stripe, or interstripe) and with respect to the area $17 / 18$ border, which is hard to estimate in the living squirrel monkey. A few injections therefore straddled stripe/non-stripe boundaries in area 18 (serving unintentionally as controls), and a few landed in area 17.

Horseradish peroxidase (wheat germ-conjugated, Sigma) was dissolved in $0.1 \mathrm{M}$ Tris buffer, $\mathrm{pH} 8.6$ (5\% $\mathrm{w} / \mathrm{v}$ ), and injected iontophoretically through glass micropipettes (tip diameter 10 to $20 \mu \mathrm{m}$ ) using $2 \mu \mathrm{A}$ squarewave current (electrode positive, $5 \mathrm{sec}$ on, $10 \mathrm{sec}$ off) for $5 \mathrm{~min}$. Survival times were 48 to $72 \mathrm{hr}$, at the end of which we anesthetized the monkey with sodium thiopental and then perfused it transcardially with fixative (0.75\% paraformaldehyde, $2.25 \%$ glutaraldehyde in buffered saline, $0.1 \mathrm{M}$ sodium phosphate, $\mathrm{pH}$ 7.4). In some experiments the occipital lobe was flattened between two pieces of Teflon or glass, and frozen. Sections were cut at 30 to $60 \mu \mathrm{m}$ thickness and alternate sections were reacted for cytochrome oxidase (Wong-Riley, 1979b) or by the tetramethylbenzidine reaction for horseradish peroxidase (Mesulam, 1982). The tetramethylbenzidinereacted sections were photographed through crossed polarizers.

Fortunately there did not seem to be any cross-reactivity between the horseradish peroxidase and the cyto- 
chrome oxidase stain. Even the injection sites did not show up on the cytochrome oxidase stain.

Most of the injection sites when stained for peroxidase showed a large $(>1 \mathrm{~mm})$ halo surrounding a small central core. We strongly suspect that the lion's share of the transport came from the central core because (1) only the core was small enough to be confined to a stripe or interstripe, but the structures labeled in area 17 were usually consistent with transport originating from a stripe or an interstripe, but not both; (2) when no core was present, usually there was no transport.

\section{Results}

\section{17-to-18 connections}

In two macaque monkeys we made nine small iontophoretic injections of wheat germ-conjugated horseradish peroxidase into area 18 , just anterior to the area $17 / 18$ border. Of the seven injections that led to labeling in area 17, two were in thin stripes, three were in interstripe regions, one was in a thick stripe, and one was in a stripe that could have been either thick or thin. Luckily, none of the injection cores straddled stripe/interstripe borders. In almost every injection in area 18 that resulted in transported label in area 17, some of this transported label was clearly in cell bodies and the very most proximal dendrites, and hence was clearly retrograde, and some of the label was diffuse, and thus very likely anterograde (Fig. 24). The dendritic labeling was insufficient to justify guesses as to cell type.

Figure 25 shows results from one macaque in which four of five injections were successful; three are shown at higher power in Figure 26. From the mirror-image mapping of area 17 onto area 18 across the area $17 / 18$ border (see, for example, Cowey, 1964), it was easy to see which patches of label in area 17 corresponded to which injection site in area 18 . The region in area 17 corresponding to the injected thin stripe in area 18 (the middle

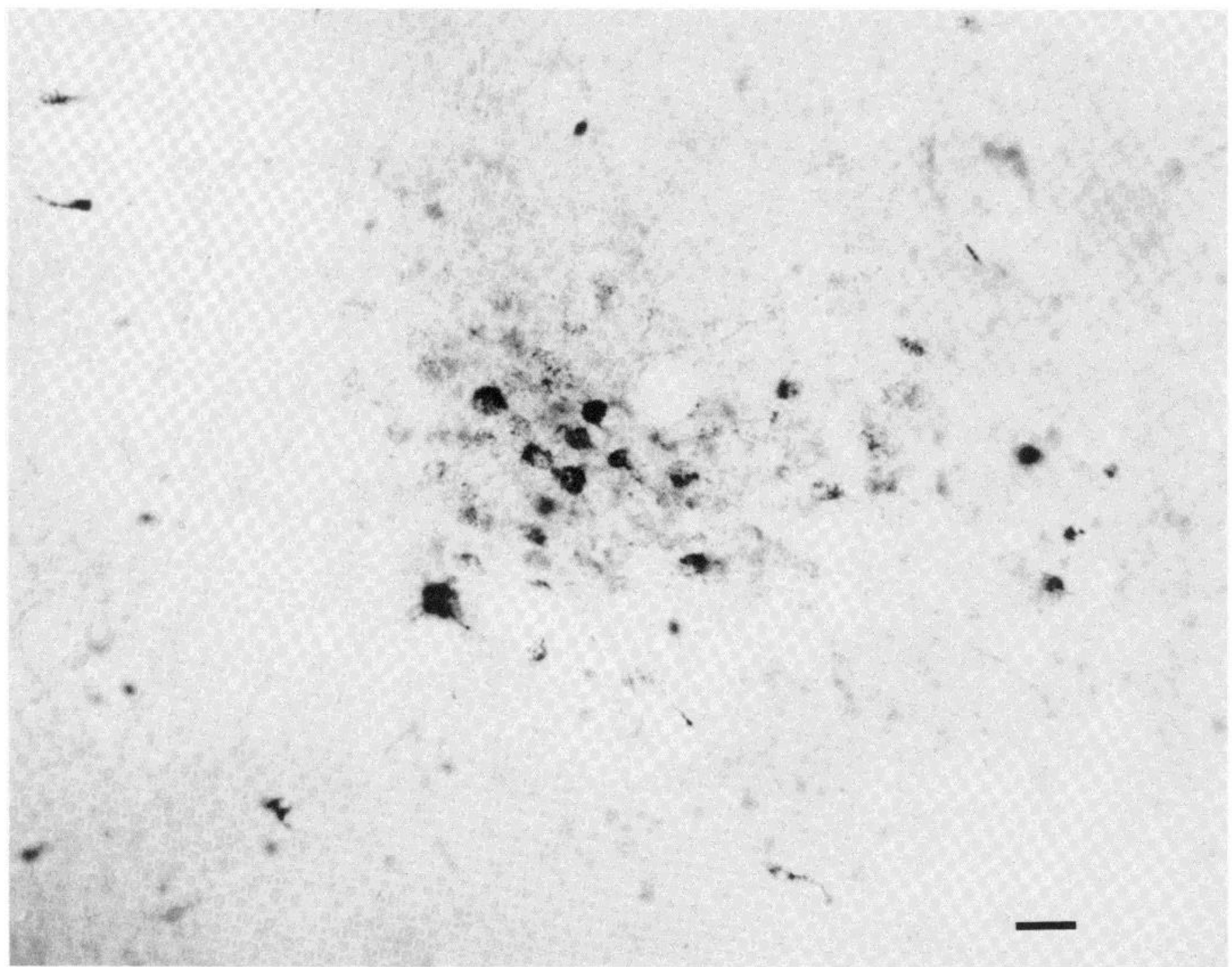

Figure 24. High power brightfield photograph of an unstained tetramethylbenzidine-reacted section showing one of the labeled patches in area 17 produced by a horseradish peroxidase injection in area 18 (the topmost injection of Fig. 30). Some of the label is in cell bodies and some is diffuse. Scale bar $=20 \mu \mathrm{m}$. 

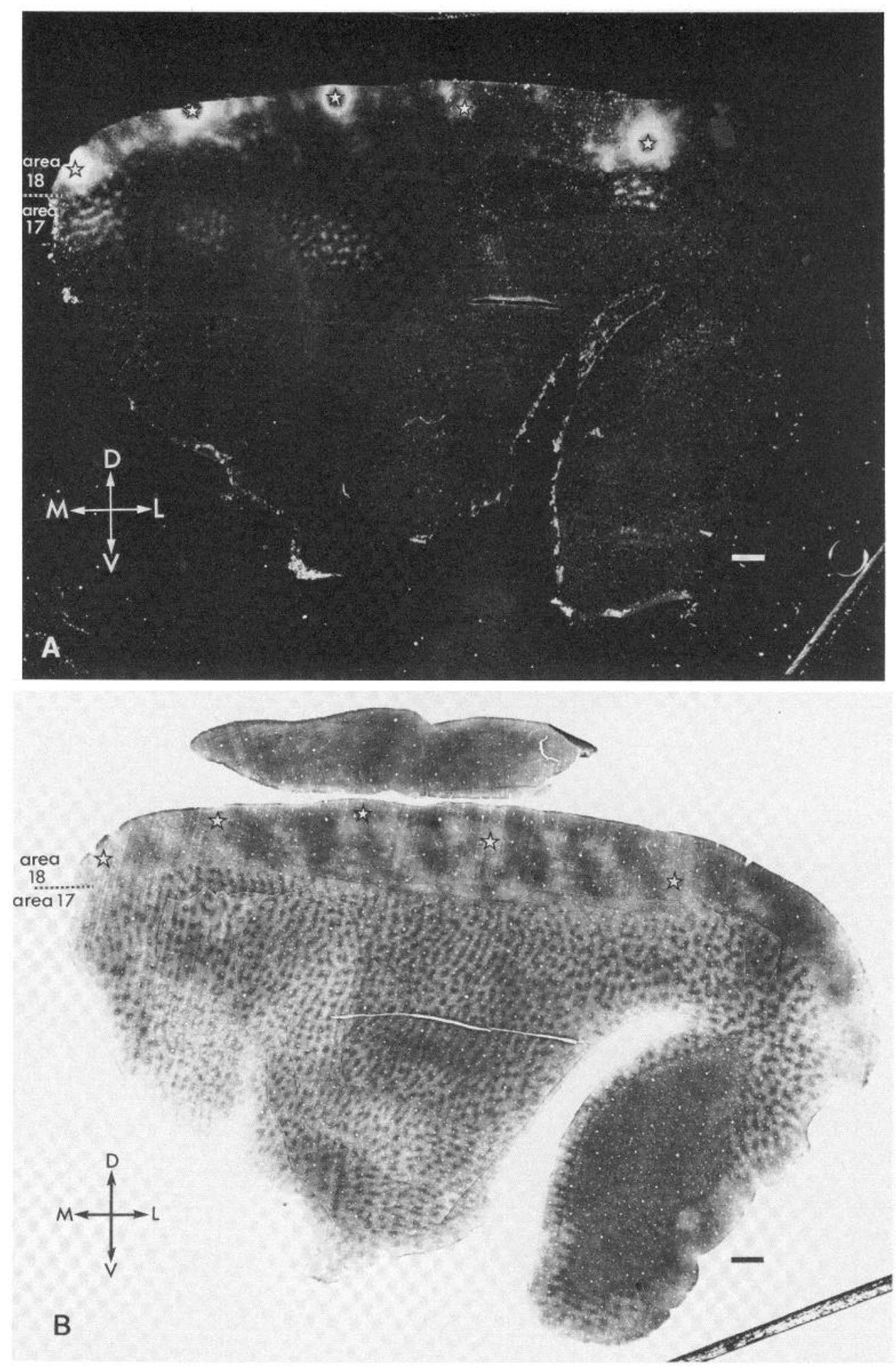

Figure 25. Sections from a macaque occipital lobe showing five horseradish peroxidase injections. Area 18 is at the top and area 17 is below. Scale bar $=1 \mathrm{~mm}$. For comparison with Figure 26. A, Darkfield photograph of a tetramethylbenzidine-reacted section showing the five injection sites and regions of retrograde labeling for four of the five injections (all but the second from the right). The dark regions at the center of each injection site are the cores and are so dense that they do not show up with darkfield. Because of the topographic projection and the mirror-image mapping of area 17 onto area 18 , it is easy to see which region of transported label corresponds to each injection site. $B$, Cytochrome oxidase-stained adjacent section. These photographs are each montages of two sections, aligned using the radial blood vessels, so that most of the region of area 17 shown is at the level of layers 2 and 3. The injection sites are indicated by stars. From this section alone it is not clear whether the middle injection is in a thick or a thin stripe, but by looking at several sections, it is reasonably clear that it is in a thin stripe. 
injection site in Fig. 25) is shown at higher power in Figure 26, $a$ and $b$ (color plate). Practically all of the labeled cells and diffuse labeling lay within blobs. On the other hand, in the regions in area 17 projecting to interstripe injection sites (Fig. 26, $c$ to $f$ ) the labeled cells and diffuse labeling did not lie in blobs, but rather in nonblob regions. The other macaque injections gave similar results. The one injection that was clearly in a thick stripe led to faint, confluent labeling in area 17 . We conclude that blobs in area 17 are reciprocally connected with thin stripes in area 18 and inter-blobs in macaque area 17 with interstripes in area 18.

Similarly, in 10 squirrel monkeys we made 50 injections of wheat germ-conjugated horseradish peroxidase into the occipital lobe. Because the area $17 / 18$ border is variable in squirrel monkeys and because we wanted to inject 18 close to the area $17 / 18$ border, 15 of these 40 injections turned out to be in area 17 . Of the 35 injections into area 18,21 produced retrogradely filled cells and diffuse labeling in area 17 . Six of the 21 injections were in thin stripes, 11 were in interstripes, and 4 were in thick stripes. A low power view of three squirrel monkey injections is shown in Figure 27. The two injections in area 18 produced puffs of label scattered around the injection site in area 18 (described below) and clumps of labeled cells and diffuse labeling in area 17. The upper injection in the figure was in an interstripe region, and the lower injection was in a thin stripe. The region in area 17 labeled by the thin stripe injection is shown at higher power in Figure 28, $a$ and $b$. The filled cells and diffuse labeling are predominantly within blobs. Figure $28, c$ and $d$, shows the region in area 17 labeled by the interstripe injection in area 18: here the label lay outside the blobs. The results of the other injections were similar: as in the macaque, injections into thin stripes selectively labeled blobs in area 17, whereas interstripe injections selectively labeled outside the blobs.

Thick-stripe injections, on the other hand, gave less clear-cut results: of eight thick stripe injections ( 7 in squirrel monkeys, 1 in a macaque) five led to rather faint, confluent labeling in area 17 , with no selective labeling of blobs or non-blobs. In the three remaining injections we saw no label in area 17. From injections in area 17, which always included both blob and non-blob cortex, we know that thin, thick, and interstripe regions in area 18 are labeled anterogradely (see, for example, Figs. 27 and 30 ). Thus we conclude that cells in blobs of area 17 are reciprocally connected with thin stripes, that interblob regions are connected with interstripe regions, and, tentatively, that both blob and non-blob regions may connect with thick stripes.

After interstripe injections in area 18 the labeling in the labeled part of area 17 did not fill the entire nonblob matrix. Most often it formed a regular periodic pattern of parallel stripes with a separation not very different from that of the blobs. This is seen in Figure $26 c$. In many places the stripes were interrupted or locally constricted by one or a series of indentations. By comparing the peroxidase sections with the cytochromes one could easily verify that the discontinuities were at the sites of blobs (e.g., see Figs. 26 and 28). One can probably think of several interpretations of these interstripe injec- tion patterns; to us the most likely has to do with the connections from area 17 to 18 that convey orientation specificty. The ordered sequences of orientation shifts found in area 18 (Hubel and Wiesel, 1974a) make it almost certain that cells of like orientation are grouped in columns, and from a few exploratory penetrations in area 18 we have the impression that it takes many millimeters of travel along area 18 to cover a full $180^{\circ}$ of orientation. This relative coarseness of visual field representation makes it likely that, in area 18 , the visual field distance corresponding to $180^{\circ}$ in orientation shift would be considerable, corresponding in area 17 to a movement crossing many modules. If, as is very likely, cells of like orientation are interconnected between area 17 and 18, then an injection into area 18 encompassing an incomplete subset of orientations should lead to labeling of corresponding subsets in area 17 , covering a fractional part of each of many modules.

The presence of diffuse labeling as well as filled cell bodies in the labeled patches is consistent with the known back projection from area 18 to area 17 (Tigges et al., 1973, 1977). Whereas the filled cell bodies were located primarily in layers 2 and 3 and presumably correspond to neurons whose axons terminate in the injection zone, the diffuse labeling occurred not only in layers 2 and 3 coincident with the clumps of labeled cells but was also present in a less distinct but clearly patchy pattern in layer 5 , where we saw no labeled cell bodies, and in layers 1 and $4 \mathrm{~A}$, where it was faintly patchy. Figure 29 shows a cross-section of a region in area 17 labeled by an injection in an interstripe region of area 18. Some of this diffuse labeling could be due to local collateral processes of the retrogradely filled cells in area 17. When Wong-Riley $(1978,1979 a)$ injected a mixture of horseradish peroxidase and $\left[{ }^{3} \mathrm{H}\right]$ leucine into area 18 , she found patchy labeling in area 17 in both the peroxidase-reacted sections and the autoradiograms, and the puffs of anterograde transport of the labeled amino acid coincided precisely with the columns of peroxidase label (both retrograde and anterograde). Our diffuse peroxidase labeling must therefore be at least partly, and perhaps entirely, due to an area 18-to-17 projection. Combining her results with ours implies that the reciprocal area 18-to-17 connections also observe a stripe-to-blob and interstripe-to-interblob segreation.

\section{18-to-18 projections}

In addition to label in area 17 , most of the injections in area 18 produced puffs of label in area 18 near the injection site, reflecting local connections (Figs. 25 and $27)$. As in the 17 -to- 18 projections, the 18 -to- 18 projections were also either stripe-to-stripe or interstripe-tointerstripe. We saw this result in both macaque and squirrel monkeys, but the segregation was not as clean as the segregation of the 17 -to- 18 connections. The 18 to- 18 projections in the macaque can be seen in Figure 25 . The labeled regions contain both labeled cell bodies and diffuse labeling, and are thus probably made up of retrogradely filled cells projecting to the injection site and anterogradely filled terminals of cells within the cells within the injection site. Similarly, Figure 30, in a squirrel monkey, shows two injection sites in thin blobs 


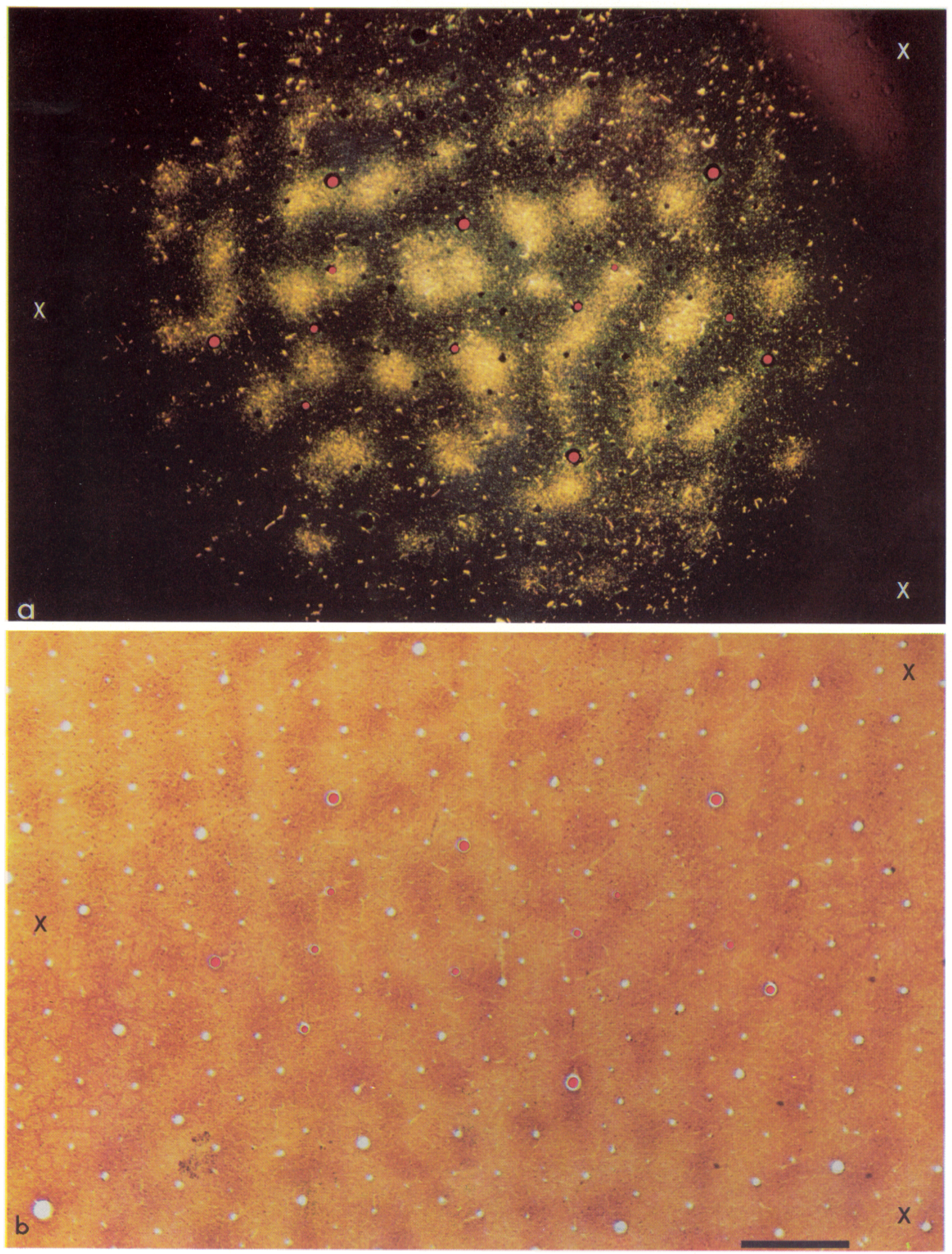



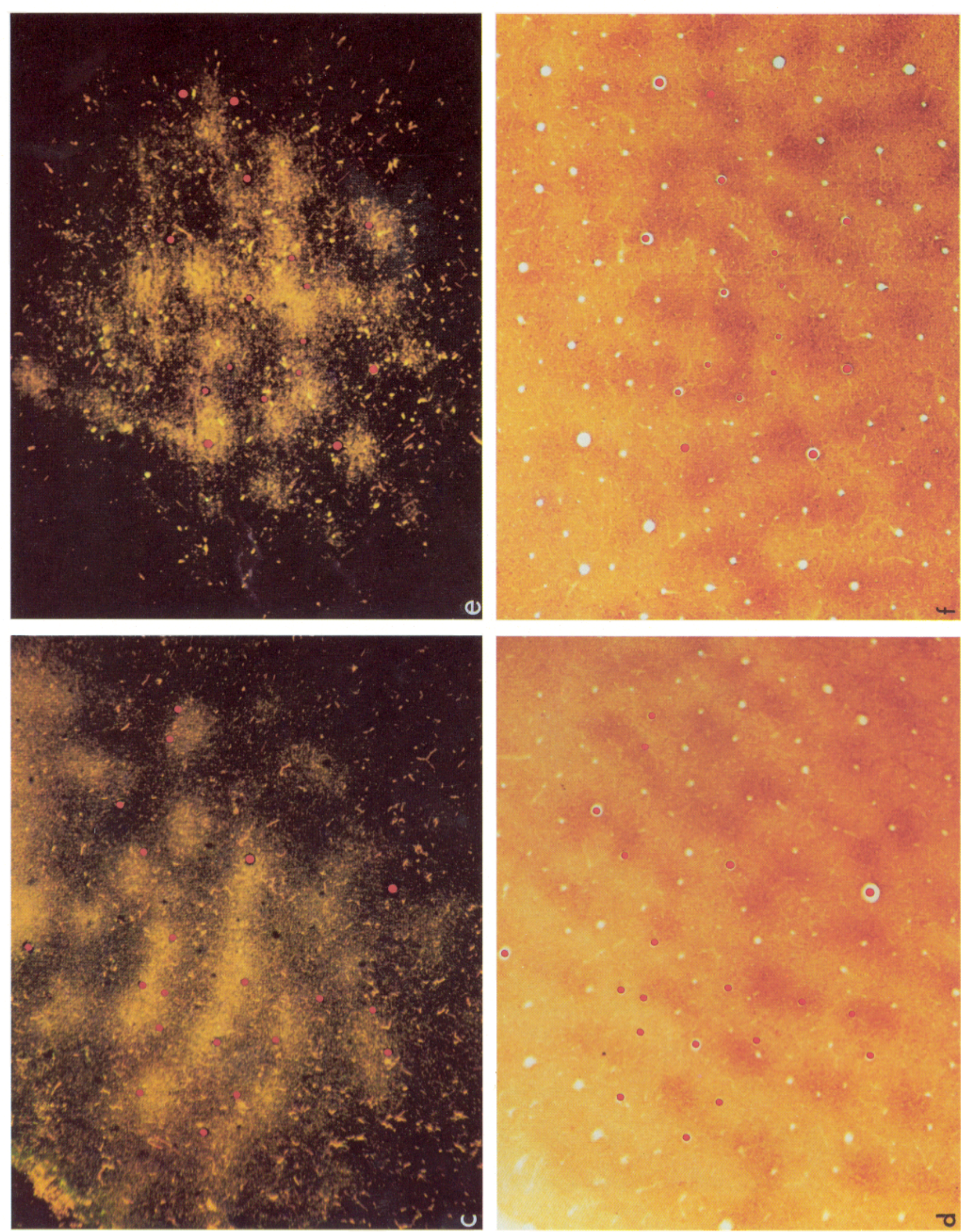

Figure 26. Higher power, color photographs of the same sections shown in Figure 25. Scale bar $=0.5 \mathrm{~mm}$. Red dots indicate corresponding blood vessels on the tetramethylbenzidine-reacted and cytochrome oxidase-stained sections. The reader is encouraged to take a piece of clear plastic and trace the blood vessel pattern and the labeled regions and then compare the tracing to the cytochrome oxidase-stained section. (This should not be necessary in the case of $a$ and $b$.) $a$ and $b$, Region labeled by the third injection from the left in Figure 25. The injection site in area 18 was in a thin blob and the labeled cells in area 17 lie almost exclusively in blobs. The overlay is a negative of the tetramethylbenzidine-reacted section. The $X$ 's are fiduciary marks for lining up the overlay. $c$ and $d$, Region in area 17 labeled by the leftmost injection, which was in a non-blob region of area 18 . The corresponding label in area 17 lies in rows almost entirely outside blobs. $e$ and $f$. Region in area 17 labeled by the rightmost injection, which was in a non-blob region of area 18. Again the label in area 17 lies predominantly outside blobs. 
with connections to the nearest thick blobs and even in one case to the thin blob beyond, skipping the intervening non-blob regions. Wong-Riley (1979a) saw these patchy intra-18 connections but, ironically, at that time, could not have made the correlation with cytochrome oxidase staining.

\section{17-to-17 projections}

Several of our injections in squirrel monkeys and macaques were inadvertently in area 17 rather than in area
18. When this occurred the labeling around the injection site formed not an even halo but rather a sunburst pattern (Fig. 31). Label was, as in the other cases, both diffuse and intracellular. A patchiness in the horseradish peroxidase transport within area 17 has been reported by Rockland and Lund (1983), but our results differ from theirs in that we find that the label farthest from the injection site was almost exclusively in blobs (Fig. 31), suggesting that blob cells have longer intrastriate connections than do non-blob cells. As previously described

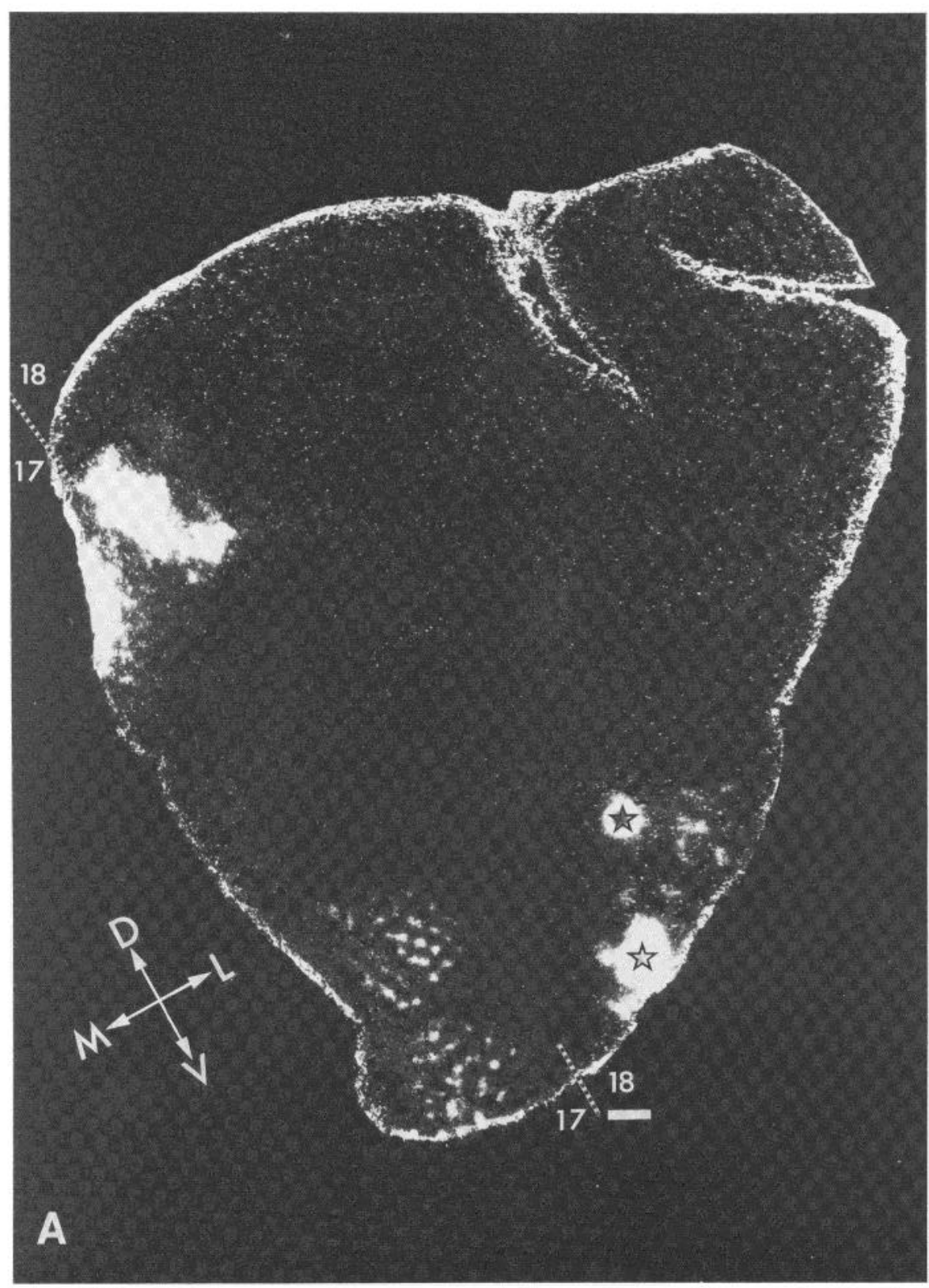

Figure 27. Montages of sections from a squirrel monkey occipital lobe showing three horseradish peroxidase injections. Area 17 is below and to the left; area 18 is above and to the right. Scale bar $=1 \mathrm{~mm}$. For comparison with Figure 28. A, Tetramethylbenzidinereacted section showing the three injection sites and the transported label from each. The two injections on the lower right were in area 18 and the transported label is to the left of each injection in area 17. The upper of these area 18 injections was in an interstripe region, the lower was in a thin blob-although the figure itself does not show this well. The uppermost injection was in area 17 and the transported label in area 18 is just to the right of the injection site and extends over thin-, thick-, and interstripe regions. $B$, Cytochrome oxidase-stained section with the injection sites indicated by stars. 
by Rockland and Lund (1983), in cross-section (Fig. 32) the patchiness extended through layers 2,3 , and $4 \mathrm{~B}$, with the patches of label in layer $4 \mathrm{~B}$ in register with patches of label and cytochrome oxidase blobs in layers 2 and 3. This patchy pattern in layer $4 \mathrm{~B}$ is consistent with our physiological finding (see Part III) that cells in layer 4B directly below blobs in layers 2 and 3 lack orientation specificity.

\section{18-to-19 projections}

In several experiments in which we injected horseradish peroxidase into area 18 , we saw label not only in areas 17 and 18 but also in an area 0.5 to $3 \mathrm{~cm}$ anterior to the anterior border of the coarse stripe pattern of area 18 (Fig. 30). This projection site is most likely in area 19 (Tigges et al., 1981); its location is consistent with the assumption (Tootell et al., 1983) that the borders of area 18 are demarcated by the coarse stripes. Whether the area beyond area 18 should be equated with visual area 3 of various authors is unclear, since of all the visual areas so far described, visual area 3 seems to be the wooliest.

\section{Thalamus-to-Area 18 projections}

The thalamus of monkeys with area 18 injections contained retrogradely filled neurons in the lateral and inferior pulvinar, but not in the geniculate. This result is consistent with previous reports that area 18 receives a direct projection from the pulvinar (Wong-Riley, 1977) and no direct projection from the lateral geniculate nucleus (Ogren and Hendrickson, 1977, 1979).

\section{Discussion}

To our surprise, what began as a project to look for differences in the physiology of cells inside and outside upper layer blobs in striate cortex has ended up immersing us in the problems of color vision and the anatomy of parallel pathways. Although the anatomical and physiological viewpoints cannot be entirely separated, it is convenient to consider them in turn and then to discuss the possible relation between them. After that we will consider the relevance that our physiological results may have to the known psychophysics of primate color vision. Finally, we will discuss the modular organization of the cortex.

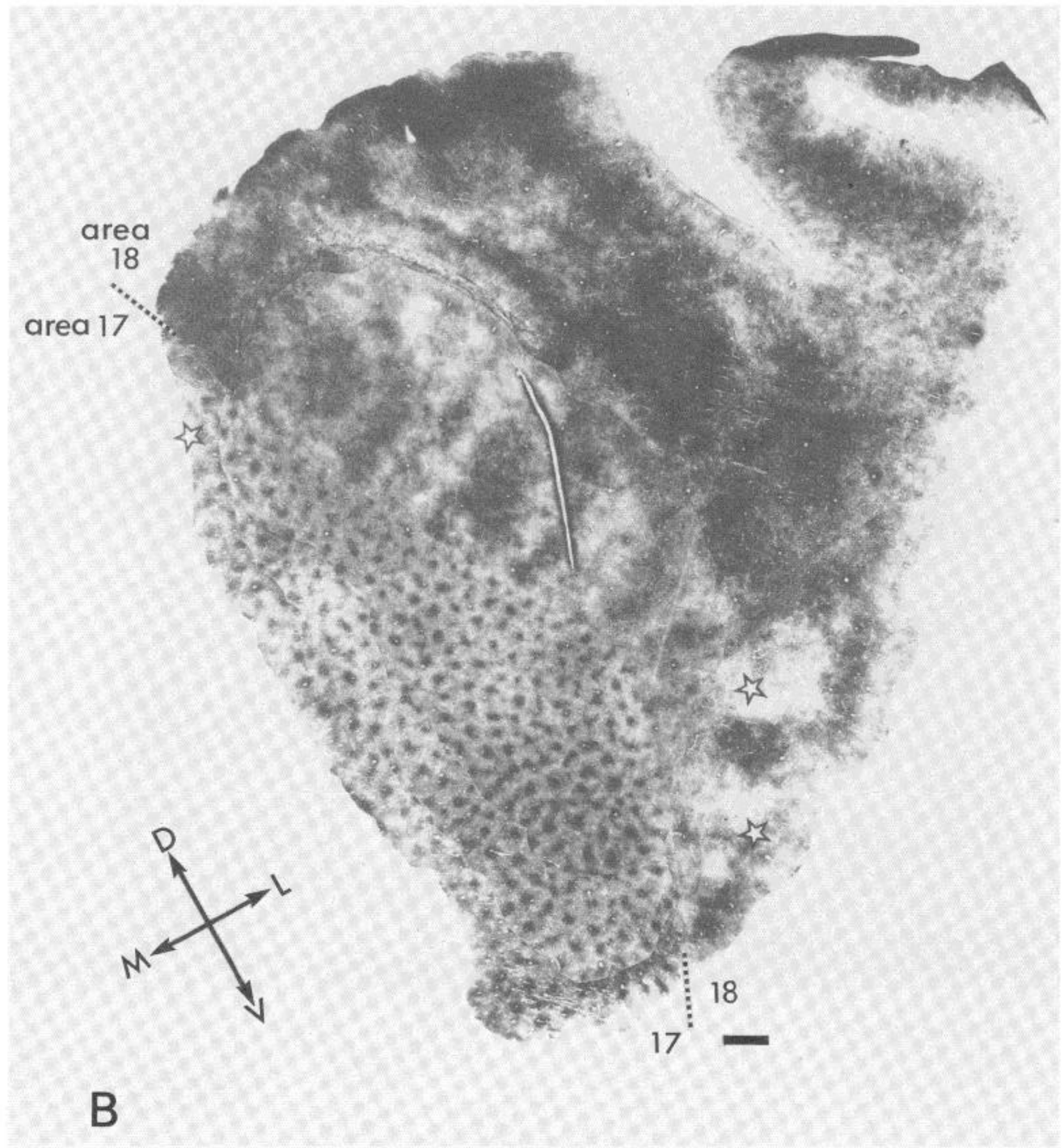

Figure 27B 

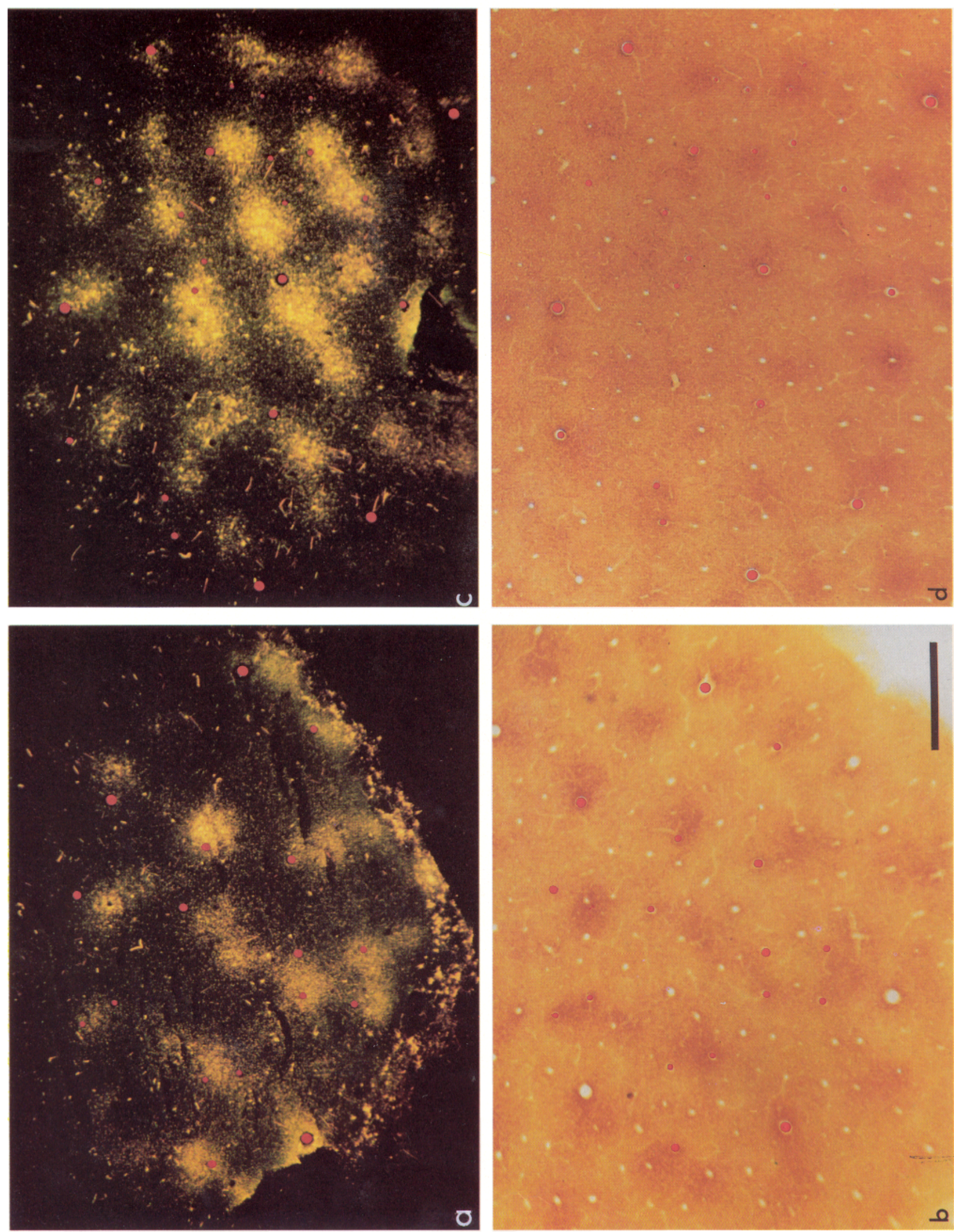

Figure 28. Higher power color photographs of the same sections shown in Figure 27. Scale bar $=0.5 \mathrm{~mm}$. Red dots indicate corresponding blood vessels in the tetramethylbenzidine-reacted and cytochrome oxidase-stained sections. As in Figure 26, the relationship between the cytochrome oxidase blobs and the horseradish proxidase-filled neurons can best be seen by using a piece of clear plastic to compare the two sections. $a$ and $b$, Region in area 17 labeled by the lower of the two area 18 injections. The injection in area 18 was in a thin blob and most cells lie within blobs. $c$ and $d$, Region in area 17 labeled by the upper of the two area 18 injections. The injection in area 18 was in an interstripe region and the filled cells in area 17 lie predominantly outside blobs. 


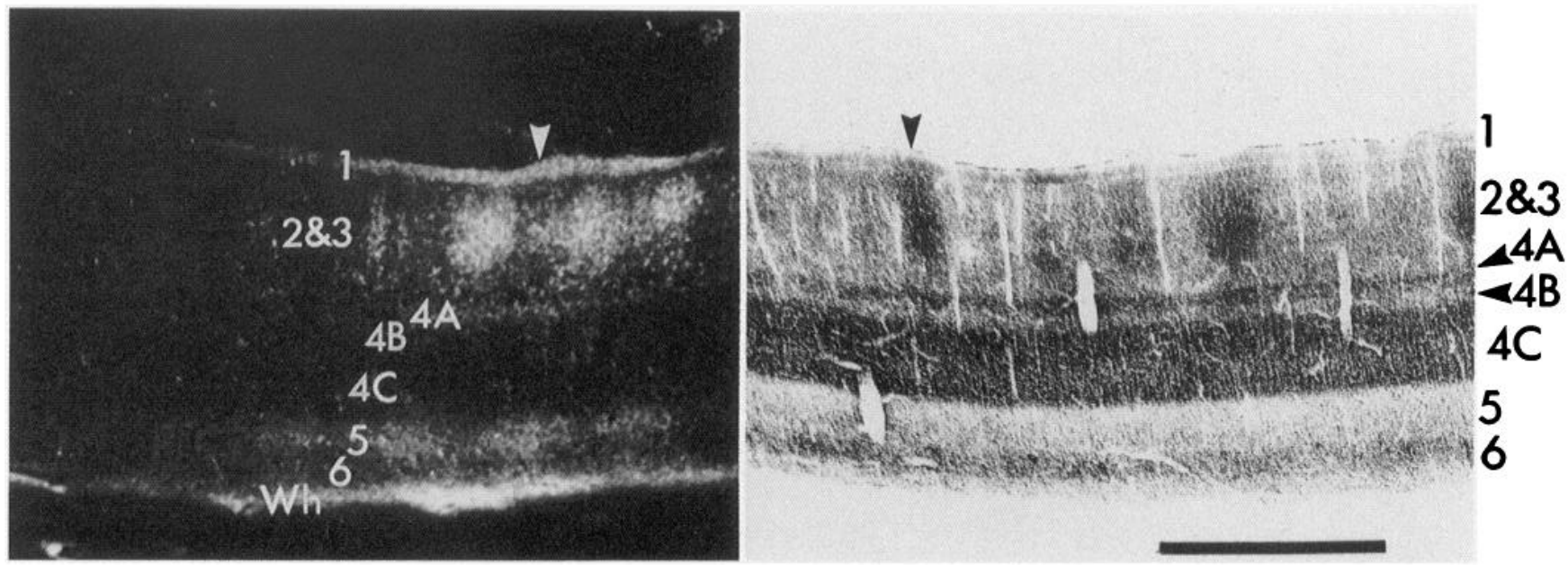

Figure 29. This figure shows the laminar distribution of label in area 17 following an injection of horseradish peroxidase into an interstripe region of area 18. The two sections, peroxidase on the left and cytochrome oxidase on the right, are mirrorsymmetric across their common boundary. There are filled cell bodies lying in non-blob regions of layers 2 and 3 . The blob indicated by the black arrowhead on the cytochrome section corresponds to a label-free region on the tetramethylbenzidine section (white arrowhead). There is also patchy, diffuse labeling in layer 5 (the patches could be shown to be aligned with those in layers 2 and 3), and non-patchy diffuse labeling in layers 1 and $4 \mathrm{~A}$. Scale bar $=1 \mathrm{~mm}$.
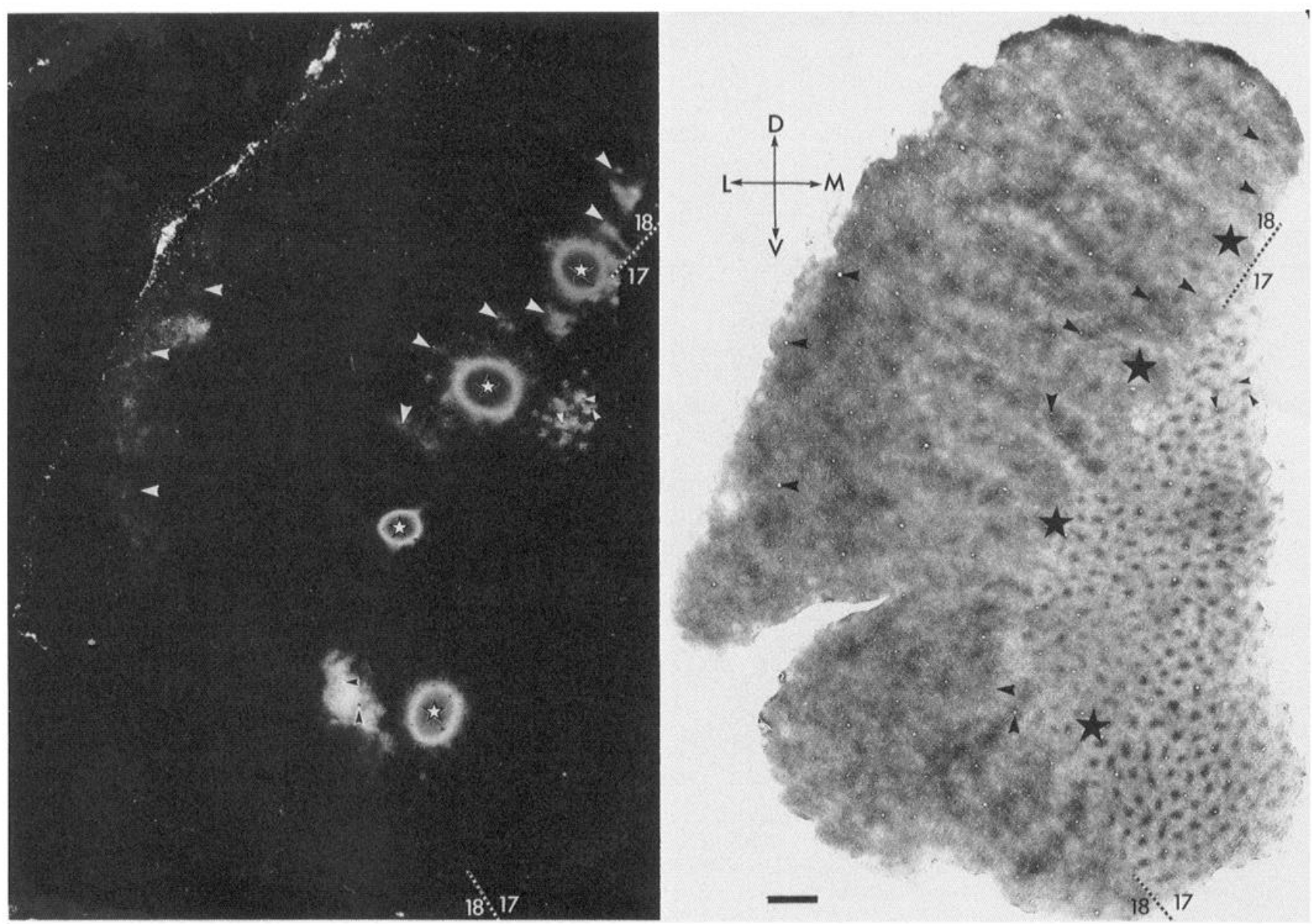

Figure 30. Adjacent sections from a squirrel monkey occipital lobe reacted with tetramethylbenzidine (left) and for cytochrome oxidase (right). The stars indicate injection sites and the arrowheads indicate corresponding blood vessels in the two sections. The two upper injections are both in thin stripes in area 18 (to the left) and both injections produced, in area 17 (to the right), filled cells in blobs (visible, in these sections, only in the case of the lower of these two injections). Both injections also produced puffs of label in area 18, which can be seen to be located predominantly in stripe regions (both thick and thin). The third injection straddled the area 17/18 border and did not produce any transported label. The bottom injection was in area 17 and resulted in transported label in area 18 in thin-stripe, thick-stripe, and interstripe regions. This same injection is shown at higher power in Figure 31. The faint labeling near the lefthand border of the tetramethylbenzidine section is probably label transported to the next prestriate area (area 19) from the two injections in area 18. This label is just beyond the border of the cytochrome oxidase stripes in area 18, a border that we assume coincides with the anterior border of area 18. Scale bar $=1 \mathrm{~mm}$. 


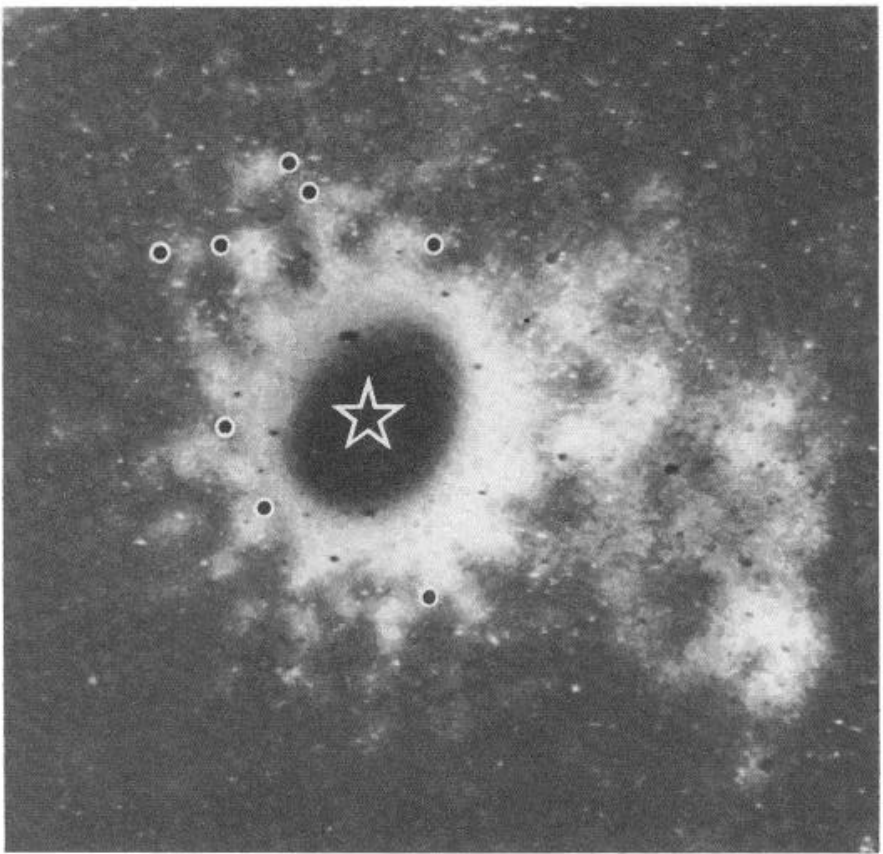

a

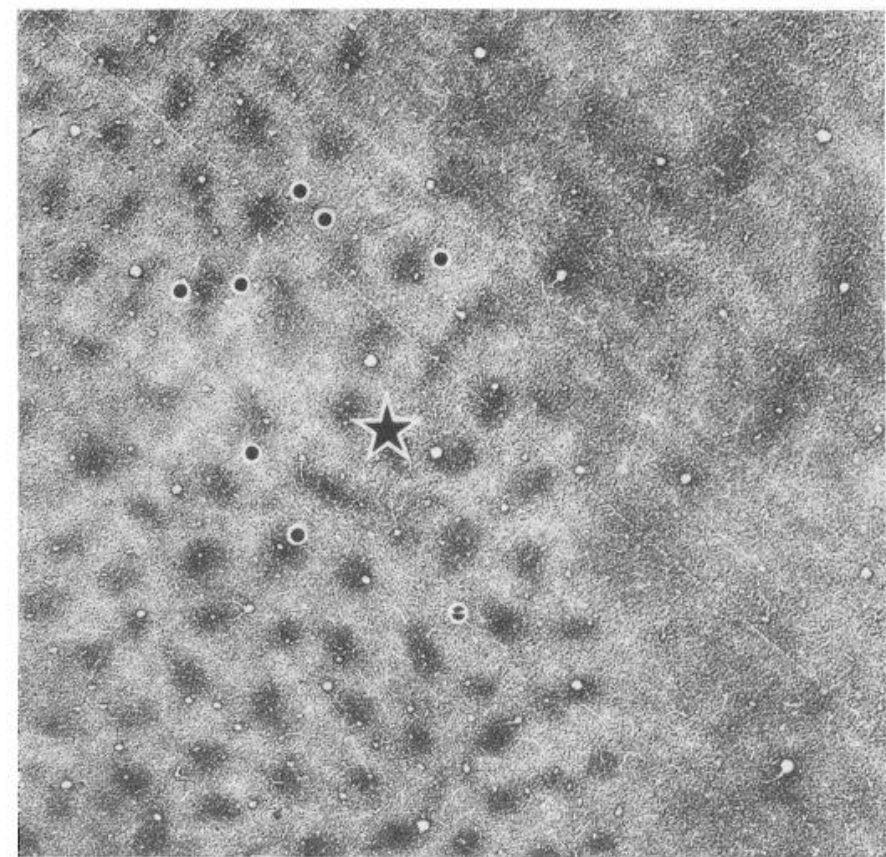

b

Figure 31. Adjacent sections from squirrel monkey area 17 stained $(a)$ with tetramethylbenzidine and $(b)$ for cytochrome oxidase showing a horseradish peroxidase injection within area 17 . Around the injection site, the label forms a sunburst pattern with the most distal labeling lying within blobs. Corresponding blood vessels on the two sections are indicated by black dots. Scale bar $=1 \mathrm{~mm}$.
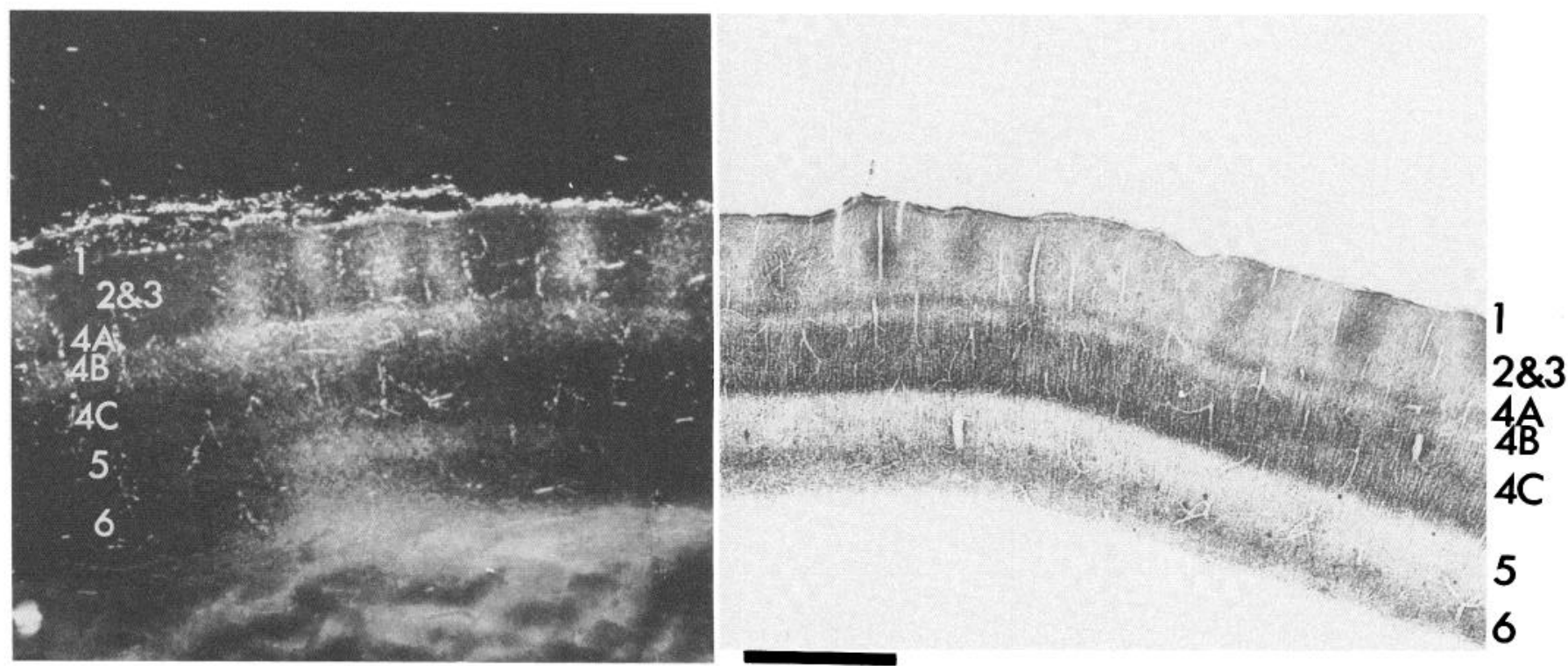

Figure 32. Cross-section through squirrel monkey area 17, at the edge of a horseradish peroxidase injection, far enough from the center of the injection site so as to pass through the periphery of the sunburst pattern (the topmost injection of Fig. 27). This figure is a montage of two adjacent sections and represents a continuous region of area 17; i.e., unlike Figure 29, the panels are not mirror symmetric. The left panel is a section reacted with tetramethylbenzidine, the right panel for cytochrome oxidase. The label is transported farthest in layers 2 and 3,4B, and 5, and is patchy in layers 2 and 3 and $4 \mathrm{~B}$. Scale bar $=1 \mathrm{~mm}$.

\section{Anatomical connections of blobs}

\section{Inputs to blobs}

The first suggestions of non-homogeneity in layers 2 and 3 of primate area 17 were the patches of label seen there after injecting radioactive amino acids into the eye or the geniculate (Weber et al., 1977, 1983; Hubel and Wiesel 1978; Hendrickson et al., 1978). The subsequent demonstration that these patches were in precise register with the cytochrome oxidase blobs made it clear that the blobs receive a special geniculate input not shared by cortex between blobs. Two questions immediately arise: 
(1) Is the input direct, or is it transneuronal through layer $4 \mathrm{C}$ ? That is, is the system closely connected with the already well known geniculate-to-layer 4 system or is it separate? (2) What part of the geniculate supplies the projection?

Both questions seem now to be answered, at least for the squirrel monkey, by a study of Fitzpatrick et al. (1983), who observed retrograde transport of horseradish peroxidase from the upper layers of area 17 to the supernumerary leaflets of cells just above and below, and perhaps also between, the magnocellular layers. They refer to these leaflets as intercalated layers. They also showed that a very small proline injection centered on the leaflet between the magnocellular and parvocellular layers (the dorsal intercalated layer) led to cortical label practically confined to the blobs and to layer $4 \mathrm{~A}$. In the macaque there is no evidence about which geniculate layers supply the input to the blobs.

These intercalated leaflets in the squirrel monkey receive a direct retinal input (Kaas et al. 1978; Fitzpatrick et al., 1983), and also an input from the superficial layers of the superior colliculus (Harting et al., 1978). In the macaque there are analogous intercalated layers above, below, and between the two magnocellular layers. Interlaminar zones containing few cells are also present between the four parvocellular layers. The layers interdigitated with the magnocellular layers receive direct retinal input (Hubel et al., 1977a; Kaas et al., 1978) and also collicular inputs (Harting et al., 1980); the interlaminar zones between the parvocellular layers receive collicular inputs (Harting et al., 1980), but they are not thought to receive direct retinal input (Guillery and Colonnier, 1970; Kaas et al., 1978).

We still do not know whether layer $4 \mathrm{C}$, the major target of the lateral geniculate, itself sends projections to the blobs. The Golgi studies that form the basis of our knowledge of intracortical connections (Lund and Boothe, 1975) show layer $4 \mathrm{C} \beta$ projecting to the deepest part of layer 3 , but presumably this projection could be restricted to the parts of layer 3 outside the blobs without that being detected by the Golgi method. Physiologically, a layer $4 \mathrm{C} \beta$-to-blob projection seems unlikely because of the profound differences between the Color-Opponent Center-Surround (type I) cells of layer $4 \mathrm{C} \beta$ and the Double-Opponent cells in blobs: it seems difficult, if not impossible, to generate a Double-Opponent cell from any straightforward combination of Color-Opponent CenterSurround cells since the surrounds have the wrong sign. The presence of orientation-selective cells in layer $4 \mathrm{C} \alpha$ makes that layer, which in any case projects to layer 4B (Lund and Boothe, 1975), also an unlikely source of input to the blob cells. Nevertheless, direct anatomical evidence would be welcome.

The blobs in the upper layers of area 17 doubtless receive other inputs. The patchiness of the pulvinar-tolayer 2 projection described by Ogren and Hendrickson (1977) hints that the pulvinar may have an input specifically to blobs, but no one has yet made the correlation.

\section{Outputs of blobs}

The outputs of the area 17 blobs are an example of the degree of specificty and precision of connections attain- able in the brain. It was already known that connections between different cortical regions can be patchy (see Gilbert, 1983, for references), and even that injections of horseradish peroxidase into area 18 can sometimes give labeling of clumps of cells in area 17 (Wong-Riley, 1978, 1979a; Maunsell et al., 1980; Tigges et al., 1981). Our results together with Wong-Riley's demonstrate two sets of patches, in two different cortical areas, with reciprocal, interdigitating blob-to-stripe and interblob-to-interstripe connections, manifesting a horizontal and laminar specificity that goes far beyond the already well known topographic interlinking of the two regions.

The horseradish peroxidase injections within area 17 produced, at the edges of the injections, preferential labeling, both cellular and diffuse, of the blobs. The labeling of cell bodies shows that cells in blobs project farther within area 17 than do cells in non-blob regions, and the non-cellular labeling indicates that blobs receive longer connections. If the non-cellular labeling is not due to recurrent collaterals of the labeled cell bodies, then these results suggest, indirectly, that the longest intrastriate connections are specifically blob-to-blob.

\section{Correlations with metabolic indicators}

There are two indications that blobs are metabolically more active than non-blob regions: their darker staining with cytochrome oxidase and succinate dehydrogenase, which are mitochondrial enzymes, and the fact that under a variety of stimulus conditions they show higher levels of 2-denxyglucose uptake (Horton and Hubel, 1981; Humphrey and Hendrickson, 1980, 1983). The idea that blobs are metabolically more active than non-blob regions is consistent with the physiological observation that blob cells have a much higher spontaneous activity than non-blob cells and will respond to visual stimuli of any orientation. We cannot be certain, however, that the observations with either metabolic indicator are due to a heightened firing of the cells themselves in the blobs. The darkest cytochrome oxidase staining and the highest deoxyglucose uptake both occur in layers $4 \mathrm{~A}, 4 \mathrm{C}$, and 6 , the very same layers that receive direct geniculate input. The geniculate fibers themselves have a very high spontaneous activity and so their terminals could account for the labeling.

The stripes of area 18, like the blobs in area 17, are distinct from the non-stripe regions in a number of ways besides cytochrome oxidase staining: they receive a direct thalamic (pulvinar) input to the very layers, 3 and 5, that are most deeply cytochrome labeled; they receive from the blobs of area 17 a direct input which, like the area 17-to-18 projection in general, is probably to layer 4 (Spatz et al., 1970). Finally, in area 18 the metabolic differences indicated by deoxyglucose uptake (Livingstone and Hubel, 1982; Tootell et al., 1983), and of course by the cytochrome oxidase stain itself, predict that the physiology inside and outside of the stripes will differ. The especially prominent labeling of the thin stripes hints that the thin and thick stripes are themselves physiologically different. The thick stripes do seem to differ from the thin stripes in the strength, and perhaps also in the type, of input from area 17. 


\section{Speculations on how Double-Opponent receptive fields are built up}

How Double-Opponent properties of cells in the monkey cortex come about through convergence of cells at lower levels is not a new problem (Hubel and Wiesel, 1968; Michael, 1978). We assume that double opponency cannot arise through convergence of many Color-Opponent Center-Surround (type I) cells, since, as already mentioned, the field-surrounds are of the wrong sign. What type I cells are good for is indeed a puzzle, but their enormous numbers and variety in the geniculate parvocellular layers and in layer $4 \mathrm{C} \beta$ force one to take them seriously. They cannot be of any use in registering color contrast of stationary images (Wiesel and Hubel, 1966; Krüger and Gouras, 1980), which is the very thing that Double-Opponent cells seem constituted for. They can, on the other hand, register color contrast across moving borders, or temporal changes in wavelength. Finally it seems possible that the information they convey is pooled at subsequent stages in such a way that simple tests for color coding fail. Krüger and Gouras (1980) have described cells that, although they lacked overt color opponency, responded to a red-green edge over all relative intensities. (A truly color blind cell should be unresponsive at some relative intensity of the green and red.) Such cells could be important in overcoming other animals' attempts at camouflage. Presumably they could be built up from type I cells. The huge numbers of complex, Broad-Band, orientation-selective cells found in the upper layers of area 17 must surely derive much of their input from the parvocellular geniculate layers and layer $4 \mathrm{C} \beta$ in the cortex, and it is hard to believe that all that color information is lost.

In any case, our recordings from layer $4 \mathrm{C} \beta$ convince us that the cells there are mainly Color-Opponent Center-Surround (type I) and Broad-Band (type III) and that Double-Opponent cells are, contrary to previous reports (Gouras, 1974; Michael, 1978), rare there, or altogether absent.

We can similarly rule out Broad-Band cells as the ancestors of dual opponent cells: to add the effects of different cones when a subtraction is needed would be just as self-defeating as using type I cells. An obvious building block would be something like a red on-center red off-surround cell, but no one has ever seen such a cell, at any level.

This leaves the Color-Opponent Center-Only (type II) cell. For a Double-Opponent cell to have its field center built up from one or a few such cells, and its surround from many of them, of opposite polarity, seems perfectly reasonable. One hint that favors this comes from a survey we have made, from old protocols (see, for example, Fig. 18, Wiesel and Hubel, 1966), of the exact positions from which nine Color-Opponent Center-Only cells were recorded in macaque geniculate. All but one were in the dorsal (parvocellular) part of the geniculate, in or very close to the zones of transition from one eye to the other. The one exceptional cell was probably in the dorsal intercalated (magno-parvo) layer. Thus in the macaque the cells near the borders between the parvocellular layers as well as the cells in the intercalated layers associated with the magnocellular layers could conceiv- ably contribute to the blobs. A search of the macaque geniculate by Daw and Pearlman (Daw, 1972) failed to find Double-Opponent cells, but at that time no one could have realized the importance of concentrating on the interlaminar zones.

Another possibility for explaining the origins of Double-Opponent cells is that they originate in the retina, with the information simply handed on to geniculate, possibly to the border zones or intercalated layers, and then to cortex. It is clear that the retina is capable of building up such cells, since they were first discovered there in the goldfish by Daw (1968). Still, no one has yet found any Double-Opponent cells in the primate retina or optic nerve.

\section{Color psychophysics}

Neurophysiological studies of primate color vision have spawned a bewildering variety of color-coded cell types. Not only have several major groups been described, but within each group many subtypes have been seen, each involving a different combination of excitatory and inhibitory cone inputs. If we are to make sense of the various categories of color-coded cells, and in particular of the Double-Opponent cells found in blobs, it must be in the context of the known psychophysics of primate color vision. The best-studied primate is the human, but behavioral studies in the macaque (DeValois et al., 1974) indicate that the macaque and human are very similar. It therefore seemed justifiable to relate the macaque physiology with the human psychophysics.

For present purposes, and admittedly artificially, we can regard the psychophysics of color as dealing with two topics. The first goes back to Newton (1704) and is concerned with what is perceived when mixtures of light of different wavelengths come to the eye from one region in space. In typical experiments the object viewed is a small test spot of light on a dark or diffusely lit white background. The results can be deeply counterintuitivethat monochromatic light seen as "blue" added in the right amount to monochromatic light that we call "yellow" produces the sensation "white," a sensation also evoked by light containing all wavelengths; that cyan (blue-green) plus red similarly produces white; that red plus green gives yellow. Over the past 300 years this branch of psychophysics has been worked out in much detail. Among other accomplishments it predicted a three-variable mechanism (trichromacy) depending on three types of cones, long before their existence was established by direct observation, and it accounted for the various common kinds of color blindness in terms of a lack of one or more cone pigments.

The second aspect of color psychophysics is concerned with the colors seen on looking at a typical complex daily life scene. The color of any small part of a scene cannot be predicted and is not determined by the wavelength composition of light reflected from that region. (To help combat the prevalent misconception that color is determined by local wavelength composition we shall avoid speaking of "perceived color:" color is a perception, and the expression is therefore redundent.) The fact that a given region of the visual field reflecting some particular composition of light can vary in color depending on the illumination of the rest of the field seems to have been 
discovered by Count Rumford (Thomson, 1974), but only relatively recently have these interrelationships been studied quantitatively (Land, 1959; Jameson and Hurvitch, 1959) or put in the context of a predictive theory (Land 1964, 1974, 1983; Land and McCann, 1971). Since Land's formulation has predictive power and makes specific proposals as to possible neural mechanisms, we may profitably start by discussing relationships between this model and the color cells found in the geniculate and the striate cortex. We will first summarize Land's Retinex theory, as we understand it.

Empirically, the color at a point is not completely determined by the spectral composition of the light coming from that point, but depends on the light coming from every point in the scene. The interdependence is such that for a given point in a scene the light source can be varied over a very wide range of spectral composition, intensity, and even uniformity, without changing the color at that or any other point. This was clear, for example, to Helmhollz (1909). On the other hand, if the light coming from a point is artificially held constant while the light falling on the rest of the scene is changed, the color at that point can be made to duplicate virtually any preassigned color. For color, including black, grays, and white, to be independent of light source is obviously useful to an animal, and an elaborate neural apparatus has evidently evolved to guarantee that independence.

If one knows the wavelength composition coming to the eye from every point in a scene it is possible, using an algorithm devised by Land (1983), to compute for each point a set of three numbers called "designators" which uniquely define the color at that point. The task of computing designators and hence color for every point in a scene is a massive one even for a modern computer, but our nervous system performs it instantaneously, and so well that a white object continues to look white whether seen in sunlight, either at noon or at sunset, or by tungsten illumination. The very success of our visual system in solving this problem is probably responsible for the failure of many people to recognize that a problem exists at all. Anyone who is unconvinced should try photographing a white surface with the same color film, outdoors and in tungsten light.

The raw information given to our visual system, from which color must be derived, is the cone signals produced by light from each point in the visual field. For a particular cone type, the signals are a function of the product of the cone's spectral sensitivity times energy, integrated over the cone's waveband. For a given waveband, the reflected energy is the product of the incident energy and the reflectance. In Land's algorithm these reflected energies at all points are used to calculate the reflectance at each point in the scene, relative to the reflectances at all other points, for each of the three cone wavebands. The incident light is thus factored out. The three relative reflectances at any point are termed "designators." Reflectance is of course a property of objects, and consequently a statement that the reflectance characteristics of an object determine color implies that color must be independent of the light source. Psychophysically, this is so over a wide range of spectral compositions and despite any gradual nonuniformities in the light source such as would be produced by oblique illumination.
The procedure Land (1983) currently employs to calculate relative reflectances from energies is the following. To the point in a scene whose color is to be computed (the "final" point) a path, straight or otherwise, is drawn from some other point. By means of a photometer whose spectral sensitivity is that of one of the three cone types, the ratios of readings coming from successive pairs of points along the path are evaluated for the entire path, and these ratios are then multiplied together. In practice, readings are made on a log scale, differences computed, and then added. Any difference that is below some empirically determined threshold value is set at zero. This amounts to adding up all of the differences across edges (corresponding to suprathreshold jumps in energy), while ignoring gradual changes. If the illumination is even, the result is obviously the ratio of the reflected energies at the final and initial points, since intermediate values cancel, and further the result is the ratio not just of the reflected energies but also of the reflectances, at the final and initial points. For uneven illumination, the result is also the ratio of reflectances, because the algorithm takes into account only ratios across edges, which are independent of evenness of illumination. This process is repeated for many other paths running to the same final point from different randomly selected initial points; about 200 paths are sufficient to give $5 \%$ accuracy, whatever the intricacy of the scene. When the numbers so obtained are averaged, the result is the ratio of reflectance at the common final point to a number roughly equivalent to the average reflectance of the entire scene, and is thus a measure of relative reflectance at the point, on the selected waveband. The entire process is now repeated for the two other cones types, and the resultant three numbers, the designators, uniquely specify the color at the point. Experimentally the triplet is, as is one's perception, independent of the incident light's spectral energy and spatial uniformity over a wide range. For example, an object which, compared to other objects in the scene, reflects middle wavelengths poorly and long and short wavelengths not at all will be dark green, regardless of the qualities of the light source.

Color can thus be plotted in a three-dimensional Cartesian system whose axes correspond to the three cone wavebands. It is important to realize (the realization did not come easily to us) that the color corresponding to a point on, say, the long-wavelength axis would not be imitated by light whose spectral content matches the red cone spectral sensitivity; such light, because of the broad overlap of the red and green cone sensitivities, would stimulate the green cone also, and its predicted color would then be represented by a point somewhere between the red and green axes, rather than one on the red axis. To stay on the red axis requires a stimulus that activates the red cone without activating the other two conesthe closest approximation to this is a very long wavelength stimulus, $640 \mathrm{~nm}$ or beyond. The green cone, with its spectral sensitivity curve sandwiched between those of the red and blue cones, is even less likely to be stimulated alone so that, unless one resorts to selectively bleaching both the red and blue receptors, the sensations represented by the green axis are even less accessible. In Retinex color space, distance from the intersection of the three axes (the depicted intersection is arbitrary since 
the axes are logarithmically scaled) corresponds to what might be called "lightness": black, grays, and white fall on a line making roughly equal angles to the three axes; in moving outward close to the green axis one goes from black to dark green to progressively brighter greens.

If the Land algorithm is, in fact, similar to the algorithm used by our nervous systems, then color at any point would seem to be determined by performing computations separately on the three cone wavebands and assembling this information only when the evaluation is complete. One should thus expect cells at some intermediate stage along the visual path to be capable of comparing the luminance of two adjacent points in the visual field, for a single cone channel. Next, still keeping the three cone paths separate, the reflectances of all points would need to be evaluated relative to the reflectances of all other points in the visual field. In the Land terminology the entire calculation is construed as being performed by an independent neural system called a Retinex, the term having been coined so as to leave open the question of whether the process occurs in the retina, the cortex, or both. Finally, the three pathways presumably must converge so that the relative reflectances on the three wavebands can somehow be interpreted as color. The fact that the color of an object can be influenced by other widely separated objects in a scene means that the neural pathways must include connections between cells representing widely separated parts of the visual field. A study done with a subject whose corpus callosum had been severed indicates that the cortex is necessary for the computations (Land et al. 1983).

Now (at last) we come to the question of the relationship between these types of psychophysical phenomena and neurons. Between the psychophysics founded by Newton, i.e., a psychophysics that is concerned primarily with such things as color mixing, rather than spatial relationships, and the behavior of any cell showing color opponency, there are obvious and compelling correlations, of which we give three examples. (1) A single opponent-color cell (type I or II) fed by red and green cones in opposition fails to respond to diffuse yellow light or to white light, and hence does not distinguish between them; furthermore, consistent with the trichromatic laws of color mixing, it does not matter whether the white or the yellow light is composed of many wavelengths or a mixture of monochromatic light of any two appropriate wavelengths. In psychophysics, the correlate is that a tritanope (someone lacking blue cones) cannot distinguish these stimuli. Likewise, Blue-Yellow opponent color cells act in a way analogous to protanopic color blindness. (2) The sensation white, intuitively different from any other color, is physiologically special in evoking no response from type II cells or from Double-Opponent color cells. (3) A consequence of subtracting, by opponency, the effects of different classes of cones should be that the most rapid changes in a cell's response as a result of changing wavelength would occur in the parts of the spectrum where the pigment absorption curves overlap the most. The psychophysical correlate is the variety of color sensations present in just those parts of the spectrum.

We turn now to the physiology behind the spatial- color psychophysical phenomena. In seeking out such a physiology one should probably begin by looking for cells sensitive to differences in wavelength composition across borders, or else for cells sensitive to intensity contrast within a single waveband, since this is the kind of thing that is done at the earliest stage in the Retinex calculations. The cell type that Retinex theory seems to require to perform this function of taking ratios of energy across borders for a single waveband, namely, a cell whose receptive field has spatially opponent subdivisions fed by a single cone type, such as red-on in one region and redoff in another, has never been observed. Indeed, the Retinex algorithm seems to require cells with asymmetric receptive fields, such as a simple cell with an excitatory and an inhibitory subfield side by side, both fed by the same cone type. Simple cells with this geometry fed by only a single cone type have never been seen; therefore, this is probably asking too much. Nevertheless, in a twodimensional algorithm proposed by Horn (1973), circularly symmetrical cells can be used to supply the necessary Laplacian operators, and a comparator across edges, which would require both orientation selectivity and directionality, becomes unnecessary. For Horn's algorithm one would need an on-center off-surround cell, again with the input to both center and surround from the same cone type. Again, such a cell has never been observed. Indeed the different cone types manifestly converge at a very early stage so that, even in the retina, both at the horizontal cell and bipolar cell levels, no cells are known to receive inputs from cones of just one type. This would not in itself constitute a refutation of the Retinex theory provided channels did exist carrying the appropriate spatial information about the three wavebands in some linear combination (Horn, 1974).

In considering the various cell types available, one would at first glance seem justified in ruling out BroadBand (type III) cells, for by definition they have the same spectral sensitivity in all parts of their receptive fields. Yet for black and white these Kufflerian center-surround cells seem to be roughly what is required. Black, white, or grays, like any other color, cannot exist in the absence of spatial comparisons, and spatial comparisons are just what these cells do. As we will point out later, the BroadBand cells probably mediate the more general attributes "darkness" or "lightness" rather than the more restricted "black," "gray," and "white."

Color-Opponent Center-Only (type II) cells can by themselves obviously make no spatial comparisons, although, as discussed below, they can be used at later stages to build up cells that do.

What about Color-Opponent Center-Surround (type I) cells? These cells clearly do not carry any spatial information about a single waveband, and the spatial information they do convey is not linearly related to the information needed by the Retinex calculation. On a simple-minded, intuitive level, a cell that does not respond to such stimuli as a red spot on a green background would not seem to do much for the problem of color contrast. To be sure, these cells would respond to a large colored object but not to a white one, and thus cannot be dismissed as playing no part in color perception-but exactly what part they do play, no one knows. 
What one finds at the level of the cortical blobs, while obviously concerned with color, might seem at first glance to be far from what the Retinex model requires. Instead of the three independent color channels we find ourselves stuck with two classes of Double-Opponent cells, a green-red and a yellow-blue, both white-blind, and a Broad-Band center-surround (type III) cell. In all three the cone influences are mixed. In Retinex theory no broad-band channel is contemplated; white sensation requires activation of all three Retinex channels, and black, grays, and white occupy in Retinex color space a single diagonal not dignified by any special properties. White is just another color, with none of the special status that its intuitive huelessness would seem to warrant. It thus seemed natural to attempt to reconcile Retinex theory with the neurophysiology simply by a change of coordinate axes. The physiology implies a coordinate system in which one parameter represents black-white, a second red-green, and a third yellow-blue.

Our first thought was to translate the Retinex color space into longitude-latitude spherical polar coordinates. Radius, in the new coordinate system, is equivalent to a dark-light scale, longitude to some location along a redgreen continuum, and latitude the relative strengths of blue as opposed to red-plus-green (i.e., yellow). Radius would then be represented by the Broad-Band center surround (type III) cell, longitude by the R-G DoubleOpponent cell, and latitude by the blue-yellow DoubleOpponent cell (Figure 33A).

Another transformation, topologically equivalent, proposed by M. Burns and F. Land (I and, 1983), is a rotation of the three axes into a new Cartesian system. The new black-white axis is the same as the diagonal of blacks and whites on the old set, a new red-green axis is at right angles to this and parallel to the (horizontal) red-green plane, and the new yellow-blue axis is a right angles to the other two, intersecting the (vertical) Retinex blue axis, and hitting the (horizontal) Retinex redgreen plane somewhere in the yellow (Figure $33 B$ ).

While these coordinate systems may be useful in visualizing the color space, they should not be taken too literally. Two neighboring opponent color cells of the same class (e.g., two red-green Double-Opponent cells) can differ in the relative strengths of the cone inputs or in the relative strengths of the center and surround; the three blob cell types vary in relative frequency with species, with eccentricity, even perhaps with sex (Jacobs, 1977; Jacobs et al., 1981). Nevertheless, what the different coordinate systems do emphasize is the likely equivalence of Land comparators that take ratios of intensities of adjacent points on one of three single wavebands, and the physiological reality (if we are correct) in which what is compared, from point to point, is (1) lightness, the sum of the three cone inputs; (2) red-greenness; and (3) yellow-(or green-) blueness.

We had been puzzled over how two Double-Opponent cell types could subserve a trivariant system and over the presence, in regions otherwise preoccupied with color, of cells apparently concerned with black and white. In the proposed scheme the three cell types subserve color in a general sense including shades of gray and for a three-coordinate system that is equivalent, by a change
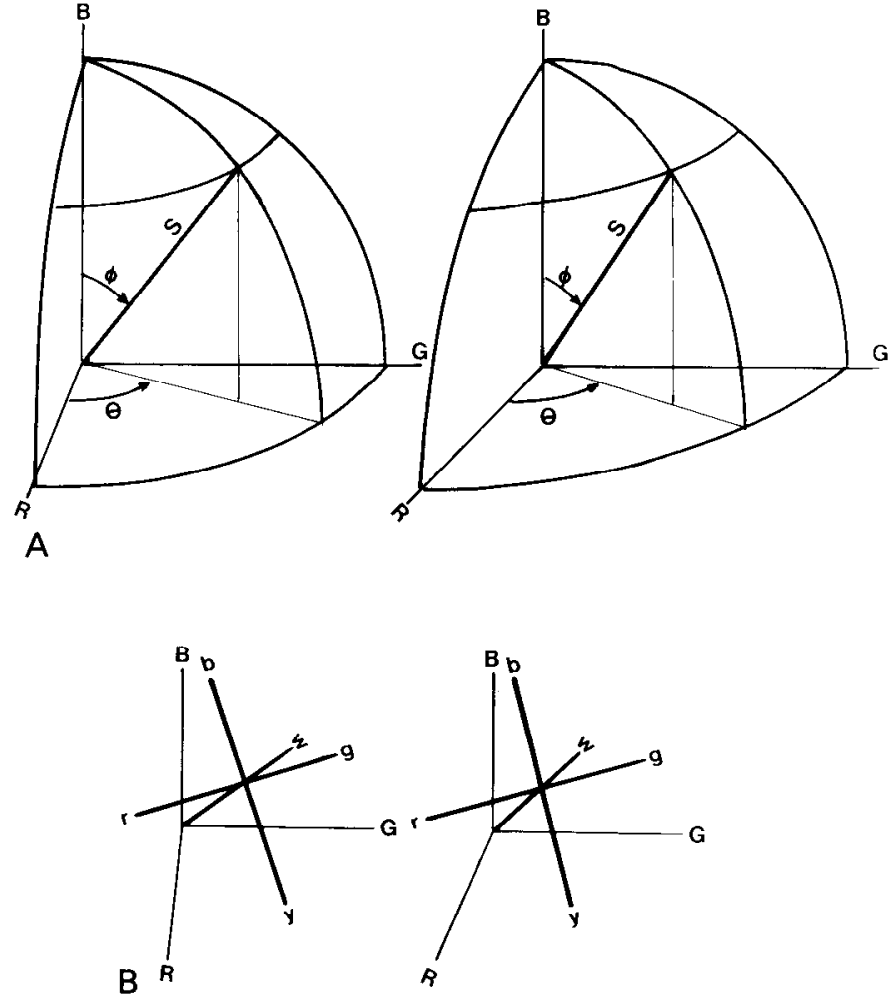

Figure 33. Stereo pairs of two equivalent transformations of Land's color space. $A$, Spherical polar coordinates, with $S$ representing brightness, $\Theta$ (longitude) representing red-greenness, and $\phi$ (latitude) representing yellow-blueness. $R, G$, and $B$ are the Retinex long, middle, and short axes. $B$, Here $R, G$, and $B$ again represent the same Retinex axes, and $r-g, b-y$, and $w$ represent three new Cartesian axes, red-green, yellow-blue, and black-white. The location of the origins is arbitrary.

of axes, to the Retinex system. The Kufflerian BroadBand center-surround cell is of course to be looked upon as subserving lightness or darkness (e.g., brown versus orange), not simply black versus white.

The exact stimuli to which the Broad-Band centersurround cells respond deserve some comment. For most such cells, at least in the lateral geniculate body and in area 17, diffuse light is ineffective or very nearly so. A response occurs when the center and surround are not balanced. (Often there is rectification, in that an imbalance favoring the surround produces no response.) A stimulus consisting simply of a constant spatial gradient in the intensity of light is also ineffective in stimulating one of these cells, because the increase in light on one half of its receptive field surround is compensated for by the decrease on the other half. What is presumably necessary for a response is a change in the gradient of the energy, a departure from zero of the second derivative of the illumination profile (Horn, 1973). The Land formulation is a solution of a two-dimensional problem using the one-dimensional technique of point-to-point comparisons along paths, and thus to discount uneven illumination must suppose an insensitivity to gradients below some arbitrary threshold. The center-surround cell, as in Horn's (1973) two-dimensional Laplacian algorithm, is already insensitive to steady changes, but is instead sensitive to changes in the energy gradients. We 
therefore wonder if the Retinex algorithm would not be more consistent with the physiology if the threshold were applied to the second derivative of the energy, rather than the first. It should be easy to learn how steep a constant gradient can be and escape detection, and how marked a change in gradient must be before it is perceived.

It might seem surprising that the cells we are proposing as an early step in color processing show strong eye preference, many being strictly monocular. This fits, however, with the fact that in a Land-type demonstration, when one wavelength is shown to only one eye and another to the other, the colors seen are poor compared to the original demonstration, and many observers see no color at all. The fact that there is any interocular transfer of color information (Geschwind and Segal, $1960)$ predicts that at least some of the cells responsiole should be binocular and therefore necessarily cortical; the fact that color interactions across the vertical midline require the corpus callosum (Land et al., 1983) together with the weakness of the interocular mixing of color information implies that at least some of the cells must be both cortical and monocular.

As in so many other sensory systems, the three physiological determinants of color come in opponent pairs: on- and off-center Broad-Band, $(\mathrm{R}+\mathrm{G}-)$ and $(\mathrm{R}-\mathrm{G}+)$ center Double-Opponent, and $(\mathrm{B}+\mathrm{Y}-)$ and $(\mathrm{B}-\mathrm{Y}+)$ center Double Opponent. Other examples of opponent pairs are seen in hot and cold receptors, and the extension and flexion signals sent from joints, but an especially attractive analogy is the six vestibular semicircular canals, with their mutual orthogonality and complementary pairing.

We cannot, of course, claim much originality for this formulation. Hering's intuition $(1874,1878,1880)$ that color vision depends on three opponent processes, blackwhite, yellow-blue, and red-green, bears a remarkable resemblance to the physiological coordinate systems. His theory nevertheless is incomplete, for, while its blackwhite system depends on spatial comparisons, the redgreen and yellow-blue systems deal with colors only at a point. Jameson and Hurvitch $(1959,1961)$ generalized Hering's theory to incorporate spatial interactions in the red-green and yellow-blue systems. This work is empirical rather than predictive, but gives results similar to the observations underlying Retinex theory, provided the axes are changed. If we are correct in speculating that the blobs are involved in color, then the physiological mechanisms fit remarkably well with an extended Hering model.

There is no denying the attractiveness of the Land system for its predictive power and its simplicity. Why should the brain adopt a strategy which, although equivalent, seems more awkward? First, the facts of classical color psychophysics-the results of color mixing, the intuitively obvious huelessness of white, the rapidity of color changes in the part of the spectrum where visual pigments overlap-all have, as mentioned earlier, compelling counterparts in color opponency. For a wide range of color sensations to be created out of three overlapping visual pigments would seem to demand a subtraction of effects. Second, across species, even mammalian species, color capabilities vary widely: most species of mammals are, compared to humans, relatively color blind. Nevertheless, most of these species probably have more than one cone type. In evolution it is easiest to imagine color vision appearing sporadically by having it engrafted on a more primitive, achromatic vision that uses pooled cone inputs, and by having the relative strengths of the three coordinates in color space subject to wide variations - red-green, for example, being downgraded in the squirrel monkey. Third, and similarly, in dark adaptation, what one sees are black, grays, and white. The problem of the coexistence of this vision and color vision can be neatly solved by having the rods feed into the black-white system but not into the Double-Opponent cells. The difficulty with the idea that primates use the unmodified Retinex algorithm is that it does not so easily account for achromatic vision.

Polyak (1957) has proposed that primate color vision co-evolved with the appearance of brightly colored fruits, especially red ones. If this is true, then it should not be surprising that the type of Double-Opponent cell that would respond maximally to a red fruit on a green leafy background (red-on green-off center, red-off green-on surround) is by far the most common type.

Even if the upper layer blob cells do play a part in spatial-color interactions, we have at present no idea how the information carried by these cells is used at later stages. Blob cells are imagined to do the equivalent of comparing one region with its immediate surround in order to detect changes in gradient and to eliminate steady changes, along three axes in a coordinate system using opponent pairs. Somehow this information has to be compiled over the visual field and digested so as to yield relative reflectances. Having done something like a double differential to get rid of steady changes, a double integration seems needed to resuscitate the steady values. This is done in the Retinex model by multiplications along multiple pathways and by the two-dimensional Laplacian Horn model in ways that tax our limited mathematical capabilities. At present, it is hard to imagine how the task is accomplished physiologically. Even more challenging is the question of what happens thenhow the three rank orderings are assembled, if in any sense they are, to give color.

\section{Modular organization}

We return, finally, to a considertion of the modular organization of the striate cortex. As Figure 34 shows, the blobs are inserted into the cortex as though by a twist drill, leaving the orientation columns apparently unperturbed. It is as if some cells with specific orientation affiliation had simply been discarded, or won over to a new (concentric) persuasion.

Superficially one might suppose that the existence of the blobs in area 17 simply adds one more variable to a list already containing ocular dominance, orientation, and retinal position-namely, presence or absence of orientation selectivity. But these items are not equivalent or on an equal footing. As has been stated before (e.g., Hubel and Wiesel, 1977), orientation and ocular dominance are variables that are engrafted upon visual field position: each must cycle through all of its possible values at least once within a given retinal position. Until recently, it seemed that each point in the cortex corre- 


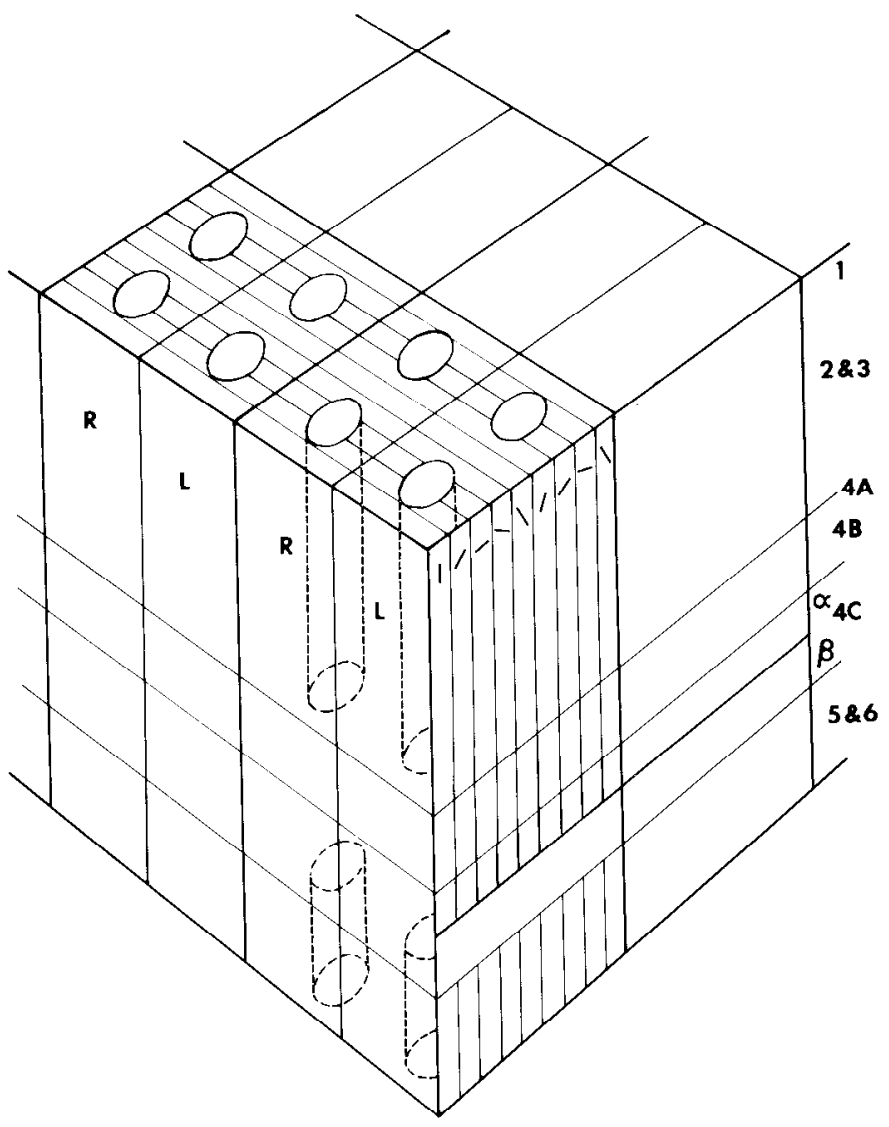

Figure 34. Our current model of the modular organization of macaque striate cortex (modified from Hubel and Wiesel, 1977).

sponded to a particular $X-Y$ position, a particular orientation and a particular eye preference-three variables for each point. The blobs represent something separate inserted into all this, but not permeating it. They live within the $X-Y$ coordinate system, partake (in the macaque) of the ocular dominance variable, but are walled off from orientation. One seems to be dealing with a processing in parallel of two kinds of information separated in columnar fashion.

This is in addition to and separate from the parallel pathways represented in the geniculate by the magnocellular and parvocellular layers, which in the cortex continue to be segregated in layers, beginning in layer $4 \mathrm{C} \alpha$ versus $4 \mathrm{C} \beta$ and, as Lund et al. (1975) have shown, maintaining their identity even as far as layer 6 . Our finding in the present study that, contrary to our previous beliefs, cells of layer $4 \mathrm{C} \alpha$ are predominantly orientation specific and simple, in contrast to those of layer $4 \mathrm{C} \beta$ which are, as far as we know, always concentric, further points up the difference in these two (magnocellular and parvocellular) systems.

On a large scale there are, of course, other kinds of nonuniformity. For example, the widths of ipsilateral ocular dominance columns shrink progressively beyond about $18^{\circ}$ from the fovea (Connelly et al., 1982). Blobs also are different, apparently, at different eccentricities: as one goes toward the fovea they get bigger, though not dramatically.

Traversing a piece of cortex roughtly 1 to $2 \mathrm{~mm}$ in extent is enough to bring one gradually from an initial region of visual field to a separate non-overlapping region (Hubel and Wiesel, 1974b). This is the basis of the modular concept. In layer $4 \mathrm{C} \beta$ a similar movement can easily be seen; it is regular and precise and indicates much less scatter in receptive field position than is found in the upper layers (Hubel et al., 1974b). It would be worth knowing whether a similar movement across the visual field can be detected as one traverses a single blob. The only substructure we have seen within blobs relates to the poorly oriented (group C) cells at the fringes. From one blob to the next we have seen no specialization except for ocular dominance, which in macaques leads to two types of blobs. On the other hand, we have seen, all in a single blob, a red-green Double-Opponent cell, a yellowblue Double-Opponent cell, and a Broad-Band cell.

We have, of course, been aware of the possibility that the path from geniculate to blobs in area 17 and then to area 18 , if it is indeed preoccupied with color, may continue on to Zeki's visual area 4. This cortical area has been implicated in color vision (Zeki, 1980), and Zeki (1978) has reported that it receives input mainly from area 18 and possibly from foveal area 17 . The blob cells we have recorded probably represent too early a stage and are probably too short range in their spatial coverage to generate the long-range interactions that occur in color perception, but they could act as building blocks contributing to whatever longer-range interactions occur in Zeki's area.

Clinically it is known that some focal prestriate lesions can lead to defects in color vision with little or no loss in form vision (Critchley, 1965; Pearlman et al., 1979; Damasio et al., 1980; Rovamo et al., 1982). This, too, suggests that modalities such as color may be coarsely segregated in prestriate areas. We hope to come closer to solving some of these problems in a step-by-step study of area 17, area 18, and the cortex beyond. If complexity continues to escalate, future papers will probably be even longer.

\section{References}

Barlow, H. B. (1953) Summation and inhibition in the frog's retina. J. Physiol. (Lond.) 119: 69-88.

Braitenberg, V., and C. Braitenberg (1979) Geometry of orientation columns in the visual cortex. Biol. Cybern. 33: 179186.

Bullier, J., and G. H. Henry (1980) Ordinal position and afferent input of neurons in monkey striate cortex. J. Comp. Neurol. 192: 913-935.

Connolly, M., S. LeVay, and D. C. Van Essen (1982) The complete pattern of ocular dominance stripes in macaque striate cortex. Soc. Neurosci. Abstr. 8: 676.

Cowey, A. (1964) Projection of the retina onto striate and prestriate cortex in the squirrel monkey, Saimiri sciureus. J. Neurophysiol. 27: 366-393.

Cragg, B. G., and A. Ainsworth (1969) The topography of the afferent projections in the circumstriate visual cortex of the monkey studied by the Nauta method. Vision Res. 9: 733 747.

Creutzfeldt, O. D., B. B. Lee, and A. Elepfandt (1979) A quantitative study of chromatic organization and receptive fields in the lateral geniculate body of the rhesus monkey. Exp. Brain Res. 35: 527-545.

Critchley, M. (1965) Acquired anomalies of colour perception of central origin. Brain 88: 711-724. 
Damasio, A., T. Yamada, H. Damasio, J. Corbett, and J. McKee (1980) Central achromatopsia: Behavioral, anatomic, and physiologic aspects. Neurology 30: 1064-1071.

Daniel, P. M., and D. Whitteridge (1961) The representation of the visual field on the cerebral cortex in monkeys. J. Physiol. (Lond.) 159: 203-221.

Daw, N. W. (1968) Colour-coded ganglion cells in the goldfish retina: Extension of their receptive fields by means of new stimuli. J. Physiol. (Lond.) 197: 567-592.

Daw, N. W. (1972) Color-coded cells in goldfish, cat and rhesus monkey. Invest. Opthalmol. 11: 411-416.

DeMonasterio, F. M., and P. Gouras (1975) Functional properties of ganglion cells of the rhesus monkey retina. J. Physiol. (Lond.) 251: 167-196.

DeMonasterio, F. M., and S. J. Schein (1982) Spectral bandwidths of color-opponent cells of geniculostriate pathway of macaque monkeys. J. Neurophysiol. 47: 214-224.

DeMonasterio, F. M., P. Gouras, and D. J. Tolhurst (1975) Trichromatic colour opponency in ganglion cells of the rhesus monkey retina. J. Physiol. (Lond.) 251: 197-216.

DeValois, R. L. (1972) Processing of intensity and wavelength information by the visual system. Invest. Ophthalmol. 11: 417-426.

DeValois, R. L., and G. H. Jacobs (1968) Primate color vision. Science 162: $533-540$.

DeValois, R. L., H. C. Morgan, M. C. Polson, W. R. Mead, and E. M. Hull (1974) Psychophysical studies of monkey vision. I. Macaque luminosity and color vision tests. Vision Res. 14: $53-67$.

Dow, B. M. (1974) Functional classes of cells and their laminar distribution in monkey visual cortex. J. Neurophysiol. 37: 927-946.

Dow, B. M., and P. Gouras (1973) Color and spatial specificty of single units in rhesus monkey foveal striate cortex. J. Neurophysiol. 36: 79-100.

Dubner, R., and S. M. Zeki (1971) Response properties and receptive fields of cells in an anatomically defined region of the superior temporal sulcus. Brain Res. 35: 528-531.

Fitzpatrick, D., K. Itoh, and I. T. Diamond (1983) The laminar organization of the lateral geniculate body and the striate cortex in the squirrel monkey (Saimiri sciureus). J. Neurosci. 3: $673-702$.

Geschwind, N., and J. R. Segal (1960) Colors of all hues from binocular mixing of two colors. Science 131: 608 .

Gilbert, C. D. (1977) Laminar differences in receptive field properties of cells in cat primary visual cortex. J. Physiol. (Lond.) 268: 391-421.

Gilbert, C. D. (1983) Microcircuitry of the visual cortex. Annu. Rev. Neurosci. 6: 217-247.

Gouras, P. (1974) Opponent-color cells in different layers of foveal striate cortex. J. Physiol. (Lond.) 238: 583-602.

Gouras, P., and E. Zrenner (1979) Enhancement of luminance flicker by color-opponent mechanisms. Science 205: 587-589.

Gouras, P., and E. Zrenner (1981) Color vision: A review from a neurophysiological perspective. Prog. Sens. Physiol. 1: 139-179.

Guillery, R. W., and M. Colonnier (1970) Synaptic patterns in the dorsal lateral geniculate nucleus of the monkey. Z. Zellforsch. 103: $90-108$.

Harting, J. K., V. A. Casagrande, and J. T. Weber (1978) The projection of the primate superior colliculus upon the dorsal lateral geniculate nucleus: Autoradiographic analysis of interlaminar distribution of tectogeniculate axons. Brain Res. 150: 593-599.

Harting, J. K., M. F. Huerta, A. J. Frankfurter, N. L. Strominger, and G. J. Royce (1980) Ascending pathways from the monkey superior colliculus: An autoradiographic analysis. J. Comp. Neurol. 192: 853-882.
Helmholtz, H. von (1909) In Hanbuch der Physiologischen Optik, J. P. Southall, ed., Vol. 2, p. 287, Dover Publications, New York.

Hendrickson, A. E., and J. R. Wilson (1979) A difference in $\left[{ }^{14} \mathrm{C}\right]$ deoxyglucose autoradiographic patterns in striate cortex between Macaca and Saimiri monkeys following monocular stimulation. Brain Res. 170: 353-358.

Hendrickson, A. E., J. R. Wilson, and M. P. Ogren (1978) The neuroanatomical organization of pathways between the dorsal lateral geniculate nucleus and visual cortex in Old World and New World primates. J. Comp. Neurol. 182: 123-136.

Hendrickson, A. E., S. P. Hunt, and J. -Y. Wu (1981) Immunocytochemical localization of glutamic acid decarboxylase in monkey striate cortex. Nature 292: 605-607.

Hering, E. (1874) Sizungsberichte der Wiener Akademie, Mathem.-Naturwissensch. Kl. 69: S.131.

Hering, E. (1878) Zur Lehre vom Lichtsinne, Springer-Verlag, Berlin.

Hering, E. (1880) Zur Erklärung der Farbenblindheit aus der Theorie der Gegenfarben. Lotos, Jb. f. Naturwiss. 1: 76-107.

Horn, B. K. P. (1973) On Lightness. M.I.T. A.I. Lab. Memo 295.

Horn, B. K. P. (1974) Determining lightnesses from an image. Computer Graphics and Image Processing, 3: 277-299.

Horton, J. C. (1983) Cytochrome oxidase patches: A new cytoarchitectonic feature of primate visual cortex. Ph.D. thesis, Harvard University, Boston.

Horton, J. C., and D. H. Hubel (1980) Cytochrome oxidase stain preferentially labels intersection of ocular dominance and vertical orientation columns in macaque striate cortex. Soc. Neurosci. Abstr. 6: 315.

Horton, J. C., and D. II. IIubel (1981) A regular patchy distribution of cytochrome-oxidase staining in primary visual cortex of the macaque monkey. Nature 292: 762-764.

Hubel, D. H. (1959) Single unit activity in striate cortex of unrestrained cats. J. Physiol. (Lond.) 147: 226-238.

Ilubel, D. H., and T. N. Wiesel (1968) Receptive ficlds and functional architecture of monkey striate cortex. J. Physiol. (Lond.) 195: 215-243.

Hubel, D. H., and T. N. Wiesel (1974a) Sequence regularity and geometry of orientation columns in the monkey striate cortex. J. Comp. Neurol. 158: 267-294.

Hubel, D. H., and T. N. Wiesel (1974b) Uniformity of monkey striate cortex: A parallel relationship between field size, scatter, and magnification factor. J. Comp. Neurol. 158: 295306.

Hubel, D. H., and T. N. Wiesel (1977) Functional architecture of macaque monkey visual cortex. Ferrier Lecture. Proc. R. Soc. Lond. (Biol.) 198: 1-59.

Hubel, D. H., and T. N. Wiesel (1978) Distribution of inputs from the two eyes to striate cortex of squirrel monkeys. Soc. Neurosci. Abstr. 4: 632.

Hubel, D. H., T. N. Wiesel, and D. M. K. Lam (1974a) Autoradiographic demonstration of ocular-dominance columns in the monkey striate cortex by means of transneuronal transport. Brain Res. 79: 273-279.

Hubel, D. H., T. N. Wiesel, and S. I eVay (1974b) Visual-field representation in layer IV C of monkey striate cortex. Society for Neuroscience Program and Abstracts 4th Annual Meeting, p. 264 .

Hubel, D. H., T. N. Wiesel, and S. LeVay (1977a) Plasticity of ocular dominance columns in monkey striate cortex. Philos. Trans. R. Soc. Lond. Biol. 278: 131-163.

Hubel, D. H., T. N. Wiesel, and M. P. Stryker (1977b) Orientation columns in macaque monkey visual cortex demonstrated by the 2-deoxyglucose autoradiographic technique. Nature 269: 328-330.

Humphrey, A. L., and A. E. Hendrickson (1980) Radial zones 
of high metabolic activity in squirrel monkey striate cortex. Soc. Neurosci. Abstr. 6: 315 .

Humphrey, A. L., and A. E. Hendrickson (1983) Background and stimulus-induced patterns of high metabolic activity in the visual cortex (area 17) of the squirrel and macaque monkey. J. Neurosci. 3: 345-358.

Jacobs, G. H. (1963) Spectral sensitivity and color vision of the squirrel monkey. J. Comp. Physiol. Psychol. 56: 616-621.

Jacobs, G. H. (1977) Visual sensitivity: Significant withinspecies variations in a nonhuman primate. Science 197: 499500.

Jacobs, G. H., J. K. Bowmaker, and J. D. Mollon (1981) Behavioural and microspectrophotom sric measurements of colour vision in squirrel monkeys. Nature 292: 541-543.

Jameson, D., and L. M. Hurvitch (1959) Perceived color and its dependence on focal, surrounding, and preceding stimulus variables. J. Opt. Soc. Am. 49: 890-898.

Jameson, D. and L. M. Hurvitch (1961) Opponent chromatic induction: Experimental evaluation and theoretical approach. J. Opt. Soc. Am. 51: 46-53.

Kaas, J. H., M. F. Huerta, J. T. Weber, and J. K. Harting (1978) Patterns of retinal terminations and laminar organizations of the lateral geniculate nucleus of primates. J. Comp. Neurol. 182: 517-554.

Kaplan, E., and R. Shapley (1982) X and Y cells in the lateral geniculate nucleus of the macaque monkey. J. Physiol. (Lond.) 330: 125-143.

Krüger, J. (1977) Stimulus dependent colour specificity of monkey lateral geniculate neurones. Exp. Brain Res. 30: 297311.

Krüger, J., and P. Gouras (1980) Spectral sensitivity of cells and its dependence on slit length in the monkey visual cortex. J. Neurophysiol. 43: 1055-1069.

Land, E. H. (1959) Color vision and the natural image. Part I. Proc. Natl. Acad. Sci. U. S. A. 45: 115-129.

Land, E. H. (1964) The Retinex. Am. Sci. 52: 247-264.

Land, E. H. (1974) The Retinex theory of colour vision. Proc. R. Inst. Gr. Brit. 47: 23-58.

Land, E. H. (1983) Color vision and the natural image. III. Recent advances in Retinex theory and some implications for cortical computations. Proc. Natl. Acad. Sci. U. S. A. 80: 5163-5169.

Land, E. H., and J. J. McCann (1971) Lightness and Retinex theory. J. Opt. Soc. Am. 172: 1-11.

Land, E. H., D. H. Hubel, M. S. Livingstone, S. H. Perry, and M. M. Burns (1983) Color-generating interactions across the corpus callosum. Nature 303: 616-618.

LeVay, S., D. H. Hubel, and T. N. Wiesel (1975) The pattern of ocular dominance columns in macaque visual cortex revealed by a reduced silver stain. J. Comp. Neurol. 159: 559576.

Livingstone, M. S., and D. H. Hubel (1982) Thalamic inputs to cytochrome oxidase-rich regions in monkey visual cortex. Proc. Natl. Acad. Sci. U. S. A. 79: 6098-6101.

Lund, J. S. (1973) Organization of neurons in the visual cortex, area 17, of the monkey (Macaca mulatta). J. Comp. Neurol. 147: 455-475.

Lund, J. S., and R. G. Boothe (1975) Interlaminar connections and pyramidal neuron organization in the visual cortex, area 17, of the macaque monkey. J. Comp. Neurol. 159: 305-334.

Lund, J. S., R. D. Lund, A. E. Hendrickson, A. H. Bunt, and A. F. Fuchs (1975) The origin of efferent pathways from the primary visual cortex, area 17 , of the macaque monkey as shown by retrograde transport of horseradish peroxidase. J. Comp. Neurol. 164: 287-304.

Maunsell, J. H. R., W. T. Newsome, and D. C. Van Essen (1980) The spatial organization of connections between V1 and V2 in the macaque: Patchy and non-patchy projections.
Soc. Neurosci. Abstr. 6: 580.

Mesulam, M. -M. (1982) Principles of horseradish peroxidase neurohistochemistry and their applications for tracing neural pathways-Axonal transport, enzyme histochemistry and light microscopic analysis. In Tracing Neural Connections with Horseradish Peroxidase, Mesulam, M. -M. ed., pp. 1151, John Wiley \& Sons, Inc., New York.

Michael, C. R. (1978) Color vision mechanisms in monkey striate cortex: Dual-opponent cells with concentric receptive fields. J. Neurophysiol. 41: 572-588.

Michael, C. R. (1981) Columnar organization of color cells in monkey striate cortex. J. Neurophysiol. 46: 587-604.

Miles, R. C. (1958) Color vision in the squirrel monkey. J. Comp. Physiol. 51: 328-331.

Newton, I. M. (1704) Optice, Lib. 1, P. II. Prop. IV-VI.

Ogren, M. P., and A. E. Hendrickson (1977) The distribution of pulvinar terminals in visual area 17 and 18 of the monkey. Brain Res. 137: 343-350.

Ogren, M. P., and A. E. Hendrickson (1979) The structural organization of the inferior and lateral subdivisions of the Macaca monkey pulvinar. J. Comp. Neurol. 188: 147-178.

The Oxford English Dictionary (1978) J. A. H. Murray, H. Bradley, W. A. Craigie, and C. T. Onions, eds., Vol. 1, p. 926, Oxford University Press, Oxford.

Palmer, L. A., and A. C. Rosenquist (1974) Visual receptive fields of single striate cortical units projecting to the superior colliculus in the cat. Brain Res. 67: 27-42.

Pearlman, A., J. Birch, and J. C. Meadows (1979) Cerebral color blindness: An acquired defect in hue discrimination. Ann. Neurol. 5: 253-261.

Poggio, G. F., F. H. Baker, R. J. W. Mansfield, A. Sillito, and P. Grigg (1975) Spatial and chromatic properties of neurons subserving foveal and parafoveal vision in rhesus monkey. Brain Res. 100: 25-59.

Polyak, S. (1957) Vision and its role in the history of man. In The Vertebrate Visual System, H. Klüver, ed., pp. 973-974, University of Chicago Press, Chicago.

Rockland, K. S., and J. S. Lund (1983) Intrinsic laminar lattice connections in primate visual cortex. J. Comp. Neurol. 216: 303-318.

Rovamo, J., L. Hyvarinen, and R. Hari (1982) Human vision without luminance-contrast system: Selective recovery of the red-green colour-contrast system from acquired blindness. Docum. Ophthal. Proc. Series 33, ed. G. Verriest. Dr. W. Junk Publ., The Hague, ISBN 9061937299.

Schiller, P. H., and J. G. Malpeli (1978) Functional specificity of lateral geniculate nucleus laminae of the rhesus monkey. J. Neurophysiol. 41: 788-797.

Shapley, R., E. Kaplan, and R. Soodak (1981) Spatial summation and contrast sensitivity of $\mathrm{X}$ and $\mathrm{Y}$ cells in the lateral geniculate nucleus of the macaque monkey. Nature 292: 543 545.

Spatz, W. B., J. Tigges, and M. Tigges (1970) Subcortical projections, cortical associations and some intrinsic interlaminar connections of the striate cortex in the squirrel monkey (Saimiri). J. Comp. Neurol. 140: 155-174.

Talbot, S. A., and W. H. Marshall (1941) Physiological studies on neural mechanisms of visual localization and discrimination. Am. J. Ophthalmol. 24: 1255-1263.

Thomson, Sir Benjamin Count of Rumford (1794) An account of some experiments on coloured shadows. Philos. Trans. R. Soc. Lond. 84: 107-118.

Tigges, J., W. B. Spatz, and M. Tigges (1973) Reciprocal pointto-point connections between parastriate and striate cortex in the squirrel monkey (Saimiri). J. Comp. Neurol. 148: 481490 .

Tigges, J., M. Tigges, and A. A. Perachio (1977) Complementary laminar terminations of afferents to area 17 originating 
in area 18 and in the lateral geniculate nucleus in squirrel monkey. J. Comp. Neurol. 176: 87-100.

Tigges, J., M. Tigges, S. Anschel, N. A. Cross, W. D. Ledbetter, and R. L. McBride (1981) Areal and laminar distribution of neurons interconnecting the central visual cortical areas 17 , 18, 19 and MT in the squirrel monkey (Saimiri). J. Comp. Neurol. 202: 593-560.

Tootell, R. B. H., M. S. Silverman, R. L. DeValois, and G. H. Jacobs (1983) Functional organization of the second cortical visual area in primates. Science 220: 737-739.

Weber, J. T., J. H. Kaas, M. F. Huerta, and J. K. Harting (1977) Connections of the lateral geniculate nucleus (LGN) of the squirrel monkey. Soc. Neurosci. Abstr. 3: 580 .

Weber, J. T., M. F. Huerta, J. H. Kaas, and J. K. Harting (1983) The projections of the lateral geniculate nucleus of the squirrel monkey: Studies of the interlaminar zones and the S layers. J. Comp. Neurol. 213: 135-145.

Welker, C. (1976) Receptive fields of barrels in the somatosensory neocortex of the cat. J. Comp. Neurol. 166: 173-190.

Wiesel, T. N., and D. H. Hubel (1966) Spatial and chromatic interactions in the lateral geniculate body of the rhesus monkey. J. Neurophysiol. 29: 1115-1156.

Wong-Riley, M. T. T. (1977) Connections between the pulvinar nucleus and the prestriate cortex in the squirrel monkey as revealed by peroxidase histochemistry and autoradiography. Brain Res. 134: 225-236.

Wong-Riley, M. T. T. (1978) Reciprocal connections between striate and prestriate cortex in squirrel monkey as demonstrated by combined peroxidase histochemistry and autoradiography. Brain Res. 147: 159-164.

Wong-Riley, M. T. T. (1979a) Columnar cortico-cortical interconnections within the visual system of the squirrel and macaque monkeys. Brain Res. 162: 201-217.

Wong-Riley, M. T. T. (1979b) Changes in the visual system of monocularly sutured or enucleated cats demonstrable with cytochrome oxidase histochemistry. Brain Res. 171: 11-28.

Zcki, S. M. (1969) Representation of central visual fields in prestriate cortex of monkey. Brain Res. 14: 271-291.

Zeki, S. M. (1978) The cortical projections of foveal striate cortex in the rhesus monkey. J. Physiol. (Lond.) 277: 227244.

Zeki, S. M. (1980) The representation of colours in the cerebral cortex. Nature 284: 412-418.

Zeki, S. M. (1983) The distribution of wavelength and orientation selective cells in different areas of monkey visual cortex. Proc. R. Soc. Lond. (Biol.) 217: 449-470. 